\title{
Healthy and Happy: Creating and Evaluating a Catalyst to Improve the Health of University Students via an Online Training System
}

\author{
Gillian E. Mandich, The University of Western Ontario
}

Supervisor: Dr. Linda Miller, The University of Western Ontario

A thesis submitted in partial fulfillment of the requirements for the Doctor of Philosophy degree in Health and Rehabilitation Sciences

(c) Gillian E. Mandich 2018

Follow this and additional works at: https://ir.lib.uwo.ca/etd

Part of the Medicine and Health Sciences Commons

\section{Recommended Citation}

Mandich, Gillian E., "Healthy and Happy: Creating and Evaluating a Catalyst to Improve the Health of University Students via an Online Training System" (2018). Electronic Thesis and Dissertation Repository. 5988.

https://ir.lib.uwo.ca/etd/5988

This Dissertation/Thesis is brought to you for free and open access by Scholarship@Western. It has been accepted for inclusion in Electronic Thesis and Dissertation Repository by an authorized administrator of Scholarship@Western. For more information, please contact wlswadmin@uwo.ca. 


\begin{abstract}
Increasingly, university students are facing unique, significant physical and mental health challenges. Additionally, they are spending more and more of their time online and are using online platforms to access mental health resources; consequently, there is a timely opportunity to explore the potential of online happiness interventions, specifically with video, to improve happiness among university students. Evidence suggests that improved happiness relates to improved physical health, mental health, and academic outcomes.
\end{abstract}

The purpose of this research was to test if an online happiness intervention, using videos to boost happiness, can increase self-reported happiness among university students. The primary outcome was self-reported happiness, and secondary outcomes included self-reported lifestyle measures such as weight, confidence in goal setting abilities, satisfaction with accomplishing daily tasks, exercise, sleep, stress, tobacco use, illicit drug use, alcohol consumption, social issues, number of close friends, leisure activities, and gratitude. Additionally, feedback regarding the online program and video modules was collected.

A total of 114 students participated in this four-week, online study. Data were collected through online self-report questionnaires. Comparisons of pre and post scores on the primary and secondary outcomes measures were conducted and qualitative feedback about the video was collected. Evaluation consisted of online self-report questionnaires.

This study demonstrated that not only are students interested in participating in online programs to boost self-reported happiness, but it is also possible to increase the self-reported happiness of university student via online videos. All five measures used to assess self-reported happiness revealed an increase in scores over the duration of the study; the increase was statistically significant for four of the five measures $(p<0.05)$. An analysis to examine the characteristics of those who dropped out of the study from those who completed 
the study add additional support to the evidence that screening and subcategorizing participants prior to an intervention in an effort to increase engagement and to meet the unique needs of individuals with particularly characteristics, may be efficacious and may increase retention.

The results provide new, valuable information to add to the body of work that suggests that happiness interventions may improve the self-reported happiness of undergraduate university students.

\section{Keywords}

Happiness, Health, Mental Health, Online Interventions, Student Health, University Students, Wellness 


\section{Acknowledgments}

My Doctoral degree would not have been possible without a number of people whose ongoing encouragement and assistance gave me the support I needed to finish my degree.

First and foremost, I would like to thank my thesis supervisor, Dr. Linda Miller. Without your guidance, open-mindedness, and support none of this would have been possible. Your encouragement and patience with me during the process of creating and completing this thesis has been much appreciated. Thank you for allowing me the freedom to explore research areas that were of interest to me. Your feedback and reviews have sharpened my writing and critical thinking skills, and I am incredibly grateful for your guidance and mentorship.

I would also like to thank my supervisory committee, Dr. Lorraine Davies, Dr. Jacqui Specht, and Dr. Kevin Wamsley for your guidance, and input throughout my graduate studies. Without your support and contributions, this thesis would not have been possible.

To my examining committee, Dr. Lorraine Davies, Dr. Jim Weese, Dr. Jennifer Massey, and Dr. Neil Buddel and my Chair of Examination, Dr. Chantelle Richmond - thank you for your time and valuable insights into this thesis.

This study would not have been possible without my study participants thank you for your time, contribution, and openness and involvement.

On a personal note, I would like to thank my friends and family who have supported me along every step of this journey. To my parents, siblings, and nieces and nephews, thank you for always being there for me as only a Mandich clan can! Sean Keane, thank you for your unwavering love and support and for being my rock during the writing process. And finally to all of my friends - thank you for your encouragement, support, and for listening to me talk about my thesis for countless hours! 


\section{Table of Contents}

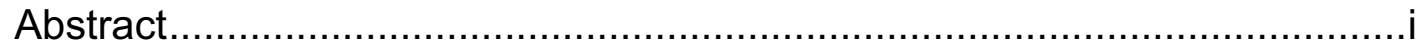

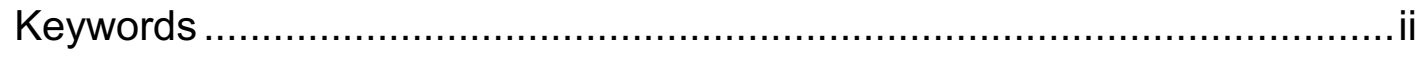

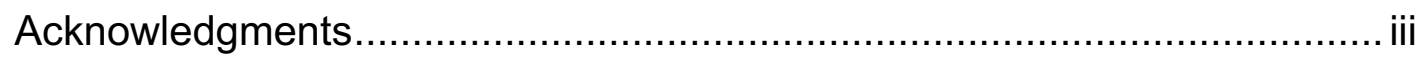

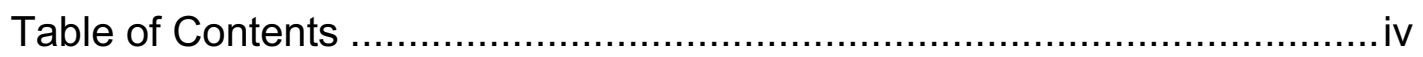

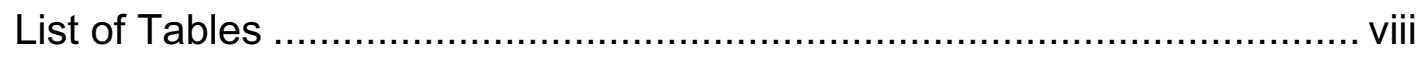

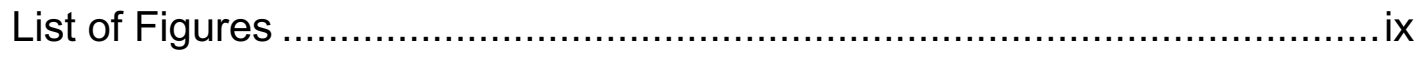

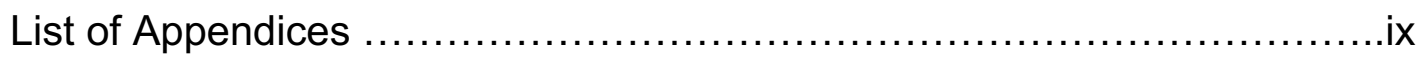

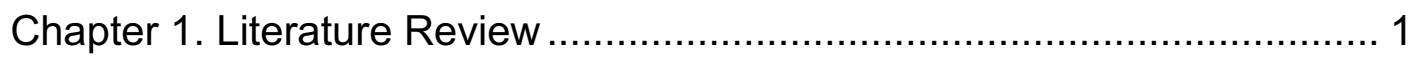

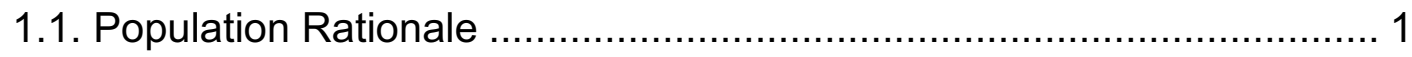

1.1.1. Undergraduate Student Enrolment and Financial Support ...... 1

1.1.2. Physical Health of Undergraduate Students ..................... 2

1.1.2.1. Physical Activity....................................... 3

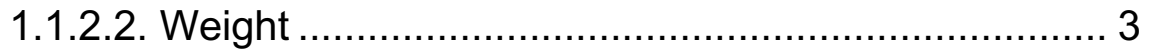

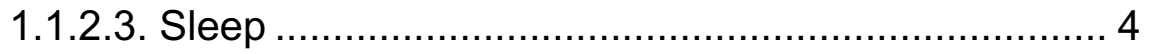

1.1.2.4. Tobacco/Illicit Drugs/Alcohol ............................ 5

1.1.3. Mental Health of Undergraduate Students ........................ 6

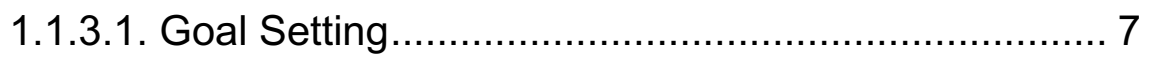

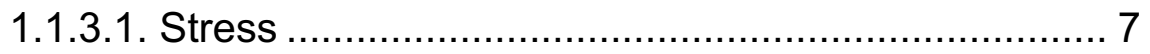

1.1.4. Online Learning and Undergraduate Students ................... 8

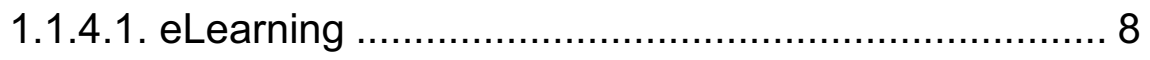

1.1.4.2. Use of Online Health Resources ...................... 10 


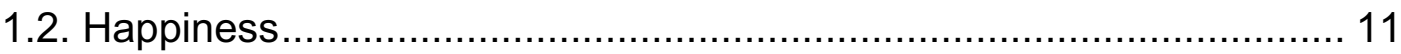

1.2.1. Defining Happiness ............................................................ 11

1.2.2. Why Happiness Is Important.......................................... 14

1.2.3. Interventions To Increase Happiness ................................ 20

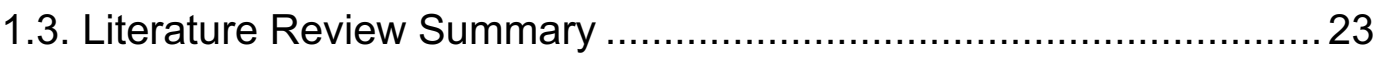

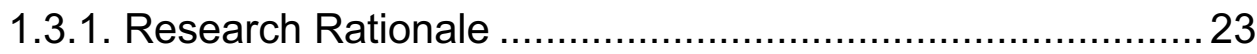

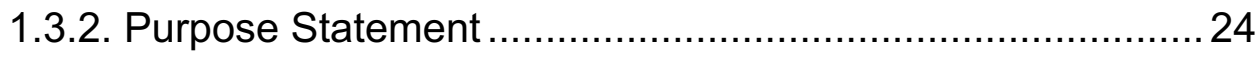

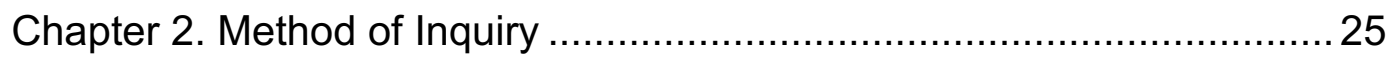

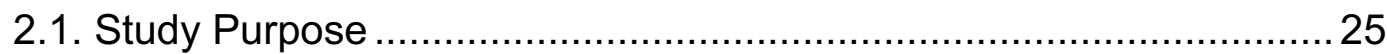

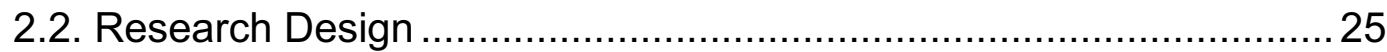

2.3. Description of Research Procedure ............................................. 26

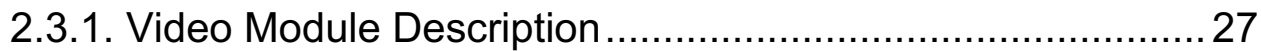

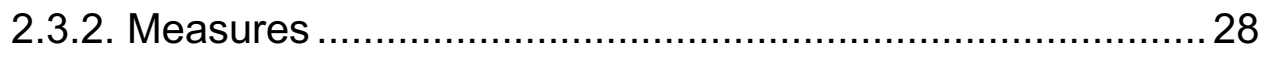

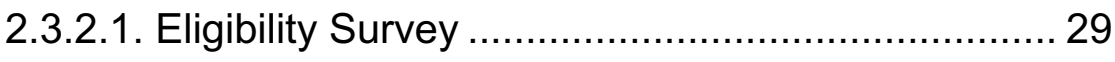

2.3.2.2. Demographic Information ................................... 29

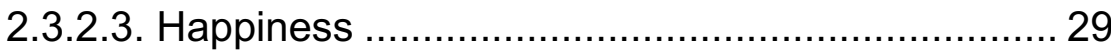

2.3.2.3.1. Authentic Happiness Inventory (AHI) ... 29

2.3.2.3.2. Subjective Happiness Scale (SHS) ...... 30

2.3.2.3.3. Fordyce Emotions Questionnaire (FEQ)32

2.3.2.3.4. Oxford Happiness Inventory $(\mathrm{OHI})$....... 33

2.3.2.3.5. Flourishing Scale (FS) ........................ 34

2.3.2.4. Lifestyle Information ............................................ 35

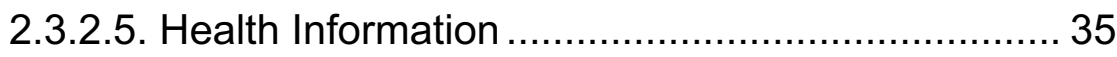


2.3.2.6. Social Information.............................................. 35

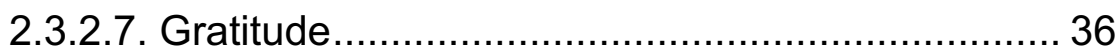

2.3.2.8. Program Feedback Questionnaire ..................... 36

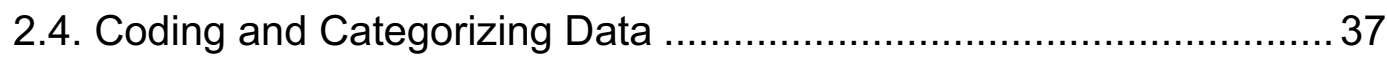

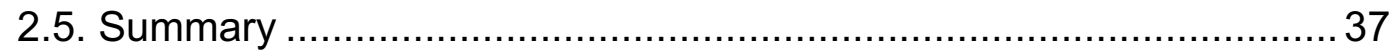

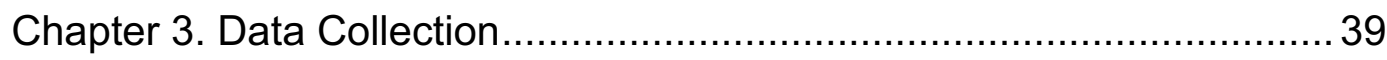

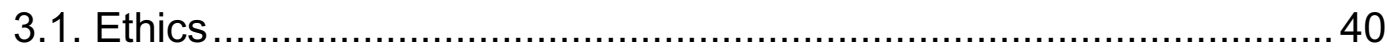

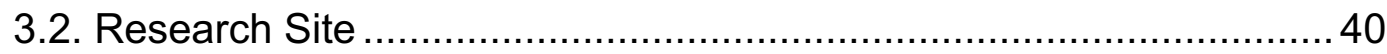

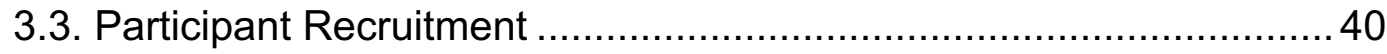

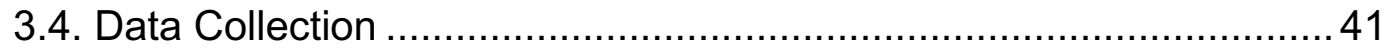

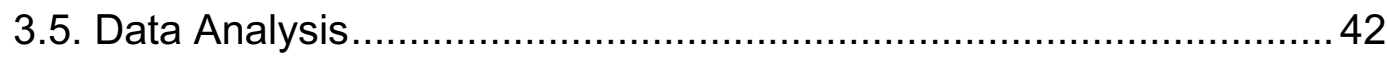

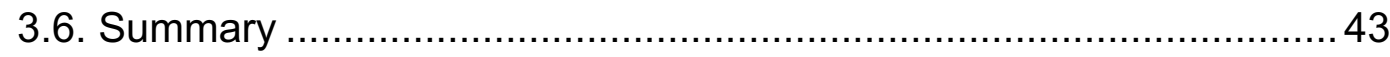

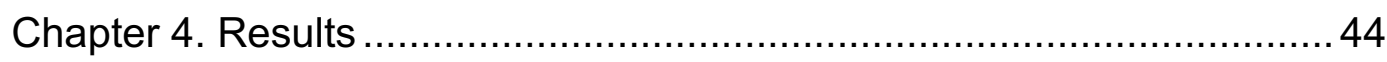

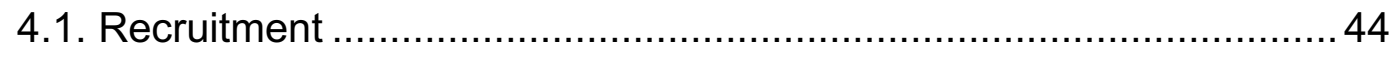

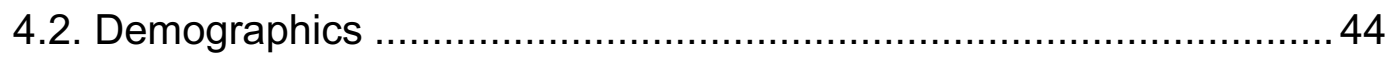

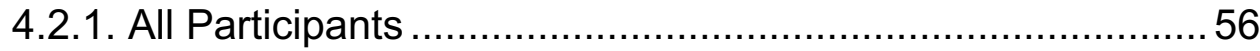

4.2.2. Completers and Non-Completers …................................. 57

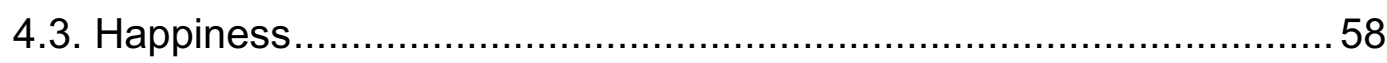

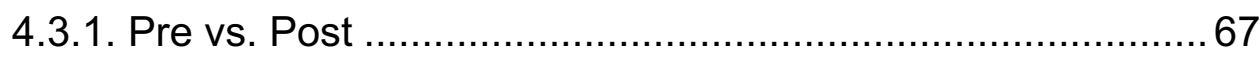

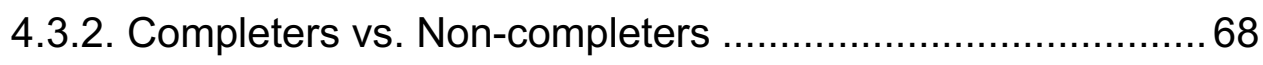

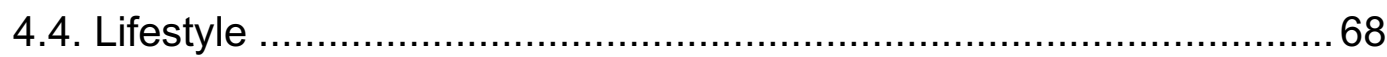

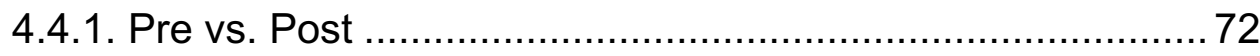

4.4.2. Completers vs. Non-completers …………..................... 74

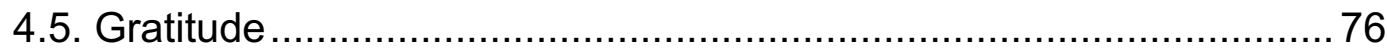




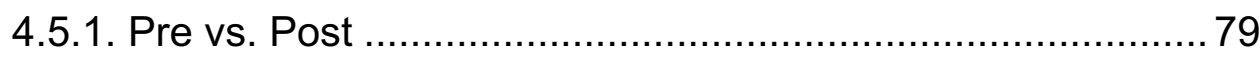

4.5.2. Completers vs. Non-completers ….................................. 80

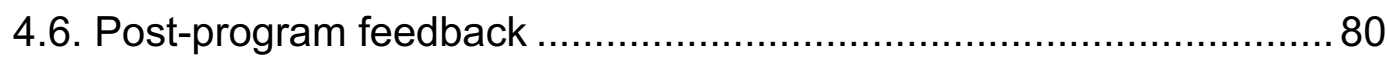

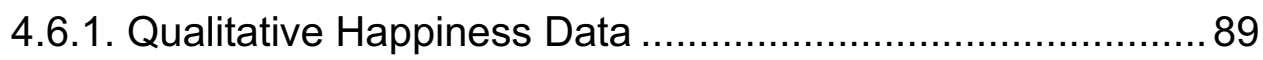

4.6.2. Video Module Feedback ................................................. 90

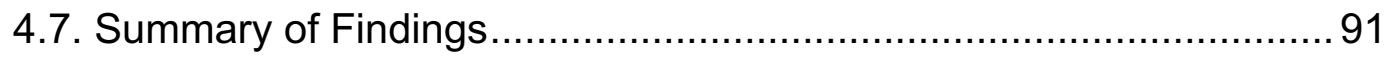

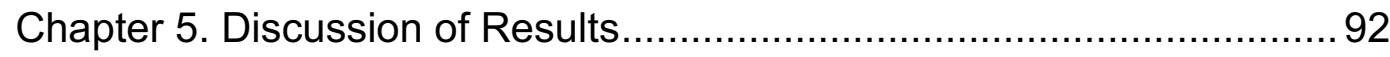

5.1. Representativeness of the Study Sample .....................................92

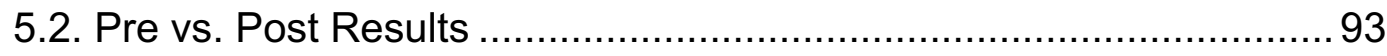

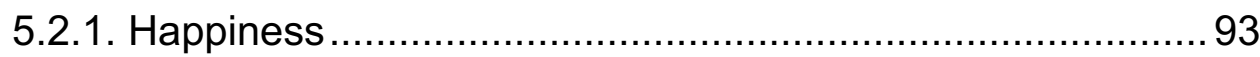

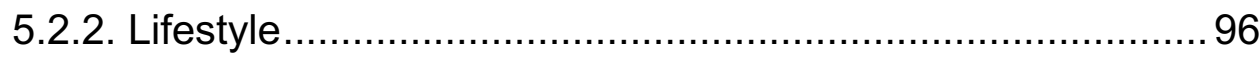

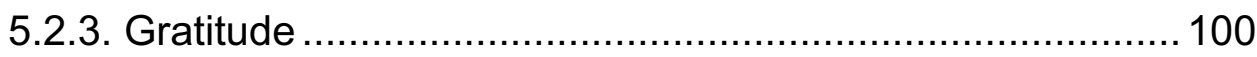

5.3. Completer vs. Non-completers Results ....................................... 101

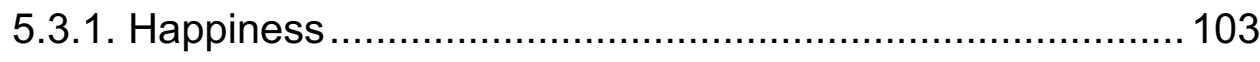

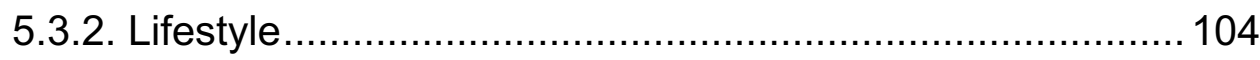

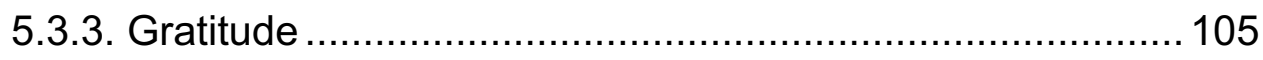

5.4. Post-Program Feedback Results................................................. 105

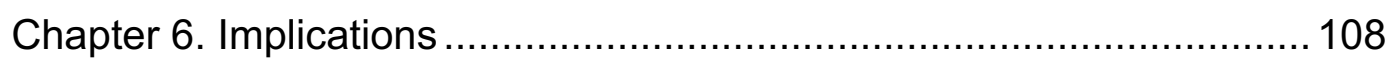

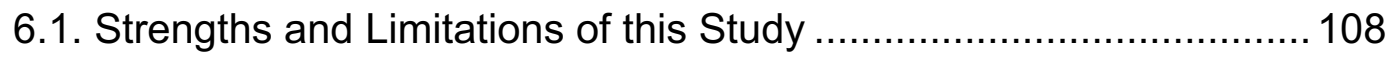

6.2. What this Research Adds to the Literature .................................... 109

6.3. Implications for Policy and Practice ............................................ 109

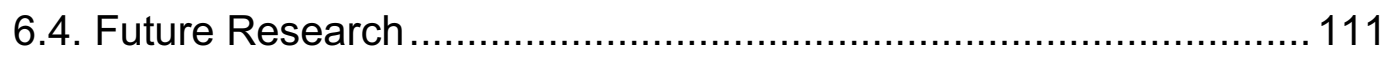

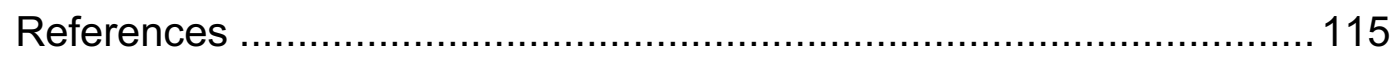

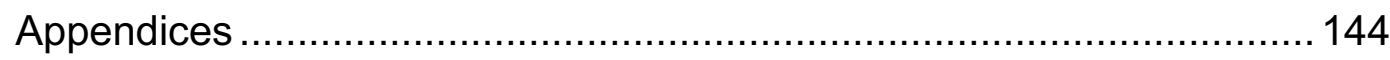

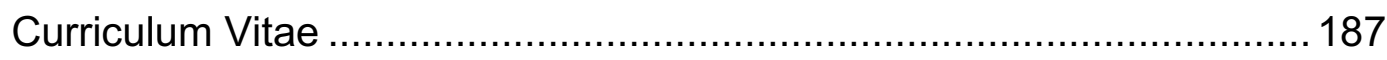




\section{List of Tables}

Table 1 Participants by year of academic study ............................................. 45

Table 2 Participants by program enrolment ………....................................... 46

Table 3 Participants by program enrolment status ......................................... 47

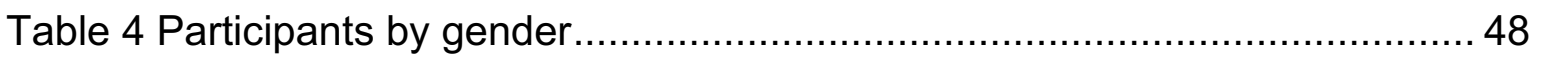

Table 5 Participants by mental health diagnosis ............................................. 49

Table 6 Participants by chronic health diagnosis ........................................... 50

Table 7 Participants by professional help for school related difficulties ............... 51

Table 8 Participants by place of residence ..................................................... 52

Table 9 Participants by how tuition expenses are paid .................................... 53

Table 10 Participants by how living expenses are paid..................................... 54

Table 11 Participants by how personal expenses are paid ............................... 55

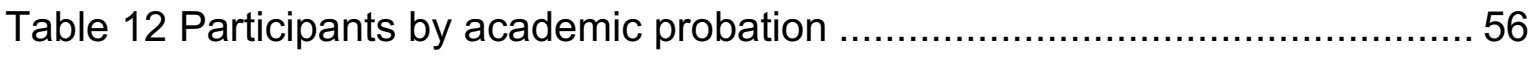

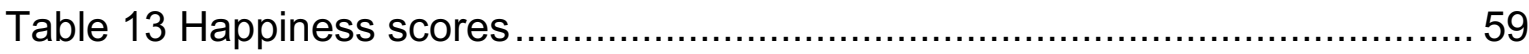

Table 14 Percent of time spent feeling happy, unhappy, and neutral ..................60

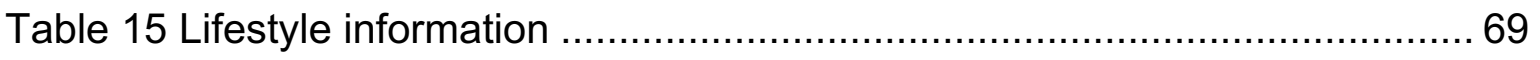

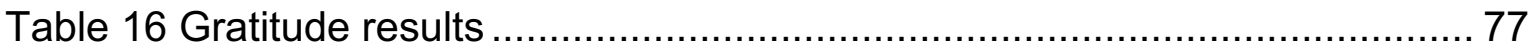

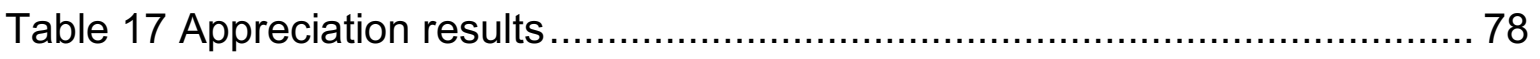

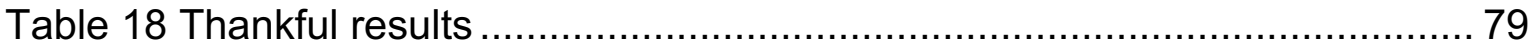

Table 19 Program feedback questionnaire happiness results .......................... 81

Table 20 Program feedback questionnaire video module results ....................... 86 


\section{List of Figures}

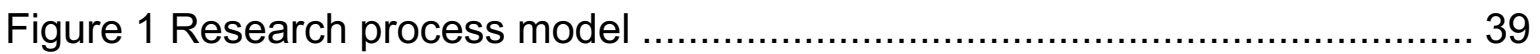

Figure 2 Year of academic study (all participants enroled) …........................... 45

Figure 3 Program enrolment (all participants enroled) …............................... 46

Figure 4 Participants by program enrolment status (all participants enroled) ....... 47

Figure 5 Participants by gender (all participants enroled) ….......................... 48

Figure 6 Participants who have been diagnosed with a mental health problem (all

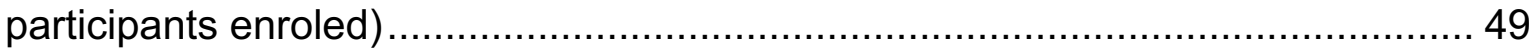

Figure 7 Participants who have been diagnosed with a chronic health problem (all

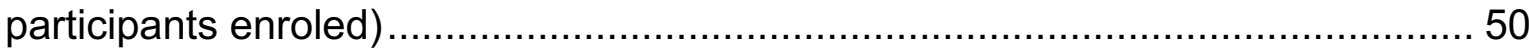

Figure 8 Participants who have sought professional help for school related difficulties (all participants enroled) .............................................................. 51

Figure 9 Participants by where they live (all participants enroled) …................. 52

Figure 10 Participants by how their tuition expenses are paid (all participants

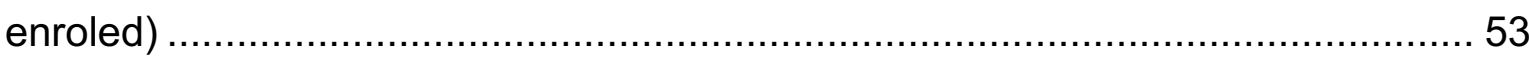

Figure 11 Participants by how their living expenses are paid (all participants enroled)

Figure 12 Participants by how their personal expenses are paid (all participants

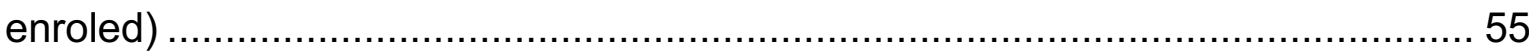

Figure 13 Participants who have been placed on academic probation (all

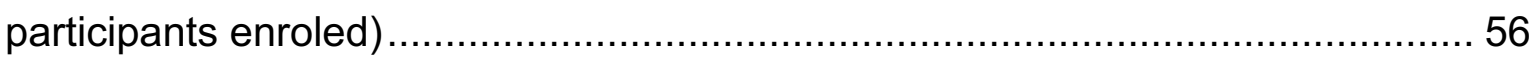

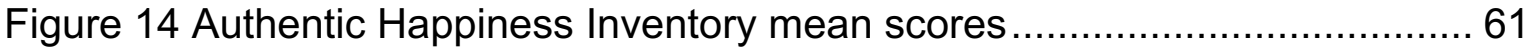

Figure 15 Subjective Happiness Scale mean scores ..................................... 62

Figure 16 Fordyce Emotions Questionnaire mean scores ................................ 63

Figure 17 Oxford Happiness Inventory mean scores ....................................... 64

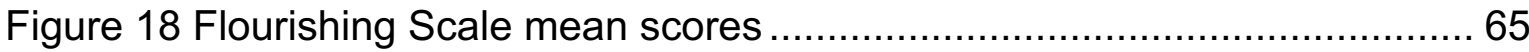


Figure 19 Percent of time spent happy, unhappy, and neutral...

Figure 20 Participants by the extent they feel grateful right now, at the present moment

Figure 21 Participants by the extent they feel appreciative right now, at the present moment 78

Figure 22 Participants by the extent they feel thankful right now, at the present moment 79 


\section{List of Appendices}

Appendix A.Letter of Information and Consent..................................141

Appendix B.Eligibility Questionnaire on Qualtrics..............................145

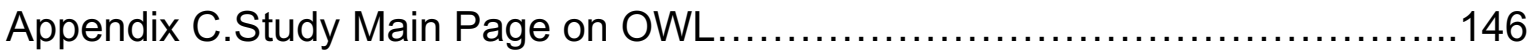

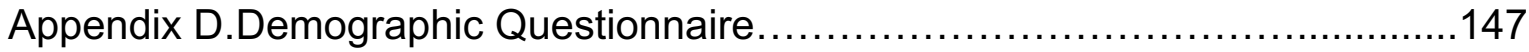

Appendix E.Pre/Post Questionnaire............................................ 149

Appendix F. Email to Be Sent to Participants Who Report Indications of High

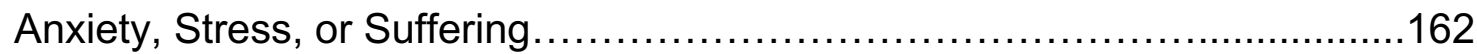

Appendix G. Email Script for Post-Program Questionnaire......................163

Appendix H.Post Program Online Questionnaire Letter of Information and

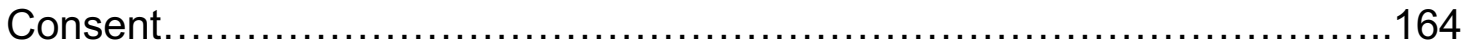

Appendix I. Post-Program Online Questionnaire ...............................167

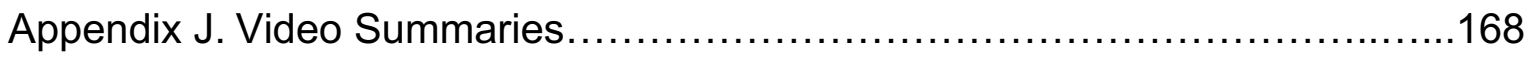

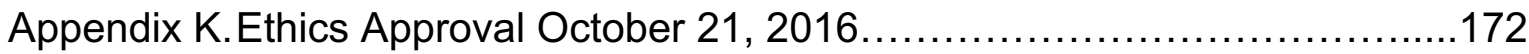

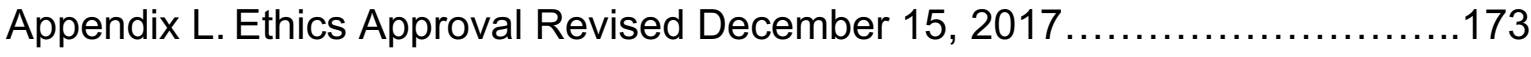

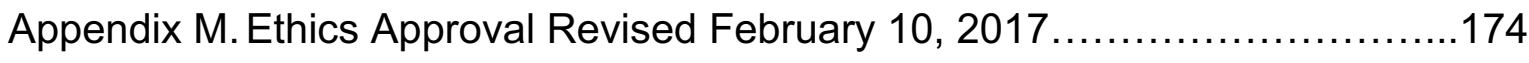

Appendix N.Ethics Approval Revised April 13, 2017 ...........................175

Appendix O. Email Script for Recruitment.......................................176

Appendix P.Reminder Email Script for Recruitment..............................177

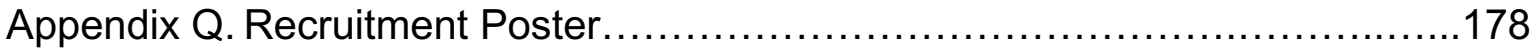

Appendix R.Script for Classroom Recruitment....................................179

Appendix S.Sample Tweets for Recruitment...................................180

Appendix T.94.9 CHRW Commercial Radio Script for Recruitment..................181

Appendix U.Advertisement for Western Gazette Newspaper.....................182

Appendix V.Western Gazette Newspaper Printed Advertisement...................183 


\section{Chapter 1. Literature Review}

This chapter will outline a review of the literature to provide background and support for the current study. First, demographic characteristics of the university student population will be described, focusing specifically on physical health, mental health, and online behaviours. Second, happiness will be defined, its importance in terms of physical and mental health will be discussed, and interventions to increase happiness will be examined.

\subsection{Population Rationale}

University is a key place of development for many young adults (Froiland, 2018) during formative years in their life. University students comprise a unique group because they are required to adapt to new academic challenges while simultaneously learning to adjust to being in a new community (often away from home), changing social networks, and new living arrangements (Jackson, Mark Pancer, Pratt, \& Hunsberger, 2000; Wrench, Garrett, \& King, 2013). The following section includes an examination of the undergraduate university student population, their physical and mental health status, and their online behaviours.

\subsubsection{Undergraduate Student Enrolment and Financial Support}

There were 1.7 million undergraduate students enroled in university in Canada in 2016, and 1,016,000 of those students were enroled full-time (Universities Canada, 2016). At Western University specifically, 23,192 full-time undergraduate students were enroled full time in the 2016-2017 academic year (Western Office of Institutional Planning, 2017).

When examining the Faculty/discipline enrolment (using the same combined categories as are later presented in this study), 7,042 Western University students were enroled in Science/Engineering; 5,151 in Social Science/Business; 4,959 in Health Sciences; 1,396 in Arts and Humanities/Music; and 966 in Information and Media Studies. More females $(12,933)$ were enroled compared to males $(10,260)$, and 
20,923 students were Canadian or Permanent Residents and 2,183 were International Students (Western Office of Institutional Planning, 2017).

In terms of financial assistance, a web-based survey conducted by the Office of the Provost and Vice-President (2017) at Western University during the 2016-2017 academic year with 1,796 graduating students reported that parents were the largest source of financial assistance ( $44.3 \%)$, followed by loans $(34.8 \%)$, self-funded $(7.1 \%)$, scholarships (2.6\%), and spouse/partner (0.3\%). Additionally, results from the National Longitudinal Survey of Children and Youth (NLSCY; Cycle 8 September 1, 2008 - July 31, 2009), a longitudinal Canadian study that follows the development and well-being of Canadian children from birth to early adulthood, found that those enroled in postsecondary education received money from personal employment (61.9\%), parents (48.5\%), savings $(40.0 \%)$, student loans $(29.3 \%)$, scholarships $(26.9 \%)$, and a loan or line of credit (10.3\%; Statistics Canada, 2009).

\subsubsection{Physical Health of Undergraduate Students}

While undergraduate students are within the same age range in Canada and the United States, United States research tends to group college and university students together, unlike in Canada where a distinction is generally made between college and university students. Data from the National Longitudinal Survey of Children and Youth (NLSCY Cycle 8; Statistics Canada, 2009), found that among youth ages 16 to 25 ( $M$ age $=20.2, S D=2.9), 66.1 \%$ of respondents would like to improve their health. Health behaviours potentially affecting university students include a wide range of habits (Deasy, Coughlan, Pironom, Jourdan, \& Mcnamara, 2015; Mouw \& Khanna, 1993), and according to the American College Health Association (2016), within in the last 12 months, students reported several health behaviours affecting their academic performance, including stress (42.9\%), depression (21.9\%), relationship difficulties $(13.0 \%)$, chronic health problem $(4.5 \%)$, alcohol use $(4.3 \%)$, and illicit drug use (2.4\%). 
Indicators of physical health, including physical activity, weight, sleep, and tobacco/illicit drug/alcohol use will be discussed specifically for an undergraduate student population.

\subsubsection{Physical Activity}

The health benefits of engaging in regular physical activity are well established (Plotnikoff et al., 2015). A systematic review by Reiner, Niermann, Jekauc, and Woll (2013) showed that physical activity is associated with better health, it could help to prevent the development of noncommunicable diseases such as coronary heart disease and type II diabetes mellitus. The prevalence of individuals who achieve physical activity recommendations declines rapidly between the ages of 18 and 24 (Grim, Hortz, \& Petosa, 2011), it is also during this time that many young adults begin university (Haase, Steptoe, Sallis, \& Wardle, 2004). Additionally, Irwin's (2004) systematic review found that students who live on campus are less likely to be active when compared to students who live off campus. According to the American College Health Association (2016), 27.6\% of college students had not engaged in any moderate intensity cardio or aerobic exercise for at least 30 minutes within the past seven days, $55.3 \%$ did on one to four days, and $17.1 \%$ did on five to seven days. Additionally, Peltzer and Pengpid (2013) assessed the physical activity behaviours of a sample of 800 university students who completed the self-administered International Physical Activity Questionnaire-short version (IPAQ-S7S) questionnaire, and found that less than half $(41.8 \%)$ engaged in the recommended amount of physical activity, defined as engaging in moderate- or vigorous-intensity activities achieving a minimum of at least 600 metabolic equivalent minutes per week (the equivalent of 150 minutes of brisk walking or 75 minutes of running per week, Craig et al., 2003).

\subsubsection{Weight}

In addition to the detrimental health consequences of physical inactivity, AbuMoghli, Khalaf, and Barghoti (2010) found that physical inactivity was related to behaviours that impact health and well-being in university students, including maintaining a healthy body weight. Given that young adults are within the age group 
that experiences the fastest weight gain (Truesdale et al., 2006), Quick et al. (2014) suggest that taking a preventative approach to weight gain could be beneficial, particularly for this population.

\subsubsection{Sleep}

In addition to physical activity, a systematic review by Ong, Kim, Young, and Steptoe (2016) revealed that getting adequate sleep is another health behaviour that has been associated with several positive health outcomes, including regulating emotions, immune function, and memory consolidation. As well, deficits in sleep quality (i.e., not feeling rested and restored upon waking) can contribute to an increased risk for morbidity and death (Jackowska, Dockray, Hendrickx, \& Steptoe, 2011; Ong et al., 2016). In a study with undergraduate students, Kelly, Kelly, and Clanton (2001) found a positive correlation between hours of sleep and school grades: students who slept more than eight hours per night had a higher grade-point-average (3.2) as compared to students who slept less than seven hours per night (2.7). In addition to sleep duration, Gomes, Tavares, and De Azevedo (2011) demonstrated that sleep quality is also a significant predictor of school grades among undergraduates, and Wong et al. (2013) found that poor sleep patterns are related to impaired academic performance.

Peltzer and Pengpid (2013) assessed the health behaviours among 800 university students and found that in a 24-hour period about one third (30.6\%) of the sample slept six hours or less. According to the American College Health Association (2016), only $13.7 \%$ of college students reported getting enough sleep to feel rested six or more days per week ( $47.7 \%$ reported that for three to five days, $27.6 \%$ reported it for one to two days, and $11.1 \%$ said they never felt they got enough sleep to feel rested in the past week). Additionally, $40.3 \%$ of college students said they felt tired, dragged out, or sleepy during the day on three to five of the last seven days, and $87.8 \%$ reported that sleepiness caused a problem during daytime activities within the past week (American College Health Association, 2016). In a Canadian sample of adolescents and young adults, $30.9 \%$ reported getting no more than six hours of sleep per night on a regular basis (Statistics Canada, 2009). 


\subsubsection{Tobacco/Illicit Drugs/Alcohol}

Other behaviours that have been found to be associated with health include use of tobacco, illicit drugs (e.g., marijuana, nonmedical use of prescription drugs), and alcohol (Piqueras, Kuhne, Vera-Villarroel, Van Straten, \& Cuijpers, 2011). Consuming tobacco substantially increases the risk of mortality from several major noncommunicable diseases (Jha \& Peto, 2015), and evidence now supports that smoking causes at least 15 types of cancer an increased risk of numerous chronic diseases including heart disease, stroke, lung disease. and diabetes (Hyland et al., 2017; Roditis, Delucchi, Cash, \& Halpern-Felsher, 2016; Shopland, 1995). Drinking and illicit drug use have been associated with a number of negative psychological consequences, such as distress and depression (Fielder, Walsh, Carey, \& Carey, 2013; Lewis, Atkins, Blayney, Dent, \& Kaysen, 2013) and decreased physical health (Clegg-Kraynok, McBean, \& Montgomery-Downs, 2011).

University students in particular are at risk of problematic tobacco, illicit drug, and alcohol consumption (Montagni, Cariou, Feuillet, Langlois, \& Tzourio, 2018). A survey of tobacco use among college students conducted by the American College Health Association (2016) found that within the past 30 days, $13.2 \%$ of college students had smoked cigarettes, $5.6 \%$ had smoked e-cigarettes, and $5.1 \%$ consumed tobacco from a water pipe (hookah). Peltzer and Pengpid (2013) found that among a sample of 800 university students, $6.9 \%$ currently use a tobacco product, and Statistics Canada (2009) reported that $18.6 \%$ of adolescents and young adults smoke cigarettes daily and $42.7 \%$ smoke cigarettes at least once a week. In addition, prevalence estimates for marijuana use and nonmedical use of prescription drugs range as high as $30 \%$ on college campuses (Parks, Frone, Muraven, \& Boyd, 2017). Finally, Peltzer and Pengpid (2013) reported that $38.6 \%$ of university students have used alcohol in the past two weeks. According to the American College Health Association (2016), $66.3 \%$ of college students reported using alcohol, with $45.8 \%$ consuming four or fewer drinks per week, $20.1 \%$ having five or six drinks per week, and $34.1 \%$ drinking seven or more drinks each week $(M=5.8$ drinks, $S D=4.4)$. 


\subsubsection{Mental Health of Undergraduate Students}

Not only are the overall rates of mental health challenges on the rise, university students as a population experience significantly higher levels of psychological distress as compared to the general population (Bayram \& Bilgel, 2008; Cooke, Bewick, Barkham, Bradley, \& Audin, 2006; Ryan, Shochet, \& Stallman, 2010). A 2016 national survey of 44,000 post-secondary students found that there has been an increase in the number of students reporting serious mental health crises (American College Health Association, 2016). A study across Ontario universities found that $14 \%$ of students had a serious psychological condition (as diagnosed by a medical professional), compared to $10 \%$ in 2013, (American College Health Association, 2016). Additionally, the NLSCY reported that $16.9 \%$ of youth ages 16 to 25 felt they could not "shake the blues" this past week (Statistics Canada, 2009). At Western University specifically, the proportion of students reporting having a mental health condition was $9.2 \%$ of students reported having a mental health condition in 2016 , which was an increase of 3\% from 2013 (Doerksen, Ezekiel, Chiodo, \& The Student Mental Health and Wellness Advisory Committee, 2018).

Research examining help-seeking behaviours has found that individuals who are more distressed are less likely to seek help (Cigularov, Chen, Thurber, \& Stallones, 2008; Ryan et al., 2010). This means that university students, a population whose unique life circumstances already place them at a higher risk for mental health problems, are also less likely to seek professional help when they are experiencing problems (Cooke et al., 2006; Eisenberg, Golberstein, \& Gollust, 2007). Ryan et al. (2010) estimate that between $45.0 \%$ and $65.0 \%$ of university students experiencing mental health problems do not seek out professional help. This finding is particularly troublesome because as students' levels of psychological distress increase, they are less likely to seek help (Ryan et al., 2010).

When university students do seek help for mental health issues, they are more likely to seek informal as opposed to formal or professional assistance (Hodges, O'Brien, \& Mcgorry, 2007; Kelly, Jorm, \& Wright, 2007; Rickwood, Deane, Wilson, \& Ciarrochi, 2005). Informal help, which often involves reaching out to family, friends, 
spouses, self-help books, or the Internet, is usually easier to access, less expensive, and not as stigmatized as seeking help from mental health professionals such as psychologists or counsellors (Ryan et al., 2010).

\subsubsection{Goal Setting}

In terms of goal setting, Wyn (2009) found that although students described that they know what it takes to be healthy, many act in ways which are incongruent with this knowledge; that is to say, many students engage in practices that paradoxically harm their health (e.g. not eating well, compromising sleep, and not seeking help for mental health challenges). Wyn (2009) also reported that while their sample of students described how although there are many aspects of their lives over which they do not have control (both in terms of their successes and their failures), students nonetheless feel responsible for many of their outcomes (Wrench et al., 2013).

\subsubsection{Stress}

While heightened stress is problematic for anyone of any age, university students face several unique stressors associated with examinations, course-work, and academic study (Denovan \& Macaskill, 2017). In addition to academic demands, it has been well documented that university students experience other unique stressors such as financial challenges from tuition, living expenses, and balancing employment with school demands, as well as and balancing other responsibilities from work, family, and a social life (Cooke et al., 2006; Pierceall \& Keim, 2007; Vaez, \& Laflamme, 2008). According to the American College Health Association (2016), 39.4\% of college students reported feeling more than average stress in the past 12 months and $11.0 \%$ felt tremendous stress. Heightened stress is of particular concern for university students because it can have adverse effects on academic achievement and quality of life (Bayram \& Bilgel, 2008; Vaez \& Laflamme, 2008). Stress has also been correlated with an impaired capacity to carry out regular, daily activities such as work or studying (Ryan et al., 2010). Additionally, higher levels of stress may exacerbate existing mental health symptoms in university students, and/or contribute to the development of greater emotional or psychological distress (Royal College of Psychiatrists, 2011). 


\subsubsection{Online Learning and Undergraduate Students}

\subsubsection{1. eLearning}

It has been predicted that bits and bytes will replace bricks and mortar in the universities of the 21st century (Buzwell, Farrugia, \& Williams, 2016), and more than ever, adolescents and young adults are spending time on computers ( $M$ hours per day $=2.9, S D=2.7$, Statistics Canada, 2009). eLearning has undergone rapid expansion in the higher education sector and is becoming more accepted by academic leaders in higher education (Otter et al., 2013). Allen and Seaman (2013) surveyed 2,800 colleges and universities and found a significant increase in the number of colleges and universities that offer eLearning options for students (from less than half of colleges and universities in 2002 to almost seventy percent in 2012). In addition to eLearning being offered on desktop and laptop computers, as other transportable devices (e.g. tablets and smartphones) continue to grow in popularity (Gikas \& Grant, 2013), eLearning platforms are expanding to include options for various devices (Gikas \& Grant, 2013).

In 2016-2017, Ontario's 45 publicly-funded post-secondary institutions had a combined total of 16,693 online courses (eCampus Ontario, 2017a). Just over half of users completed their eLearning on their computer (52\%), and the remaining accessed their courses via mobile devices (43\%) and tablets (55\%; eCampus Ontario, 2017a). Western University, specifically, now offers more than 250 courses online (eCampus Ontario, 2018).

In addition to the increase in eLearning at universities, the number of students who own a laptop has risen by $83 \%$ from 2004 to 2012 . Renuka and Gurunathan (2017) reported that $98.7 \%$ of university students have access to a computer and $98 \%$ have Internet access. University students are heavier users of the Internet compared to the average population (Kemp \& Grieve, 2014). Students also have increased access to computers provided by their university, which makes access to online resources readily available and easily accessible (Gordon, Juang, Linda, \& Syed, 2007; Hanauer, Dibble, Fortin, Nananda, 2010). 
In terms of favourability towards online learning, a survey conducted by eCampus Ontario, which included 300 undergraduate students aged 18 to 23 found that $71 \%$ of undergraduate respondents felt favourably towards an online program or eLearning course (eCampus Ontario, 2017b). Among those who preferred online learning, convenience, ability to adapt their schedule, and opportunity to work at their own pace were cited as reasons why (eCampus Ontario, 2017b).

Students are increasingly embracing eLearning, and Educase Center For Applied Research (2012) reported that $67 \%$ of the students they surveyed believe that mobile devices are important to their academic success and $87 \%$ of students use their devices for academic activities. For a substantial proportion of university students, online learning is now common (Kemp \& Grieve, 2014), and a growing number (15\% in 2008 to $31 \%$ in 2012) of university students have taken a class completely online (Educase Center For Applied Research, 2012). Allen and Seaman (2013) reported that $39.0 \%$ of all currently enroled undergraduate students have taken at least one online course. In addition to fully online courses, $74.0 \%$ of students have taken at least one course that includes online components, and $54.0 \%$ said they were more actively involved in courses that use technology (Educase Center For Applied Research, 2012).

According to Grummon (2005), eLearning is one of the few relatively unrestricted avenues for innovation in both teaching and learning. It offers new opportunities because it goes beyond the walls of a traditional classroom, removes the limits of time and space, and gives students the flexibility to learn when and where is best for them(Hathaway, 2009). Mobile devices can also provide educational opportunities for students to access course content, as well as interact with instructors and peers wherever they are located (Cavus \& Ibrahim, 2009; Gikas \& Grant, 2013; Kukulska-Hulme \& Shield, 2008).

De Araujo et al. (2016) concluded that eLearning can have a positive impact on academic achievements of students. Furthermore, the use of eLearning has been 
shown to improve students' attitude, motivation and academic achievement (Zare, Sarikhani, Salari, \& Mansouri, 2016).

\subsubsection{Use of Online Health Resources}

A National Survey in the United States found that $80 \%$ of Internet users look for health information online, and $21.0 \%$ of those searches are for depression, anxiety, stress, or mental health information (Culjak, Kowalenko, \& Tennant, 2016). University students, specifically, are amongst the highest users of the Internet for both educational purposes as well as for communication and recreation (Rennis, McNamara, Seidel, \& Shneyderman, 2015). They regularly use the Internet as a source of health information (Horgan \& Sweeney, 2012), and when looking explicitly in terms of mental health, students are increasingly using the Internet as a medium to access information (Horgan \& Sweeney, 2012; Montagni et al., 2018). A survey of university students found that $42 \%$ were interested in learning from a mental health information website, and websites were the second most preferred source (after friends and family) for seeking advice for mental health problems (Ryan et al., 2010).

A study by Montagni et al. (2018) reported that almost all (94.8\%) of students surveyed had searched online for health-related information at least once in the last 12 months. The most commonly searched topics included nutrition (68.1\%); pain and illnesses (64.5\%); and stress, anxiety, or depression (51.1\%). Although Wikipedia $(79.7 \%)$ and general health websites $(77.9 \%)$ were the most frequently consulted sources, the majority (92.2\%) of students considered institutional or official websites (i.e. websites made by local, department ,or national governments) as the most credible sources for health information (Montagni et al., 2018).

When asked about Internet browsing behaviour, most students were not familiar with self-help websites for emotional health (Culjak et al., 2016). After being exposed to a self-help website; however, more students reported visiting websites for emotional health than those who had not been exposed (Culjak et al., 2016). 
In addition to academic purposes, the Internet plays an important role in communication and for personal use (e.g., email, Facebook). Social media platforms (e.g. Facebook and Twitter), are increasingly being used by students to communicate with both their friends and professors (Diug, Kendal, \& Ilic, 2016; Eşkisu, Hoşoğlu, \& Rasmussen, 2017; Sheldon, 2016). Facebook is the most popular site among students in the United States aged 18 to 24 (Zaremohzzabieh et al., 2014), and 25.3\% students stated that YouTube was their favorite site (Renuka \& Gurunathan, 2017).

Additionally, students are expanding their eLearning platforms to include audiobooks, podcasts, and apps (Alam et al., 2016; Jou, et al., 2016; Solcova \& Magdin, 2016). Montagni, Cariou, Feuillet, Langlois, and Tzourio, (2018) reported that $34.9 \%$ of the students surveyed had at least one health app, and almost half (49.4\%) of students used apps for general health monitoring (41.4\%).

\subsection{Happiness}

The following section includes a review of the research literature regarding the definition of happiness, why happiness is important (including its effects on physical and mental health), and online interventions that have been documented to boost happiness.

\subsubsection{Defining Happiness}

There is substantial ambiguity and variation regarding the definition of happiness (Norrish \& Vella-Brodrick, 2008), and Seligman, Steen, Park, and Peterson (2005) stated that happiness is a scientifically unwieldy term. It is also often used interchangeably with subjective well-being, well-being, and positive affect, which are often considered more scientific terms (Lyubomksky, Sheldon, \& Schkade, 2005; Norrish \& Vella-Brodrick, 2008; Sagiv \& Roccas, 2004; Sheldon \& Lyubomirsky, 2004). According to Lyubomirsky (2008), "academic researchers prefer the term subjective well-being (or simply well-being) because it sounds more scientific and does not carry the weight of centuries of historical, literary, and philosophical subtexts" (p. 32). 
Robbins, Francis, and Edwards (2010) explain that "happiness is an important construct within positive psychology, and yet it remains elusive to define and problematic to assess" (p. 89). Several definitions of happiness have been used in scientific writing, and definitions are continually evolving. Numerous definitions of happiness are found in the literature, including:

- "An overriding emotional sense of well-being [that] serves as a global index of life satisfaction" (Fordyce, 1977, p. 511).

- "A positive affective-cognitive state of mind" (Diener, Suh, Lucas, \& Smith, 1999, p. 280).

- "Positive emotion and pleasure (the pleasant life), engagement (the engaged life), meaning (the meaningful life)" (Seligman, 2002, p.45).

- "A cognitive component assessing overall satisfaction with life and an affective component which is further divided into the presence of positive affect and the absence of negative affect" (Norrish \& Vella-Brodrick, 2008, p. 394).

- "The experience of joy, contentment, or positive well-being, combined with a sense that one's life is good, meaningful, and worthwhile" (Lyubomirsky, 2008, p. 32).

Seligman's Authentic Happiness Theory (Seligman, 2002) has been commonly cited in positive psychology literature because it is comprehensive and a synthesis of three popular happiness theories (Saricam, 2015). This theory states that happiness is the sum of three determinants: a set range, circumstances, and factors under voluntary control. The theory is formulated as "H = S + C + V" (Seligman, 2002, p. 45) where $S$ is a genetic element that is stable throughout life, $C$ is life circumstances (e.g. education, income, and marital status), and $\mathrm{V}$ is engagement with voluntary activities (Seligman, 2002).

Sheldon and Lyubomirsky (2007) built upon Seligman's definition (2002) by developing a theory of happiness that encompasses a genetic element, life circumstances, and engagement with the voluntary activities; additionally, it accounts 
for unexplained variance in one's experience of happiness. Sheldon and Lyubomirsky's (2007) definition suggests that happiness equals $\beta 0$ (a set point, determined by genetics and fixed temperament), plus $\beta 1$ (effects of circumstances, e.g. current demographics and circumstances including income, health, marital status, religious affiliation, etc.), plus $\beta 2$ (current activities), plus unaccounted for variance.

Sheldon and Lyubomirsky's (2007) theory recognizes the happiness set point that has been well documented in the literature (Lyubomksky et al., 2005), and it also includes a genetic component. Studies of twins who were separated at birth have estimated that the heritability of happiness ranges between 0.4 to 0.7 (with 0.5 being most commonly cited, Nes, 2010). It has been widely accepted in the literature that perhaps the single most important determinant of happiness is genetics (Lykken \& Tellegen, 1996), and approximately $50 \%$ of the variability of happiness may be attributable to one's genes (Sheldon \& Lyubomirsky, 2007).

In addition to the genetic component, the Sheldon and Lyubomirsky (2007) definition also accounts for life circumstances, the fact that elements of happiness can be actively pursued via intentional activities that address factors that are under the individual's control (the things people choose to do and think in their daily lives), and error. This definition is based primarily from Lyubomirsky, King, and Diener's (2005) work from existing evidence that suggests that happiness is approximately $50 \%$ a happiness set point from genetics (Braungart, Plomin, DeFries, \& Fulker, 1992; Lykken \& Tellegen, 1996), 10\% life circumstances (Argyle, 1999; Diener et al., 1999), and $40 \%$ intentional activity (Lyubomksky et al., 2005). It is also consistent with the view that happiness is somewhat malleable (Lykken, 1999), yet still has a more primitive, genetic component (Nes, 2010; Sheldon \& Lyubomirsky, 2007; Stubbe, Posthuma, Boomsma, De Geus, \& Versaevel, 2005). Additionally, Lyubomirsky (2008) has further described happiness as, "the experience of joy, contentment, or positive well-being, combined with a sense that one's life is good, meaningful, and worthwhile" (p.32). 
Given that Sheldon and Lyubomirsky's (2007) definition encompasses happiness' well documented genetic component, life circumstances, current activities, as well as unexplained variance, it is the definition that has been used in this dissertation.

\subsubsection{Why Happiness Is Important}

Across the world, people view feeling happy as both important and valuable (Diener, 2000). In fact, people often rate happiness as one the most important aspects of their lives; in an International sample of 7,204 respondents from 42 countries, 69\% of respondents rated happiness as their top priority (Diener, 2000). Recently, several countries (including Canada) began to include national happiness as an indicator of national progress (Zhang \& Chen, 2018). In addition to being valued globally, the study of happiness is considered a worthy scientific pursuit (Norrish \& Vella-Brodrick, 2008). Since its beginnings more than 30 years ago (Diener, 1984), the study of happiness has grown to include thousands of publications each year across disciplines such as psychology, economics, science, and sociology (Kushlev et al., 2017). The systematic study of happiness has gained significant momentum (Norrish \& Vella-Brodrick, 2008).

With respect to gender, on average males and females do not differ in terms of happiness (Csikszentmihalyi \& Hunter, 2003). The work of Bahrami, Rajaeepour, Rizi, Zahmatkesh, and Nematolahi (2011) provided additional evidence of this, specifically with a student population, a finding that was also seen by Garaigordobil, (2015) who found no differences in terms of happiness between genders. Additionally, Zullig, Huebner, and Pun (2009) conducted a between-groups analysis of variance to look for differences in well-being in relation to university students' year in school, gender, race, and the interactions of these variables. They found that the mean overall well-being scores did not differ significantly by gender, year in school, or race.

Research suggests that increasing happiness contributes to multiple advantages, including benefits to health, relationships, and work (Piqueras, et al,. Lyubomirsky et al. (2005) concluded that "happiness is positively correlated with indicators of superior mental and physical health" (p. 825). A review conducted by Sheldon and Lyubomirsky (2007) revealed a range of benefits associated with 
happiness, including greater career success, improved relationships, and enhanced creativity. Schiffrin and Nelson (2010) also found that increased happiness was associated with improved work performance and higher salaries. Veenhoven (2008) found a significant relationship between happiness and longevity. Additionally, a 15year study by Koopmans, Geleijnse, Zitman, and Giltay (2010) found that lower mortality and morbidity were related to higher levels of happiness.

While the relationship between happiness and health is not yet fully understood, several psychologists and researchers have found a positive association between health and happiness (King \& Pennebaker, 1998; Norrish \& Vella-Brodrick, 2008; Seligman \& Csikszentmihalyi, 2000). Lyubomirsky et al. (2005) concluded that happiness is positively correlated with indicators of strong mental and physical health, and collectively, the increasing volume of happiness research and the physical and mental health benefits of happiness suggest that happiness is worth pursuing, not only because it feels good, but also because it is a wise investment to improve quality of life.

The relationship between health behaviours and happiness has been well established (Peltzer \& Pengpid, 2013). Many health behaviours have been found to be positively associated with happiness, including maintaining a normal body weight (Chang \& Nayga, 2010; Piqueras et al., 2011) and physical activity (Diener \& Tay, 2012; Piqueras et al., 2011; Zhang \& Chen, 2018). Rasmussen and Laumann (2014) found that happiness had a significant, positive (although weak) correlation with current exercise ( $r=0.2$ ), and Fox (1999) found that present exercise is connected to happiness, meaning that people who are currently exercising tend to be happier than people who are not. A meta-analysis by Zhang and Chen (2018) reported a consistent, positive relationship between physical activity and happiness; however, due to the limited number of randomized controlled trials available, the authors could not draw firm conclusions about the causal relationship between physical activity and happiness. Although the specific relationship between happiness and physical activity is yet to be fully understood, Zhang and Chen (2018) suggested that physical activity frequency and volume are essential components of the relationship between physical 
activity and happiness. They noted that even a small increase in physical activity levels can have a positive impact on happiness.

A connection has been documented between exercise and happiness in adolescents as well as adults (Fox, 1999; Norris, Carroll, \& Cochrane, 1992; Rasmussen \& Laumann, 2014). Given that exercise during adolescence can predict exercise in adult life (Hallal, 2006; Telama et al., 2005), it is important to consider physical activity as a means to improve physical health, as well as happiness.

Appropriate sleep is necessary for a balanced and healthy life, and it is commonly observed that sleep has a relationship with mental health and happiness (Mushtaq, Ghayas, \& Niazi, 2014; Thoits \& Hewitt, 2016). Luo and Inoué (2000) demonstrated that sleep and happiness are positively correlated, and Kawada, Kuratomi, and Kanai (2009) found that happiness was associated with having at least six hours of sleep per night. Wong et al. (2013) also noted that growing evidence suggests poor sleep patterns are related to impaired academic performance, physical health, mood, and psychological well-being among college students. Mood is of particular importance for university students as Okun, Levy, Karoly, and Ruehlman (2009) have found evidence that mood is related to academic motivation and grades.

In terms of health behaviours, not using tobacco, taking illicit drugs, or drinking excessive alcohol have been found to be associated with happiness (Piqueras et al., 2011). Stickley et al. (2015) examined happiness in nine countries and found that nonsmokers were happier than routine smokers. A study by Ataeiasl et al. (2018) found that after controlling for several behaviours (including experience of self-injury, substance abuse, smoker friend[s], smoker[s] in the family, attitudes toward smoking, and average grades in the previous year), those with higher happiness scores were less likely to smoke cigarettes. Specifically in adolescents, Kye, Kwon, and Park (2016), found that happiness and smoking were negatively related, and Ataeiasl et al. (2018) determined that in students, happiness scores were negatively associated with cigarette smoking. Additionally, Heizomi, Allahverdipour, Jafarabadi, and Safaian (2015) concluded that adolescents with a history of smoking over the past six months 
had significantly lower happiness scores as compared to adolescents who did not smoke during the same period.

The term illicit drugs includes a wide variety of substances that either stimulate (e.g. cocaine or amphetamines) or inhibit (e.g. heroin or sedative-hypnotics) the central nervous system or cause hallucinogenic effects (e.g marijuana or LSD) to the effect that their use has been prohibited globally, and research on their effects on happiness is limited and requires further investigation. Piqueras et al. (2011) examined marijuana consumption and happiness and did not find any significant relationship. Fischer (2015) conducted a prospective, longitudinal study examining the association between cannabis use and quality of life and found that after adjusting for potential confounders (e.g socio-demographic characteristics), participants who used cannabis more frequently had a lower quality of life at a 21-year follow-up. In terms of other types of drugs, Veenhoven (2003) found that the use of psychotropic drugs had a slightly negative correlation to happiness. The use of hard drugs (e.g heroin and cocaine) and stimulants (e.g coffee and energy drinks) followed an inverted U-shaped pattern where people who consume a large quantity of stimulants are less happy than modest consumers (Veenhoven, 2003); and taking prescribed or non-prescribed tranquilizers had a moderate and negative relationship with happiness Piqueras et al. (2011). Finally, Veenhoven (2003) reported that early use of illicit drugs (in high school) did not predict later happiness; however, early unhappiness (reported as unhappiness during high school) predicted later illicit drug use.

In a similar pattern to the relationship between stimulants and happiness reported by Veenhoven (2003), correlations between alcohol consumption and happiness tend to also have a curvilinear relationship; moderate drinkers are the happiest (Ventegodt, 2003) while problematic drinking is associated with lower happiness (Geiger \& MacKerron, 2016). Interestingly, Zhou, O'Brien, and Heim (2014) examined happiness in a sample of 243 university student "sportspeople" (defined as students who play and/or attend sporting events). They found that higher self-reported alcohol consumption was associated with elevated self-reported scores of happiness; however, further analyses indicated that these positive correlations were fully 
mediated by the role of team cohesion (Zhou et al., 2014). That is to say that the positive relationship between alcohol consumption and happiness was due to the positive role drinking can have on team cohesion (Zhou et al., 2014).

In terms of alcohol consumption among adolescents, Toumbourou et al. (2007) noted that alcohol is particularly hazardous for adolescents because it contributed to $18.5 \%$ of the deaths and diseases among young people in developed nations. When examining adolescent alcohol misuse specifically, Viner and Taylor (2007) reported that it was associated with many adverse consequences for well-being, including decreased happiness. Finally, Akhtar and Boniwell (2010) conducted a positive psychology group intervention (eight in-person workshops on topics including happiness, strengths, optimism, and gratitude) with alcohol-misusing adolescents and saw significant increases in happiness, optimism, and positive emotions as well as a decline in alcohol dependence and consumption at the end of the intervention.

For nearly 40 years, research has been documented that happiness can be intentionally increased, at least in the short term and potentially over longer periods of time (Fordyce, 1977; Lyubomirsky, Dickerhoof, Boehm, \& Sheldon, 2011; Seligman et al., 2005). Heller, llies, and Watson (2004) as well as Lyubomirsky et al. (2005) found that engaging in activities that boost happiness (e.g committing to important goals) has the potential to improve levels of happiness for significant periods of time. Additionally, Schultheiss, Jones, Davis, and Kley (2008) found that individuals experienced greater feelings of happiness when they reported high levels of goal progress. Kiaei and Reio (2014) also found that goal-striving ability and task accomplishment positively impacted happiness. While there is still much to understand regarding the relationship between goal setting, task accomplishment, and happiness, data from MacLeod, Coates, and Hetherton (2008) provides preliminary evidence that goal setting may have a causal link to happiness.

Perceptions of, and responses to, stress can cause many psychological problems (Siegrist, 2008; Wolkowitz, Epel, Reus, \& Mellon, 2010), and research has often shown an inverse relationship between stress and happiness (Schiffrin \& Nelson, 
2010). The connection between happiness and stress is complex and multidimensional; it has been examined both in terms of the negative effects of stress on happiness as well as the role of happiness in buffering against stress (Suh, Diener, \& Fujita, 1996). Specifically, among college students, a significant, linear, inverse correlation between happiness and stress has been documented (Schiffrin \& Nelson, 2010) indicating that as stress increases, happiness decreases.

Happiness not only feels good, it also appears to play a causal role in relationships (Diener, Oishi, \& Lucas, 2015; Lyubomirsky et al., 2005; Lyubomirsky \& Layous, 2013). Happy people tend to be more cooperative, prosocial, charitable, and other-centered (Kasser \& Ryan, 1996; Lyubomirsky et al., 2005; Williams \& Shiaw, 1999). They also gain tangible benefits from their positive state of mind, including larger social rewards, higher odds of marriage, lower chances of divorce, more friends, stronger social support, and richer social interactions (Estrada, Young, \& Isen, 1994; Harker \& Keltner, 2001; Marks \& Fleming, 1999; Staw, Sutton, \& Pelled, 1994). Happiness is also believed to lead to adaptive characteristics, including altruism, and effective conflict resolution skills (Norrish \& Vella-Brodrick, 2008). Positive social relationships have also been shown to be an important factor in happiness across age and culture (Buzwell et al., 2016). A study by Jackowska et al. (2011) found that low levels of social support were more prevalent among those less happy, and Lyubomirsky et al. (2005) found that compared to less happy people, happier people had an increased likelihood of having successful relationships (Lyubomirsky et al., 2005). Additionally, Parks, Della Porta, Pierce, Zilca, and Lyubomirsky (2012) gave participants a list of 14 activity categories, and about half (52.6\%) of respondents selected "nurturing my social relationships" as the most important or meaningful item to them. Specifically, when looking at adolescents, Lambert et al. (2014) found that caring relationships were an important contributor to happiness.

Gratitude has been defined as both a state and a trait (Chen \& Kee, 2008; Emmons \& McCullough, 2003; Watkins, Woodward, Stone, \& Kolts, 2003). It can be conceptualized as a subjective feeling of wonder, thankfulness, and appreciation for life (Emmons \& Shelton, 2002). It is a positive emotion that orients people toward 
noticing and appreciating the positive in life (Wood, Froh, \& Geraghty, 2010). Hasemeyer (2013) found that gratitude may also lead to better psychological and academic functioning.

Although gratitude overlaps with happiness, it also possesses a unique pattern of appraisals that distinguishes it from happiness (Emmons \& McCullough, 2015). There have been promising developments that suggest that gratitude has positive effects on happiness (Norrish \& Vella-Brodrick, 2008) and has been shown to be a robust predictor of happiness (McCullough, Emmons, \& Tsang, 2002; Wood, Maltby, Gillett, Linley, \& Joseph, 2008).

Experimental evidence has also demonstrated the short-term efficacy of increasing gratitude to increase happiness (Emmons \& McCullough, 2003; Lee Duckworth, Steen, \& Seligman, 2005). A survey found that over $90 \%$ of respondents indicated that expressing gratitude helped them to feel extremely or somewhat happy (Emmons \& McCullough, 2015). Additionally, a study by Emmons and McCullough (2003) demonstrated that manipulating gratitude levels resulted in changes in happiness; and research found that people feel happier after expressing gratitude (Lyubomirsky et al., 2011).

\subsubsection{Interventions To Increase Happiness}

While the idea of happiness interventions is not new (Fordyce, 1977), there has been a surge in the amount of research investigating various programs to boost happiness (Sheldon \& Lyubomirsky, 2012). The number of scientific publications on happiness has also increased significantly, particularly since the 1990's (Veenhoven, 2015). Given the multitude of benefits that are related to happiness as previously discussed, researchers are increasingly conducting studies investigating strategies to boost happiness (Norrish \& Vella-Brodrick, 2008) and sustain it over time (Seligman et al., 2005). In addition to the what of happiness-boosting interventions, Sheldon and Lyubomirsky (2007) suggests the why is also important. That is to say, the authors found that although content matters in a happiness intervention, if participants felt the 
activity was uninspiring, was not a positive experience, or did not provide an opportunity for personal growth they did not experience an improvement in happiness.

The definition of happiness used in this dissertation states that happiness equals $\beta 0$ (set point), plus $\beta 1$ (circumstances), plus $\beta 2$ (current activities), plus unaccounted for variance. From this perspective, given that $\beta 0$ (set point) includes a fixed genetic component and $\beta 1$ (circumstances), which have been shown to affect happiness (although the effects tend to be short lived and small), Lyubomksky et al. (2005) suggest that the element of the equation that is most amenable to intervention is $\beta 2$ (current activities). This element has the greatest opportunity to elevate people into the upper end of their happiness range and boost happiness (Sheldon \& Lyubomirsky, 2007); however, to date, the most effective methods to increase $\beta 2$ have yet to be determined (Schiffrin \& Nelson, 2010).

Sheldon and Lyubomirsky (2006) concluded that changes in activities can have positive consequences for happiness levels. When examining happiness interventions with a student population specifically, Van Zyl and Rothmann (2012) found that their happiness intervention did increase perceived happiness among participants. Ouweneel, Le Blanc, and Schaufeli (2014) found similar results as their student participants scored higher on positive emotions after their happiness intervention. While the best types of happiness interventions are yet to be determined, Regehr, Glancy, and Pitts (2013) have noted that the high prevalence of mental health problems among university students highlights a need for accessible interventions that can address the specific challenges and needs of this population. Additionally, Plotnikoff et al. (2015) have described how higher education institutions have access to a large proportion of students living away from home for the first time, consequently, they have the capacity to provide support to help establish healthy behavioural patterns that may continue throughout the lifespan.

While most happiness interventions to date have been in-person, researchers have begun to explore the possibility of administering happiness interventions online. Online formats have been demonstrated to be a viable treatment modality for weight 
loss (Crane, Lutes, Ward, Bowling, \& Tate, 2015; Tate, Jackvony, \& Wing, 2003), and it has been suggested that online interventions have the potential to improve the psychological well-being and happiness of university students (Griffiths, Farrer, \& Christensen, 2007; Hanauer et al., 2010; Lauder, Chester, \& Berk, 2007).

Although studies that involve an online intervention to improve happiness are still scarce (Manthey, Vehreschild, \& Renner, 2016), some noteworthy work has been done. Seligman et al. (2005) conducted a randomized, placebo-controlled Internet study that investigated the effects of different self-administered happiness interventions. When compared to the control group, three of the five interventions led to an increase in happiness, a change that was sustained when assessed one-month post-intervention. The three interventions were a gratitude visit (participants wrote and delivered a letter of gratitude to someone for whom they were thankful), gratitude writing (participants wrote down and explained three things that went well in the past week), and using signature strengths (participants received feedback on their five strongest character strengths and used one of them in a new way).

Given that university students are a high-risk population for mental health problems, yet few seek professional help when experiencing problems (Ryan et al., 2010), the possibility of online happiness-boosting interventions shows great promise. Denovan and Macaskill (2017) report that funding for universities has not kept pace with the student population growth, which has resulted in changes to the student experience. For example, funding for support services such as counselling has not kept pace with the growth in student numbers. Creating online health programs for students may be beneficial not only because a growing number of students are already looking online to access health information (Horgan \& Sweeney, 2012; Montagni et al., 2018), but also because they may provide an opportunity for universities to provide accessible assistance to students. Online health programs could help to improve access and participation, increase flexibility and autonomy for delivery, and target students' unique lifestyle challenges. Ryan et al. (2010) explored the role of an online intervention for promoting well-being in university students, and found that although students were less likely to seek help as psychological distress 
increased, their intention to use an online intervention increased at higher levels of distress (low, moderate, and severely distressed students said they would use an online program to support their well-being, $39.1 \%, 49.4 \%$ and $57.7 \%$, respectively).

Beyond simply administering happiness-boosting interventions online, Manthey et al. (2016) noted that, to the best of their knowledge, their 2016 study was the first Internet-based happiness intervention that also included a video element. FinlayJones, Kane, and Rees (2017) have also published evidence that participants experienced significant increases in happiness after their online happiness program, which included a video component. Given that video is increasingly being incorporated with success to online happiness interventions, more study is warranted.

\subsection{Literature Review Summary}

The literature regarding university students suggests that there is an opportunity to improve both the physical and mental health of undergraduate students. This population is also increasingly using online platforms to access both academic and health information; consequently, it may provide an opportunity to target and improve their health and quality of life.

Although the definition of happiness is varied and continually evolving in research literature, it is clear that there are many physical, mental, and social benefits to happiness. Interventions that aim to boost happiness have shown promise, and further research, particularly examining online interventions with video for undergraduate students is warranted.

\subsubsection{Research Rationale}

Despite a growing body of evidence supporting the efficacy of happiness interventions to improve physical health, mental health, and social relationships, many questions still remain. More specifically, when examining the unique needs of university students, further investigation into both the efficacy of happiness interventions and the optimal methods and platforms for delivery is needed. Given that university students face unique physical and mental health challenges, and they are 
increasingly online and using online platforms to access mental health resources, there is a timely opportunity to explore the potential of online happiness interventions, specifically with video, to improve happiness among university students.

\subsubsection{Purpose Statement}

The purpose of this study is to test whether an online happiness intervention using videos to boost happiness can increase self-reported happiness among university students. It is hypothesized that when university students learn about happiness online, their self-reported happiness, lifestyle outcomes, and gratitude will increase. The primary outcome of the current study is self-reported happiness. Secondary outcomes include self-reported lifestyle outcomes (weight, confidence in goal setting abilities, satisfaction with accomplishing daily tasks, exercise, sleep, stress, tobacco use, illicit drug use, alcohol consumption, social issues, number of close friends, and leisure activities) and self-reported gratitude. Additionally, given the exploratory nature of this study, feedback regarding the online program and video modules was also collected. 


\section{Chapter 2. Method of Inquiry}

This chapter outlines the research design and methods used in this study. The purpose of this study is discussed and linked to the methodological choice.

\subsection{Study Purpose}

The purpose of this study was to evaluate the effectiveness of online happiness video modules as a catalyst to improve the health of undergraduate university students. The rationale for the study is based on positive psychology and happiness theories.

Over four weeks, online video modules were used to guide participants to explore ways to enhance their own self-reported happiness, physical well-being, and mental health. The primary outcome assessed was self-reported happiness, which was measured pre and post using five validated questionnaires (the Authentic Happiness Inventory [AHI; Seligman et al., 2005], the Subjective Happiness Scale [SHS; Lyubomirsky \& Lepper, 1999], the Fordyce Emotions Questionnaire [FEQ; Fordyce, 1987], the Oxford Happiness Inventory [OHI; Argyle et al., 1989], and the Flourishing Scale [FS; Diener et al., 2009]). Secondary outcomes that were assessed included self-reported lifestyle information (weight, goal setting, and task accomplishment), self-reported health behaviours (exercise, sleep, stress, tobacco use, illicit drug use, and alcohol use), self-reported social behaviours (social issues, friendships, and leisure activities), and self-reported gratitude.

\subsection{Research Design}

In the current study both qualitative and quantitative data were collected. The data collected were primarily quantitative (self-reported happiness; lifestyle measures including weight, confidence in goal setting abilities, satisfaction with accomplishing daily tasks, exercise, sleep, stress, tobacco use, illicit drug use, alcohol consumption, social issues, number of close friends, and leisure activities; and gratitude), although they were supplemented by qualitative data (feedback regarding the online program and video modules). 


\subsection{Description of Research Procedure}

Ethics approval was received from Western University's Research Board for Health Sciences Research (HSREB). Prior to enrolment in the study, participants received a Letter of Information (Appendix A), and consent was indicated by participants' voluntary agreement to respond to the online questionnaires. The study used pre and post self-report and open-ended questionnaires to assess self-reported happiness, physical well-being, mental health, and gratitude. OWL (Western's online learning management system that has high security and privacy features) was used to deliver the four learning modules about happiness.

Participants completed a short (3 question) online eligibility survey (Appendix B) administered via Qualtrics (Western University's chosen online survey software). Once it was determined that they met the study criteria, reviewed the Letter of Information, and consented to participate in the study via email, within 24 hours they were added to the study's OWL site (Appendix C) and were invited to begin the study. Participants logged on to OWL using their student identification and saw Happy and Healthy Study as a module on their dashboard. Participants received a weekly notification through OWL reminding them of a new video available for viewing on YouTube. Each week a new approximately 30 -minute video module was available to participants (one new video per week for four weeks) that taught happiness skills such as gratitude, empathy, and mindfulness.

Evaluation consisted of online self-report questionnaires administered through OWL. At the beginning of the study, participants completed an online demographic questionnaire (Appendix $D$ ) as well as a set of validated assessments measuring selfperceptions regarding several health indicators and behaviours such as happiness; mental health; physical health; tobacco, illicit drug, and alcohol and use; and expressions of gratitude (Appendix E). Following the completion of the final module, participants once again completed the same set of online assessments of health indicators and behaviours (Appendix E). Within 24 hours of submission of the questionnaires at both pre and post, the responses were reviewed and if any of the participant's responses indicated high anxiety, stress, or suffering a follow-up email 
would be sent (Appendix F) to the participant with information about how to access mental health resources on campus. During this study all responses were reviewed and no follow up emails due to high anxiety, stress, or suffering were necessitated or sent.

Upon submission of the post-program questionnaire, participants were invited via email to complete a program feedback questionnaire (Appendix $G$ ). Participants received an additional Letter of Information (Appendix $\mathrm{H}$ ) prior to completion of the feedback questionnaire. The program feedback questionnaire (Appendix I) used openended questions and was designed to: (1) elucidate participants' thoughts, ideas, and views regarding the content of the video modules, (2) elucidate the impact of the video modules on participants' concept of happiness; (3) identify specific strategies, topics, and video module components that participants perceived to be important or valuable; (4) understand if, and how, the participants anticipate that they will incorporate the knowledge from the video modules into their life; and (5) obtain feedback on how to change or improve the modules.

\subsubsection{Video Module Description}

Participants were asked to spend approximately 30 minutes per week online watching the videos and completing short self-study activities. Each week for four weeks participants received new videos that they were instructed to watch on their own schedule. The video links were provided to participants in OWL, and the videos were available via YouTube.

The videos were created by a team at UC Berkeley's Greater Good Science Center. After consulting with the Chief Operating Officer at Project Happiness, part of a coalition that includes the Greater Good Science Center, and the Science Director at the Greater Good Science Center, it was recommended that the current study use four of the eight weeks of videos from their Science of Happiness Course. Four weeks of videos were recommended for this study by the Greater Good Science Center because they were interested in testing a shorter version of the course to evaluate its effectiveness and to obtain feedback from participants. Although the eight-week 
version of the course was well-received at Berkeley, feedback from participants who completed the eight-week course suggested that a shorter version of the course would be preferred; consequently, for this study the Greater Good Science Center team recommended the videos that they felt were most important based on their survey of the most recent and relevant happiness research.

During week one, participants watched videos that included topics such as "what makes you happy?", the benefits of happiness, how to define and measure happiness, misconceptions about happiness, and positive emotions. They were also taught an exercise called three good things that instructed them to remember and write down three good things that happened to them that day. Week two consisted of topics such as social connection, healthy relationships, friendships, and empathy. During week three participants learned about mindfulness, meditation, and breath awareness. Gratitude and overall reflections about the videos were covered during week four. A more detailed description of the modules can be found in Appendix $\mathrm{J}$.

\subsubsection{Measures}

Interested students were required to complete an eligibility survey (Appendix B) to determine if they met the study criteria (enroled full time at Western and between the ages of 17 and 24). Once it was determined that students met the study eligibility criteria, they were enroled in the study. The same questionnaire that assessed selfreported happiness, lifestyle, and gratitude (Appendix E) was administered to participants at the beginning and completion of the study. The primary outcome measure in the current study was self-reported happiness, which was assessed using five happiness questionnaires. Secondary outcome measures included self-reported lifestyle outcomes (weight, confidence in goal setting abilities, satisfaction with accomplishing daily tasks, exercise, sleep, stress, tobacco use, illicit drug use, alcohol consumption, social issues, number of close friends, and leisure activities) and selfreported gratitude. In addition, an optional program feedback questionnaire was administered at the end of the study that asked a total of seven open-ended questions about happiness as well as feedback about the online video modules (Appendix I). 


\subsubsection{Eligibility Survey}

A three-item online questionnaire was administered to students who expressed interest in participating in the study via Qualtrics (Appendix B). The first item asked if the student was enroled full-time in a Western University undergraduate program. The second item asked if the student was between the ages of 17 and 24 . The third item asked students to enter their Western email address, and this was required to add students to the study's OWL site if they met the inclusion criteria (enroled full time at Western and between the ages of 17 and 24).

\subsubsection{Demographic Information}

A demographic questionnaire consisting of 14 items was administered to participants at the beginning of the study (Appendix D) via the study's OWL site. The information collected included date of birth; Faculty of enrolment; program of study; year of study; International student status; gender identity; history of mental health diagnosis; if professional help for school-related difficulties had ever been sought; current residence (e.g. university residence, at home with parents, off-campus, etc.); a record of academic probation; and financial questions regarding how their tuition, living expenses, and personal expenses were paid.

\subsubsection{Happiness}

Self-reported happiness was measured pre and post using five validated questionnaires (the Authentic Happiness Inventory [AHI; Seligman et al., 2005], the Subjective Happiness Scale [SHS; Lyubomirsky \& Lepper, 1999], the Fordyce Emotions Questionnaire [FEQ; Fordyce, 1987], the Oxford Happiness Inventory [OHI; Argyle et al., 1989], and the Flourishing Scale [FS; Diener et al., 2009]) administered to participants via an online questionnaire available on the study's OWL site.

\subsection{Authentic Happiness Inventory (AHI)}

The AHI, also sometimes referred to as the Steen Happiness Index, is used to measure Seligman's definition of overall happiness (Schiffrin \& Nelson, 2010). It measures overall, or state happiness by assessing three aspects of happiness: 
pleasure, engagement, and meaning (Parks et al., 2012, Seligman et al., 2005). Given that the $\mathrm{AHI}$ assesses state happiness, and consequently was designed to be sensitive to changes in happiness levels, especially toward upward changes (Seligman et al., 2005), Schiffrin and Nelson (2010) recommend this tool to be used to assess increases in happiness that may occur as a result of an intervention.

The questionnaire consists of 24 items, and participants are asked to choose the statement that best describes them on a five-point Likert scale ranging from negative (e.g., "My life does not have any purpose or meaning") to extremely positive (e.g., "I have a very clear idea about the purpose or meaning of my life"). The AHI takes approximately three to five minutes to complete. (Jarden, 2011).

Research has demonstrated the reliability of the AHI. Cronbach's alphas greater than 0.9 have been reported in the literature (Finlay-Jones et al., 2017; Schiffrin \& Nelson, 2010). When comparing this tool with two other tools used in this study, a convergent validity of 0.8 was found with the Subjective Happiness Scale (SHS) and 0.7 with Fordyce Emotion Questionnaire (FEQ; Schiffrin \& Nelson, 2010; Seligman et al., 2005).

To determine the overall measure of happiness, the responses to all of the items are summed, and a mean is calculated. The final score ranges from 1 to 5 where a higher score indicates higher overall happiness (Schueller \& Seligman, 2010).

\subsection{Subjective Happiness Scale (SHS)}

The SHS measures current happiness, and it is a global or trait measure of happiness (Schiffrin \& Nelson, 2010). Lyubomirsky and Lepper (1999) stated that the SHS reflects "a broader category of well-being and taps into more global psychological phenomena" (p. 139). This four-item tool was derived from an initial 13 item tool that was administered to a sample of college students in a pilot study. After the pilot, six items were discarded because of their high semantic similarity and an additional three questions were removed because analysis revealed that they did not load onto a single interpretable factor (Lyubomirsky \& Lepper, 1999). The new four-item tool was 
then further tested with 2,732 participants that included high school students, college students, and adults in the United States and Russia (Lyubomirsky \& Lepper, 1999). The tool has been used in several studies (Rasmussen \& Laumann, 2014; Sheldon \& Lyubomirsky, 2006b).

The questionnaire consists of four items that assess participants' subjective sense of global happiness, which is happiness that is more enduring than momentary happiness, yet still somewhat malleable over time (Lyubomksky et al., 2005). Each of the four items are rated on a seven-point Likert scale with descriptions at the end points (e.g. 1 [less happy] to 7 [more happy]). The first item asks participants the extent to which they are a happy person (1 [not a very happy person] to 7 [a very happy person]). The second item asks participants to describe their happiness compared to their peers (1 [less happy] to 7 [more happy]). The third and fourth items ask how well descriptions of a chronically happy and a chronically unhappy person describe them (1 [not at all] to 7 [a great deal]). The first two items ask participants to characterize themselves using both absolute ratings and ratings relative to peers (e.g., "In general, I consider myself a very happy person"), and the last two items require participants to give brief descriptions of happy and unhappy individuals and to assess the extent to which each characterization described the participants themselves (Lyubomirsky \& Lepper, 1999). The SHS takes approximately two minutes to complete (Jarden, 2011).

Despite its brevity, the SHS has been shown to have good to excellent internal consistency, demonstrating comparability across 14 different samples of varying ages, occupations, languages, and cultures $(M=0.9$; Lyubomirsky \& Lepper, 1999; McCullough et al., 2002; Schiffrin \& Nelson, 2010). The construct validation studies of convergent and discriminant validity confirmed the use of this scale to measure subjective happiness (Jarden, 2011; Lyubomirsky \& Lepper, 1999), and the convergent validity has been demonstrated by correlations with other published measures of happiness (using three college student samples) ranging from 0.5 to 0.7 ( $M=0.6$; Lyubomirsky \& Lepper, 1999). The SHS has also been found to have a good test-retest reliability of 0.7 (Lyubomirsky \& Lepper, 1999; McCullough et al., 2002). 
Additional studies using the tool have also indicated good internal consistency $(0.8$, Caunt, Franklin, Brodaty, \& Brodaty, 2013; and 0.7 Peltzer \& Pengpid, 2013).

Howell, Rodzon, Kurai, and Sanchez (2010) have also tested the SHS for use on the Internet using both a college student sample and an adult sample and provided support for the reliability, validity, and generalizability for its Internet format.

To score the SHS, the last item is reverse-scored, and then the responses for each item are added up to give an overall score ranging from 4 to 28 . That number is then divided by four to give a composite score for global subjective happiness. Thus, the possible range of scores is from 1 to 7 , and a higher total score indicates greater subjective happiness (Lyubomirsky \& Lepper, 1999; Lyubomirsky, Sousa, \& Dickerhoof, 2006).

\subsection{Fordyce Emotions Questionnaire (FEQ)}

The FEQ is a measure of emotional well-being that provides an indication of a person's perceived current happiness (Fordyce, 1987). The FEQ is a two-item questionnaire that assesses both intensity and frequency of current happiness affect; the first item measures intensity, and the second item estimates frequency (Fordyce, 1987). Fordyce (1972) expanded on work from Wessman and Ricks (1966) to create the FEQ. The initial FEQ (Fordyce, 1972) had only one item, and was refined to include a second item that asks people to estimate the amount of time they spend in happy, unhappy, and neutral moods each day (Fordyce, 1987). This tool is unique because it provides the widest range of responses and variance of any established happiness scale, and it contains anchoring descriptions at each point on its 11-point scale to ensure a better cross-comparability of subject responses (Fordyce, 1987). According to Fordyce (1988) the questionnaire is "considered by some to be the granddaddy of them all [of happiness measures]" (p. 65).

The first item on the FEQ asks participants to rate their average happiness on an 11-point Likert scale that ranges from 0 (extremely unhappy) to 10 (extremely happy), with 5 being neutral. The second item asks participants to identify what 
percentage of time each day they feel happy, unhappy, and neutral (Fordyce, 1987). The FEQ takes one minute to complete (Fordyce, 1987).

Fordyce (1987) reported a test-retest coefficient of 0.9 for a two-day period, 0.8 for two weeks, and 0.8 for one month, and found a high internal consistency over several dozen testings with a variety of ages, occupations, gender, race, and socioeconomic backgrounds. The FEQ has also demonstrated a strong and consistent convergence with several other happiness instruments, and has good utility in repeated measures and pre-posttest designs (Fordyce, 1987).

The FEQ uses the raw numbers from its two items to determine two scores: a rating of perceived happiness and an estimation of time spent feeling happy, unhappy, and neutral. For the first item, participants receive a score ranging from 0 to 10 , which gives an indication of perceived current happiness (higher scores indicate higher happiness). The second item provides three percentage estimates about the amount of time spent feeling happy, unhappy, and neutral each day (Fordyce, 1987; Jarden, 2011).

\subsection{Oxford Happiness Inventory $(\mathrm{OHI})$}

The OHI measures happiness as a trait (Argyle et al., 1989; Francis, Brown, Lester, \& Philipchalk, 1998; Furnham \& Christoforou, 2008; Robbins et al., 2010). It was developed by Argyle et al. (1989) at Oxford University as a means to counter measures of depression by reversing 21 items from the Beck Depression Inventory (BDI; Beck, Ward, Mendelson, Hock, \& Erbaugh, 1961) and adding 8 additional items to measure other aspects of well-being.

The questionnaire consists of 29 items. Each item requires participants to select a response on a Likert scale ranging from 1 (strongly disagree) to 6 (strongly agree). The $\mathrm{OHI}$ takes approximately four to six minutes to complete (Argyle et al., 1989).

Argyle et al. (1989) reported an internal reliability of 0.9 and a seven-week testretest reliability of 0.8 (Francis et al., 1998). High validity was also established against happiness ratings reported by friends, and correlations with measures of positive 
affect, negative affect, and life satisfaction (Argyle et al., 1989; Furnham \& Christoforou, 2008; Robbins et al., 2010). No significant sex differences were reported in a sample of students at Oxford University (Argyle \& Lu, 1990).

To score the $\mathrm{OHI}, 12$ of the items are reverse-coded, and the mean score is calculated. The final score indicates overall state happiness and ranges from 1 (not happy) to 6 (very happy).

\subsection{Flourishing Scale (FS)}

The FS measures flourishing, otherwise known as social-psychological prosperity (Diener et al., 2009). This tool was initially called Psychological Well-being; however, Diener et al. (2009) changed the name to more accurately reflect the fact that the scale's content assessed more than psychological well-being.

The FS consists of eight items that describe aspects of human functioning such as positive relationships, competence, contributing to the happiness of others, and having meaning and purpose in life. All the items are phrased in a positive direction, and participants are required to rate their answer on a Likert scale ranging from 1 (strongly disagree) to 7 (strongly agree). The AHI takes approximately two minutes to complete (Jarden, 2011).

Diener et al. (2009) administered the FS to 689 college students in the United States and found high internal consistency, a good Cronbach alpha (0.8), and moderately high (0.7) one-month temporal reliability.

To score the FS, the mean of responses to all eight items is calculated. The final score ranges from 1 to 7 , and higher scores signify that respondent views themselves in positive terms in important areas of functioning in their life (Jarden, 2011). A high score also represents a person with many psychological resources and strengths (Jarden, 2011). 


\subsubsection{Lifestyle Information}

Participants were asked three questions on a four-point scale (ranging from never true of me to always true of me) about their weight and confidence in their ability to accomplish goals and daily tasks. All three of the items were from the Student Developmental Task and Lifestyle Assessment (SDTLA), an assessment tool designed specifically for college students (Winston, Miller, \& Cooper, 1999). This tool was chosen because it is based specifically on concepts and principles of human development that typically occur within college settings. It collects information concerning college students' activities, feelings, attitudes, aspirations, and relationships. It is designed to help students learn more about themselves and for colleges to learn how to assist students more effectively. Data from 2,800 college students revealed reliability estimates that the scales are sufficiently homogeneous for research with groups of students (Winston, 1990). Wachs and Cooper (2002) also conducted a four-year longitudinal study with 1,458 students from 31 colleges and universities in the United States and Canada and found further evidence for the validly of the SDTLA; and they found the tool was sensitive enough to detect behaviour change within individuals across time (Wachs \& Cooper, 2002).

\subsubsection{Health Information}

Participants were asked six questions about health behaviours that solicited information about the frequency of physical activity, sleep, stress, tobacco products, illicit drugs, and alcohol consumption. These items were also from the SDTLA (Winston et al., 1999).

\subsubsection{Social Information}

Participants were asked three questions about social issues, close friends, and if they had leisure activities they did just for fun. Items were again taken from the SDTLA (Winston et al., 1999). 


\subsubsection{Gratitude}

Participants were asked three questions on a five-point scale (ranging from very slightly/not at all to extremely) about the extent they felt grateful, appreciative, and thankful in the present moment. The items were also from the SDTLA (Winston et al., 1999).

\subsubsection{Program Feedback Questionnaire}

Howell et al. (2010) found that people who complete an Internet-based survey (as compared to pen and paper) provide longer, more detailed answers to open-ended questions, and so the open-ended program feedback questions were included to gain additional insight from participants about happiness as well as their insight into the video modules. After participants completed the post-program questionnaire they were invited to complete an additional online program feedback questionnaire administered via OWL consisting of seven questions that took approximately ten minutes to complete.

Participants were asked open-ended questions about happiness, such as "what does happiness mean to you?", "what makes you happy?", "what makes you feel unhappy?", "how often do you feel happy?", "how important is it to you to feel happy?", and "are your friends happy?".

In addition to the open-ended questions about happiness, because the creators of the videos at UC Berkeley's Greater Good Science Center were interested in learning about the effectiveness of a shorter, four-week program (as compared to their current eight-week program) it was important to ask additional questions about the video topics and delivery. Additionally, the effectivnesss of a shorter program is appealing to learn about for implementation with undergraduates at Western because it would be easier to implement campus-wide for undergraduate students to increase commitment and decrease dropouts. Also, given the pilot nature of this study and the novelty of using online videos to administer the program, gaining insight about participants' experiences and learning from the course was important to assess. 
Participants were asked questions about the video modules, such as "did the video content impact your concept of happiness?"; "did your view of happiness change after watching the videos?"; "did you continue to think about the videos after you watched them?"; "did certain videos have more of an impact than others?"; "did you learn anything from the videos that impacted your life?"; "have you learned anything from the videos that you have or plan to incorporate into your life?"; "did you share anything you learned in the videos with your friends?", and "was there anything about the videos you would change, improve, or remove?".

\subsection{Coding and Categorizing Data}

Immediately after consent was obtained, a unique participant identification number was assigned to each participant. This identifier was used for all data collection to allow responses from the demographic questionnaire and pre- and postprogram questionnaires module to be linked. A master list of participant names and identification numbers was maintained and kept separate from data records.

The qualitative data collected were analyzed using inductive content analysis. Several techniques were used to promote the trustworthiness and credibility of the findings. All of the five happiness tools had more than one question and each question was required to calculate the overall happiness score; consequently, participants scores were only included in the analysis if they completed all of the questions in the tool.

In order to minimize the bias of an individual investigator, analysis was completed by more than one researcher (Grossoehme, 2015). Additionally, to ensure criterion validity (Collingridge \& Gantt, 2008), results were compared and contrasted with other research.

\subsection{Summary}

This chapter presented the methods and measures used to conduct this research study. Both quantitative and qualitative measures were used to address the research question for this study because the purpose of the study was to describe and 
evaluate the effectiveness of online happiness video modules as a catalyst to improve the health of undergraduate university students based on positive psychology and happiness theories. 


\section{Chapter 3. Data Collection}

This chapter discusses the procedures employed to collect the data for this study; the research process model can be seen in Figure 1. Ethical considerations are explored, and a description of the research site is provided. Participant recruitment and data collection are described. The data analysis methods are also presented.

Timeline (2017)

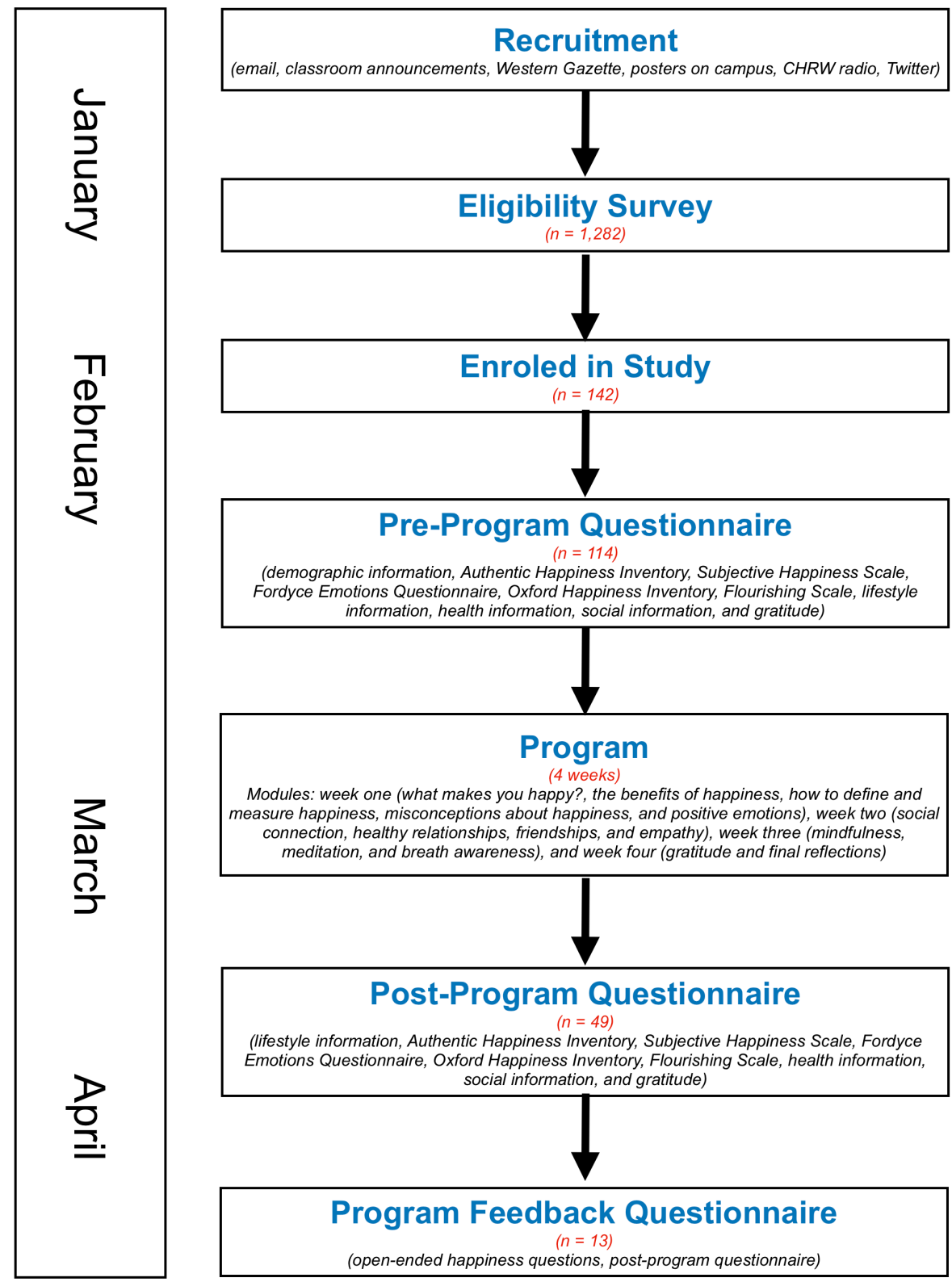

Figure 1. Research process model 


\subsection{Ethics}

Ethics approval to conduct the study, "Healthy and Happy: Creating and Evaluating a Catalyst to Improve the Health of University Students via an Online Training System" was received from Western University's Research Board for Health Sciences Research (HSREB) on October 21, 2016 (Appendix K). An amendment to the study protocol to change the online survey platform from Qualtrics to Online Western Learning (OWL) for ease of participant access was approved on December 15, 2016 (Appendix L), and an additional amendment to the study protocol to increase the number of participants was approved on February 10, 2017 (Appendix M). Finally, due to the end of the study coinciding with the spring exam period, a revision to change the post-program focus groups to an online questionnaire was approved on April 13, 2017 (Appendix N).

\subsection{Research Site}

This study was conducted at Western University located in London, Ontario, Canada. According to Western Office of Institutional Planning (2017) there were 23,193 full-time undergraduate students enroled at the university in the winter 2017 term; 2,183 (9.4\% of total enrolment) of the students were International students.

In 2017, there were 10,260 full-time male and 12,933 full-time female undergraduate students enroled at Western's main campus (Western Office of Institutional Planning, 2017). Undergraduate enrolment included Faculties (using the same combined categories as presented in this study) such as Science/Engineering $(7,042)$, Social Science/Business $(5,151)$, Health Sciences $(4,959)$, Arts and Humanities/Music $(1,396)$, and Information and Media Studies (966).

\subsection{Participant Recruitment}

The population of interest for this study was full-time Western University undergraduate students. Based on a sample size calculation using Horatio, a program used to perform sample size and power estimation in parametric research design (Lee, 2012), it was determined that 60 subjects were required for this study. Accordingly, 
ethics approval was initially sought for 60 participants; however, based on the overwhelming interest to participate, an amendment was approved to include up to 400 subjects on February 10, 2017 (Appendix M). The final sample consisted of 114 participants.

Six methods were used to recruit students to participate in the study: an initial e-mail invitation to participate in the study (Appendix O), a follow-up reminder e-mail invitation to participate in the study (Appendix $P$ ), posters on campus (Appendix $Q$ ), classroom presentations (Appendix $\mathrm{R}$ ), Twitter (Appendix $S$ ), radio advertisements on 94.9FM CHRW (Appendix T), and advertisements in The Gazette, Western University's student newspaper (Appendix $U$ and Appendix V). Interested students were invited to complete a short eligibility survey administered via Qualtrics.

A total of 142 participants completed the eligibility survey, 114 participants completed the demographic and pre-program questionnaire, 49 completed the postprogram questionnaire, and 13 participants completed the program feedback questionnaire. $75.4 \%$ of the sample was female, $22.8 \%$ male, and $0.9 \%$ identified as other. Participants spanned all years of undergraduate enrolment, with $24.5 \%$ in year $1,23.7 \%$ in year $2,24.6 \%$ in year $3,19.3 \%$ in year $4,5.3 \%$ in year 5 , and $2.8 \%$ did not indicate their enrolment year. International students comprised $10.5 \%$ of the sample, and participants were from a range of Faculties and programs: Social Science/Business (30.7\%), Science/Engineering (28.9\%), Health Science/ Kinesiology (18.4\%), Arts and Humanities/Music (9.7\%), and Information \& Media Studies (7.9\%).

\subsection{Data Collection}

Evaluation consisted of online self-report questionnaires. At the beginning of the study participants were asked to complete an online demographic questionnaire (Appendix D) and an online pre-program questionnaire that assessed perceptions of health indicators and behaviours such as lifestyle habits, social information, gratitude, and happiness (Appendix E). Assessments were administered via OWL, Western's learning management system. OWL was also used to deliver the weekly video modules for participants. At the completion of the study participants were invited to 
complete the same assessment (post-program questionnaire) about their perceptions of health indicators and behaviours (lifestyle, health, social information, gratitude, and happiness; Appendix E) via an online questionnaire also administered though OWL. Upon completion of the study, participants received an invitation to complete an optional program feedback questionnaire (Appendix I), also available in OWL.

\subsection{Data Analysis}

All data were collected via OWL and exported to Microsoft Excel and SPSS (version 25.0, SPSS Inc., Chicago) for analysis. To protect personal information and ensure participants' identities remained confidential, immediately after consent was obtained and participants were enroled in the study, a unique identification number was assigned to each participant. This identifier was subsequently used for all other data collection and records. Additionally, to protect the confidentiality of the data, it was stored on a password protected computer where only the research team had access to the data.

During analysis, participants were separated and categorized into two groups to distinguish those who completed the study (completers) and those who did not (noncompleters). The comparison of completers and non-completers was not part of the original plan or the purpose of the study; however, the opportunity to analyze the data to see if there were differences between those who completed and those who was done to investigate the differences between participants who completed the study was done. It was determined that the differences between the two groups could be valuable in terms of considering the potential value of online happiness modules.

Lifestyle information (e.g. body image and goal setting), health behaviours (e.g. exercise habits, stress, tobacco use, illicit drug use, alcohol use), social information (e.g. social issues and friendships), and gratitude were coded and the frequencies and/or means pertaining to each question were calculated. The happiness scores for the five validated tools (the Authentic Happiness Inventory [AHI; Seligman et al., 2005], the Subjective Happiness Scale [SHS; Lyubomirsky \& Lepper, 1999], the Fordyce Emotions Questionnaire [FEQ; Fordyce, 1987], the Oxford Happiness 
Inventory [OHI; Argyle et al., 1989], and the Flourishing Scale [FS; Diener et al., 2009]) were calculated.

Paired samples t-tests (when comparing pre and post means for the completers) and independent samples t-tests (when comparing the means of the completers vs. the non-completers) were calculated. Additionally, Cronbach's alpha was used to determine internal consistency for all pre scores and Cohen's $d$ was calculated to determine effect size between pre and post for completers. To analyze the post-program feedback questionnaire responses, the researchers used inductive content analysis and investigator triangulation.

\subsection{Summary}

This chapter presented information about the methods that were used to collect and analyze the data. Ethics approval was described, and a description of the research site was provided. Participant recruitment, data collection, and data analysis methods were also presented. 


\section{Chapter 4. Results}

This chapter presents detailed results from this study. Recruitment and demographic information are described and then happiness, lifestyle, and gratitude results are presented. Pre/post results are presented for participants who completed the study, and an analysis of pre results for those who did not complete the study is presented to identify characteristics that distinguish the study completers from the noncompleters (i.e., those who dropped out of the study). Finally, post-program feedback regarding happiness and video module feedback is described.

\subsection{Recruitment}

Study recruitment took place between January and February 2017. A total of 1,282 Western University students responded by completing the recruitment eligibility survey administered via Qualtrics. The initial ethics approval obtained for the study targeted recruitment of up to 60 participants; however, due to the overwhelming response, a request to revise the original ethics protocol to recruit a new total of 400 participants was submitted. The amendment approval was granted 2.5 weeks after the request. At that point, additional participants were contacted and invited to participate in the study in the order in which they responded: participants who responded first were contacted first.

\subsection{Demographics}

Participant characteristics are provided in Tables 1-12 and Figures 2-13 for all participants enroled, those who completed the study, and those who did not complete the study. One hundred and forty-two participants were enroled in this study, 114 completed the pre-program questionnaire, 49 participants completed the study, and 13 participants completed the post-program feedback questionnaire. 
Table 1

Participants by year of academic study

\begin{tabular}{lccc}
\hline $\begin{array}{l}\text { Year of } \\
\text { study }\end{array}$ & $\begin{array}{c}\text { All enroled pre \% } \\
(\mathbf{N})\end{array}$ & $\begin{array}{c}\text { Completers pre \% } \\
(\mathbf{N})\end{array}$ & $\begin{array}{c}\text { Non-completers pre \% } \\
(\mathbf{N})\end{array}$ \\
\hline 1 & 25.00 & 29.17 & 21.88 \\
& $(28)$ & $(14)$ & $(14)$ \\
2 & 24.10 & 16.67 & 29.69 \\
& $(27)$ & $(8)$ & $(19)$ \\
3 & 25.00 & 25.00 & 25.00 \\
& $(28)$ & $(12)$ & $(16)$ \\
4 & 19.64 & 22.92 & 17.19 \\
& $(22)$ & $(11)$ & $(11)$ \\
5 & 6.25 & 6.25 & 6.25 \\
& $(7)$ & $(3)$ & $(4)$ \\
\hline
\end{tabular}

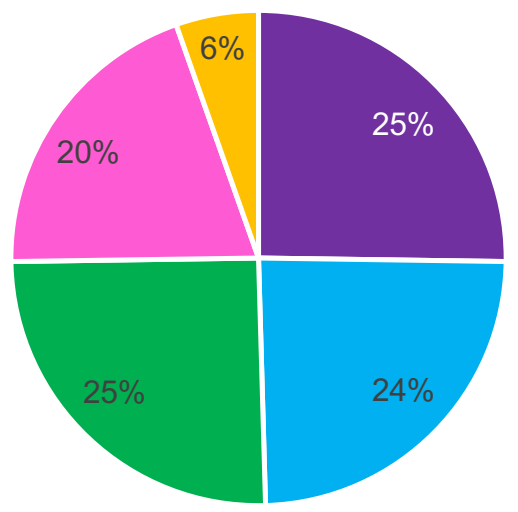

$-1-2 \cdot 3=4=5$

Figure 2. Year of academic study (all participants enroled) 


\section{Table 2}

Participants by program enrolment

\begin{tabular}{lccc}
\hline \multicolumn{1}{c}{ Program } & $\begin{array}{c}\text { All enroled pre } \% \\
(\mathbf{N})\end{array}$ & $\begin{array}{c}\text { Completers pre \% } \\
(\mathbf{N})\end{array}$ & $\begin{array}{c}\text { Non-completers pre \% } \\
(\mathbf{N})\end{array}$ \\
\hline Science/Engineering & 38.05 & 36.73 & 39.06 \\
& $(43)$ & $(18)$ & $(25)$ \\
Social Science/HBA & 30.09 & 22.45 & 35.94 \\
& $(34)$ & $(11)$ & $(23)$ \\
Health Science/Kinesiology & 18.58 & 30.61 & 9.38 \\
& $(21)$ & $(15)$ & $(6)$ \\
Arts and Humanities/Music & 8.85 & 8.16 & 9.38 \\
& $(10)$ & $(4)$ & $(6)$ \\
Information and Media & 4.42 & 2.04 & 6.25 \\
Studies & $(5)$ & $(1)$ & $(4)$ \\
\hline
\end{tabular}

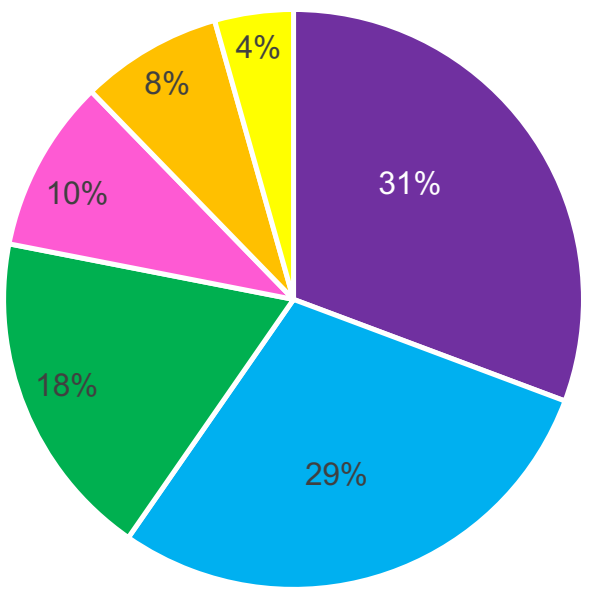

- Social Science/HBA

- Science/Engineering

- Health Science/ Kinesiology

- Arts and Humanities/Music

- No response given

- Information \& Media Studies

Figure 3. Program enrolment (all participants enroled) 


\section{Table 3}

Participants by program enrolment status

\begin{tabular}{lccc}
\hline Status & $\begin{array}{c}\text { All enroled pre \% } \\
(\mathbf{N})\end{array}$ & $\begin{array}{c}\text { Completers pre \% } \\
(\mathbf{N})\end{array}$ & $\begin{array}{c}\text { Non-completers pre \% } \\
(\mathbf{N})\end{array}$ \\
\hline Canadian or & 89.38 & 87.76 & 90.63 \\
Canadian Permanent & $(101)$ & $(43)$ & $(58)$ \\
Resident & & & \\
International Student & 10.61 & 12.24 & 9.38 \\
& $(12)$ & $(6)$ & $(6)$ \\
\hline
\end{tabular}

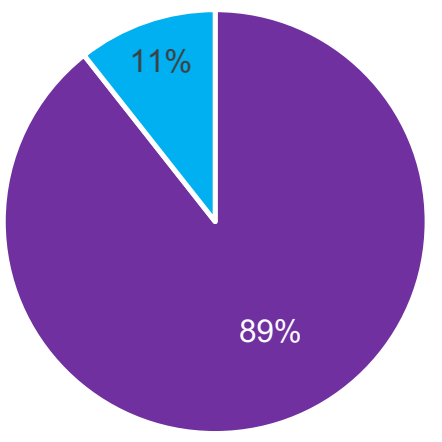
- Canadian or Permanent Resident
- International Student

Figure 4. Program enrolment status (all participants enroled) 
Table 4

Participants by gender

\begin{tabular}{lccc}
\hline Gender & $\begin{array}{c}\text { All enroled pre } \% \\
(\mathbf{N})\end{array}$ & $\begin{array}{c}\text { Completers pre \% } \\
(\mathbf{N})\end{array}$ & $\begin{array}{c}\text { Non-completers pre \% } \\
(\mathbf{N})\end{array}$ \\
\hline Female & 76.11 & 77.55 & 75.00 \\
& $(86)$ & $(38)$ & $(48)$ \\
Male & 23.01 & 22.45 & 23.44 \\
& $(26)$ & $(11)$ & $(15)$ \\
Other & 0.88 & 0.00 & 01.56 \\
& $(1)$ & $(0)$ & $(1)$ \\
\hline
\end{tabular}

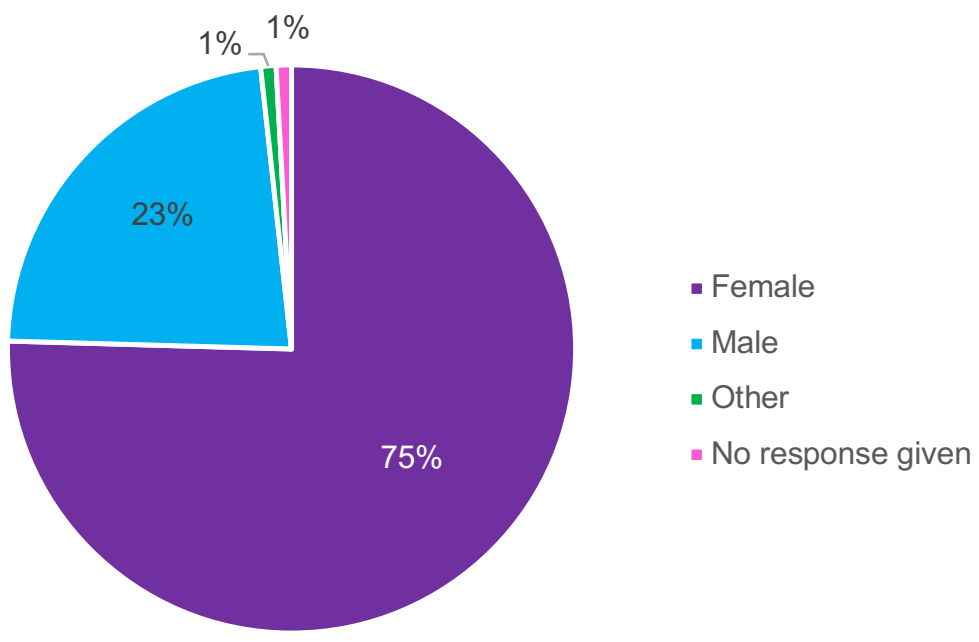

Figure 5. Gender (all participants enroled) 


\section{Table 5}

Participants by mental health diagnosis

\begin{tabular}{lccc}
\hline $\begin{array}{l}\text { Have you ever been } \\
\text { diagnosed with a mental } \\
\text { health problem? }\end{array}$ & $\begin{array}{c}\text { All enroled pre \% } \\
(\mathbf{N})\end{array}$ & $\begin{array}{c}\text { Completers pre \% } \\
\text { (N) }\end{array}$ & $\begin{array}{c}\text { Non-completers pre \% } \\
\text { (N) }\end{array}$ \\
\hline No & 76.79 & 83.33 & 71.88 \\
& $(86)$ & $(40)$ & $(46)$ \\
Yes & 23.21 & 16.67 & 28.13 \\
& $(26)$ & $(8)$ & $(18)$ \\
\hline
\end{tabular}

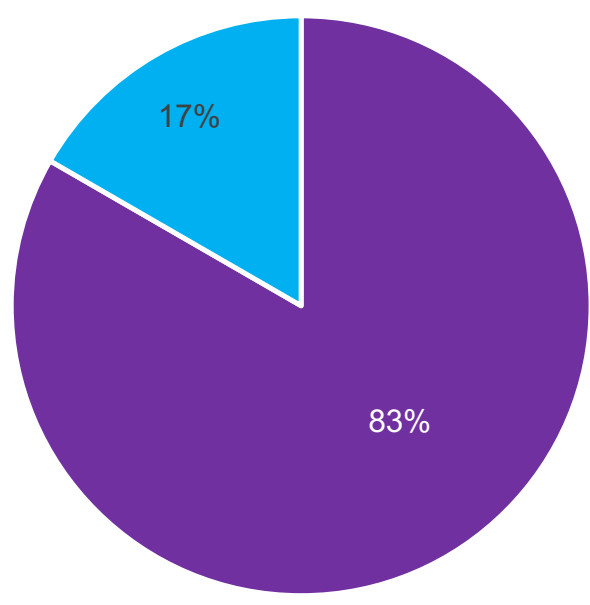

- No $\quad$-Yes

Figure 6. Mental health diagnosis (all participants enroled) 
Table 6

Participants by chronic health diagnosis

\begin{tabular}{lccc}
\hline $\begin{array}{l}\text { Have you ever been } \\
\text { diagnosed with a chronic } \\
\text { health problem? }\end{array}$ & $\begin{array}{c}\text { All enroled pre \% } \\
(\mathbf{N})\end{array}$ & $\begin{array}{c}\text { Completers pre \% } \\
(\mathbf{N})\end{array}$ & $\begin{array}{c}\text { Non-completers pre \% } \\
\text { (N) }\end{array}$ \\
\hline No & 86.73 & 91.84 & 82.81 \\
& $(98)$ & $(45)$ & $(53)$ \\
Yes & 13.27 & 08.16 & 17.19 \\
& $(15)$ & $(4)$ & $(11)$ \\
\hline
\end{tabular}

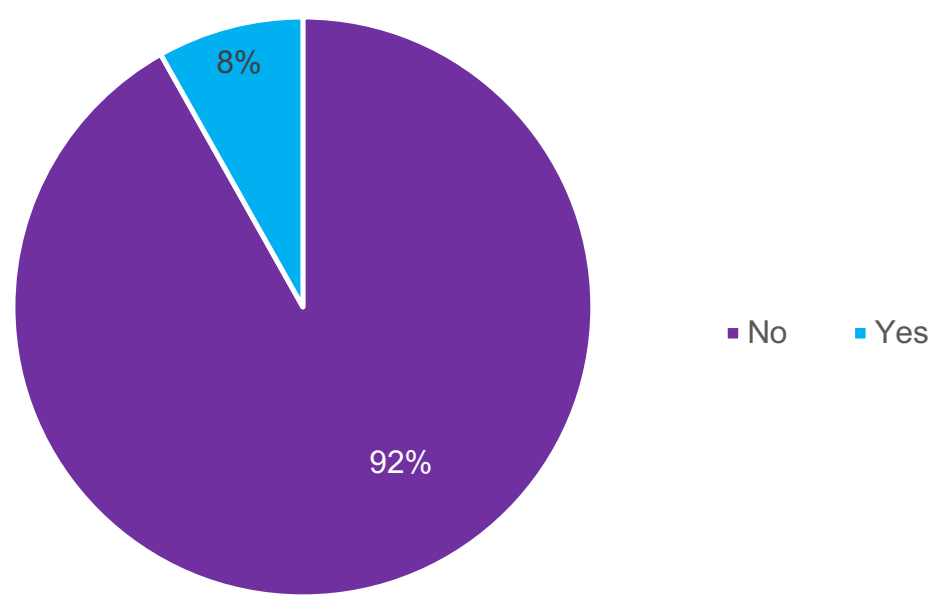

Figure 7. Chronic health diagnosis (all participants enroled) 
Table 7

Participants by professional help for school related difficulties

\begin{tabular}{lccc}
\hline $\begin{array}{l}\text { Have you ever sought } \\
\text { professional help for } \\
\text { school related difficulties? }\end{array}$ & $\begin{array}{c}\text { All enroled pre \% } \\
\text { (N) }\end{array}$ & $\begin{array}{c}\text { Completers pre \% } \\
(\mathbf{N})\end{array}$ & $\begin{array}{c}\text { Non-completers pre \% } \\
(\mathbf{N})\end{array}$ \\
\hline No & 53.71 & 64.58 & 45.31 \\
& $(60)$ & $(31)$ & $(29)$ \\
Yes & 46.43 & 35.42 & 54.69 \\
& $(52)$ & $(17)$ & $(35)$ \\
\hline
\end{tabular}

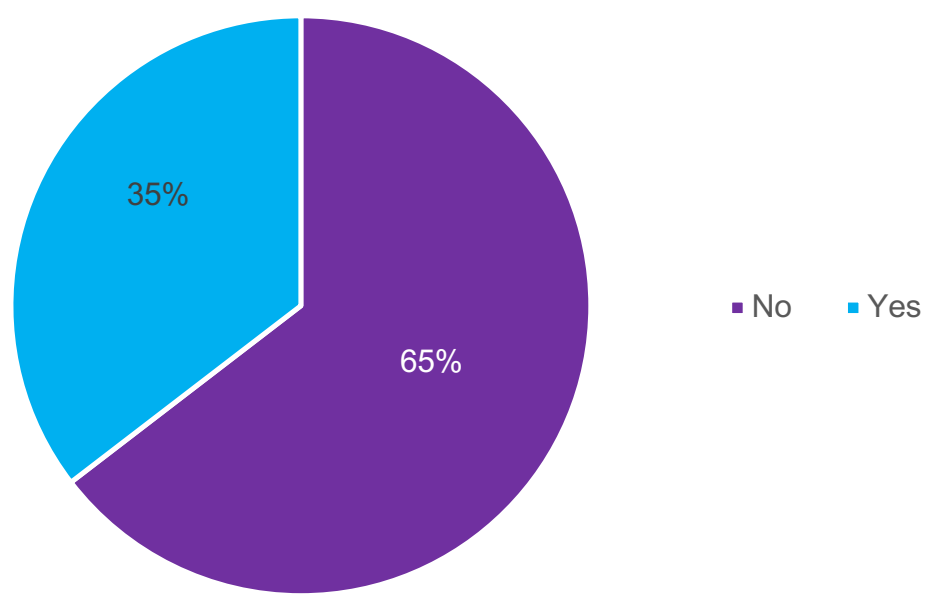

Figure 8. Professional help for school related difficulties (all participants enroled) 


\section{Table 8}

Participants by place of residence

\begin{tabular}{lccc}
$\begin{array}{l}\text { Where do you presently } \\
\text { live? }\end{array}$ & $\begin{array}{c}\text { All enroled pre } \% \\
(\mathbf{N})\end{array}$ & $\begin{array}{c}\text { Completers pre \% } \\
(\mathbf{N})\end{array}$ & $\begin{array}{c}\text { Non-completers pre \% } \\
(\mathbf{N})\end{array}$ \\
\hline Off-campus in an & 53.10 & 44.90 & 59.38 \\
apartment/house with at least & $(60)$ & $(22)$ & $(38)$ \\
one other person who is not & & & \\
a parent or spouse/partner & 24.78 & 30.61 & 20.31 \\
In residence & $(28)$ & $(15)$ & $13)$ \\
& 12.39 & 14.29 & 10.94 \\
At home with parent(s) & $(14)$ & $(7)$ & $(7)$ \\
& 3.54 & 6.12 & $(1)$ \\
Off-campus in an & $(4)$ & $(3)$ & 4.69 \\
apartment/house on my own & 3.54 & 2.04 & $(3)$ \\
In a university-owned & $(4)$ & $(1)$ & 3.12 \\
apartment/townhouse & 2.65 & 2.04 & $(2)$ \\
At home with spouse/partner & $(3)$ & $(1)$ & 0.00 \\
& 0.00 & 0.00 & $(0)$ \\
In fraternity/sorority house & $(0)$ & $(0)$ & \\
\end{tabular}

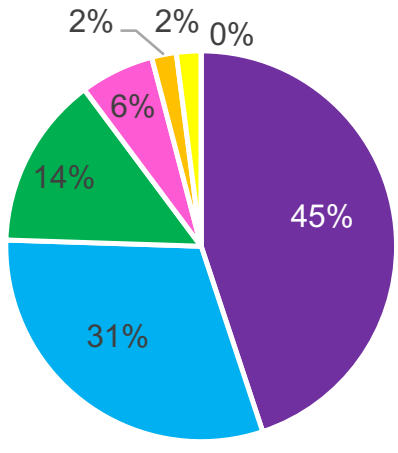

- Off-campus in an apartment/house with at least one other person who is not a parent or spouse/partner - In residence

- At home with parent(s)

- Off-campus in an apartment/house on my own

- In a university-owned apartment/townhouse

At home with spouse/partner

Figure 9. Place of residence (all participants enroled) 
Table 9

Participants by how tuition expenses are paid

\begin{tabular}{lccc}
\hline $\begin{array}{l}\text { How are your tuition } \\
\text { expenses paid? Check all } \\
\text { that apply. }\end{array}$ & $\begin{array}{c}\text { All enroled pre \% } \\
\text { (N) }\end{array}$ & $\begin{array}{c}\text { Completers pre \% } \\
\text { (N) }\end{array}$ & $\begin{array}{c}\text { Non-completers pre \% } \\
\text { (N) }\end{array}$ \\
\hline Family & 38.70 & 36.19 & 40.80 \\
& $(89)$ & $(38)$ & $(51)$ \\
Loans & 23.04 & 21.90 & 24.00 \\
& $(53)$ & $(23)$ & $(30)$ \\
Scholarship & 21.74 & 21.90 & 21.60 \\
& $(50)$ & $(23)$ & $(27)$ \\
Self-funded & 16.52 & 20.00 & 13.60 \\
& $(38)$ & $(21)$ & $(17)$ \\
\hline
\end{tabular}

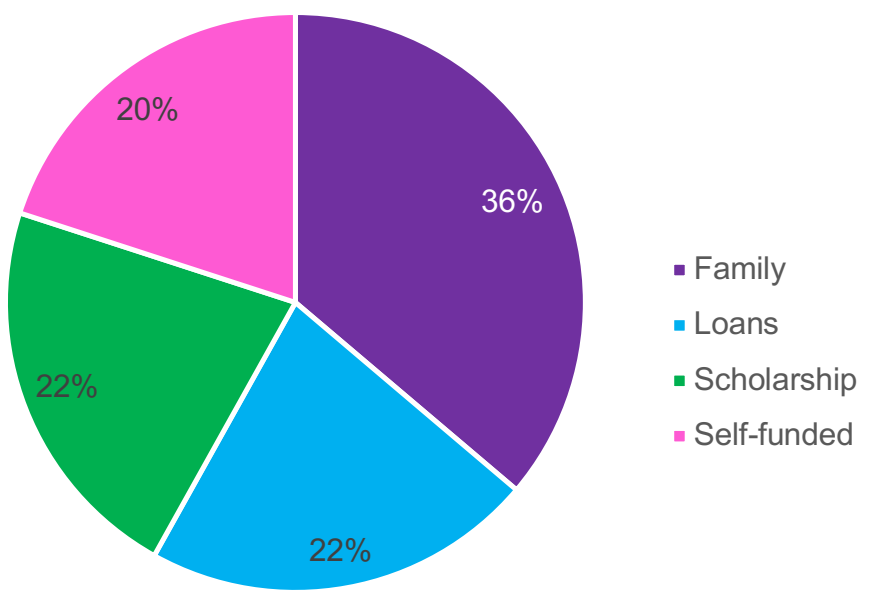

Figure 10. How tuition expenses are paid (all participants enroled) 
Table 10

Participants by how living expenses are paid

\begin{tabular}{lccc}
\hline $\begin{array}{l}\text { How are your living } \\
\text { expenses paid? }\end{array}$ & $\begin{array}{c}\text { All enroled pre } \% \\
\text { (N) }\end{array}$ & $\begin{array}{c}\text { Completers pre } \% \\
\text { (N) }\end{array}$ & $\begin{array}{c}\text { Non-completers pre \% } \\
\text { (N) }\end{array}$ \\
\hline Family that apply. & & 49.43 & 48.04 \\
& 48.68 & $(43)$ & $(49)$ \\
Self-funded & $(92)$ & 27.59 & 26.47 \\
& 26.98 & $(24)$ & $(27)$ \\
Loans & $(51)$ & 16.09 & 16.67 \\
& 16.40 & $(14)$ & $(17)$ \\
Scholarship & $(31)$ & 6.90 & 8.82 \\
& 7.94 & $(6)$ & $(9)$ \\
\hline
\end{tabular}

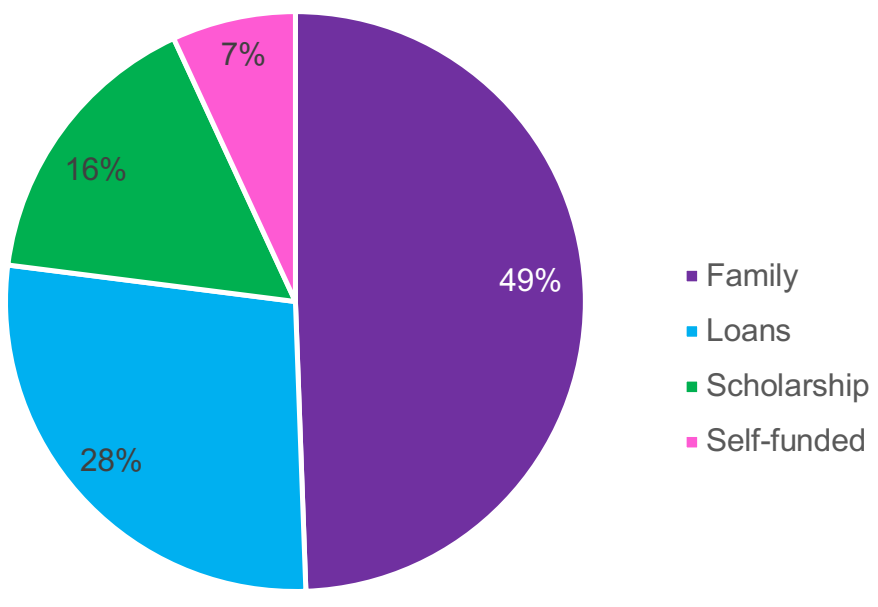

Figure 11. How living expenses are paid (all participants enroled) 
Table 11

Participants by how personal expenses are paid

\begin{tabular}{lccc}
\hline $\begin{array}{l}\text { How are your personal } \\
\text { expenses paid? Check all } \\
\text { that apply. }\end{array}$ & $\begin{array}{c}\text { All enroled pre \% } \\
\text { (N) }\end{array}$ & $\begin{array}{c}\text { Completers pre \% } \\
\text { (N) }\end{array}$ & $\begin{array}{c}\text { Non-completers pre \% } \\
\text { (N) }\end{array}$ \\
\hline Self-funded & 47.13 & 50.67 & 44.44 \\
Family & $(82)$ & $(38)$ & $(44)$ \\
& 36.21 & 34.67 & 37.37 \\
Loans & $(63)$ & $(26)$ & $(37)$ \\
& 10.92 & 9.33 & 12.12 \\
Scholarship & $(19)$ & $(7)$ & $(12)$ \\
& 5.75 & 5.33 & 6.06 \\
\hline
\end{tabular}

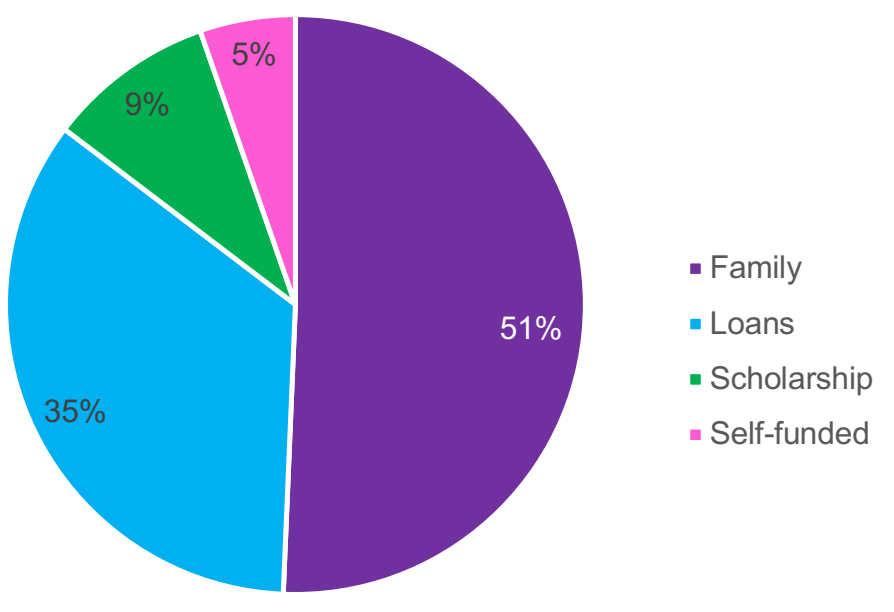

Figure 12. How personal expenses are paid (all participants enroled) 
Table 12

Participants by academic probation

\begin{tabular}{lccc}
\hline $\begin{array}{l}\text { During your university } \\
\text { studies have you ever been } \\
\text { placed on academic } \\
\text { probation? }\end{array}$ & $\begin{array}{c}\text { All enroled pre \% } \\
\text { (N) }\end{array}$ & $\begin{array}{c}\text { Completers pre \% } \\
\text { (N) }\end{array}$ & $\begin{array}{c}\text { Non-completers pre \% } \\
\text { (N) }\end{array}$ \\
\hline No & & & \\
Yes & 96.46 & 95.92 & 96.88 \\
& $(109)$ & $(47)$ & $(62)$ \\
& 3.54 & 4.08 & 3.13 \\
$(4)$ & $(2)$ & $(2)$ \\
\hline
\end{tabular}

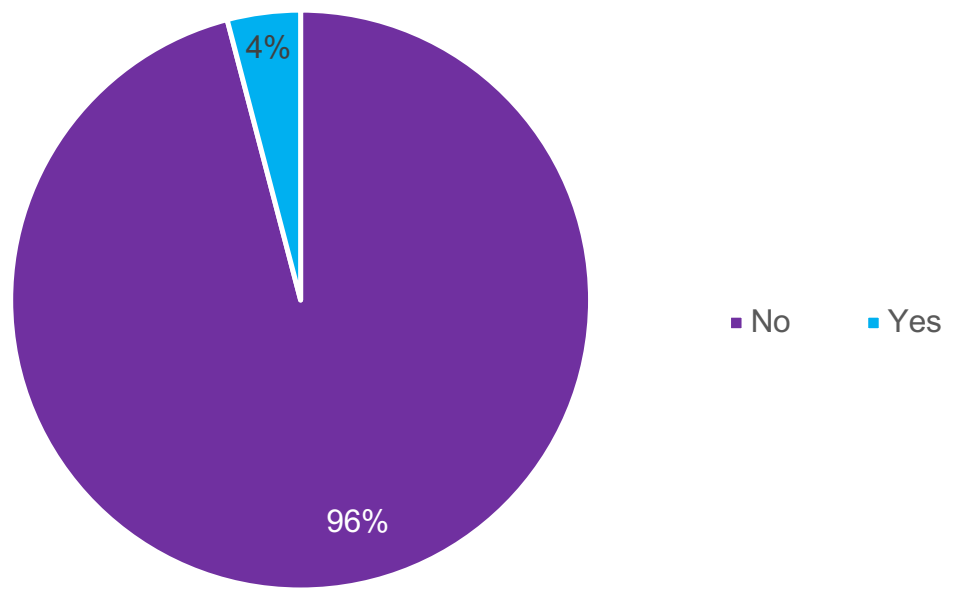

Figure 13. Academic probation (all participants enroled)

\subsubsection{All Participants}

Approximately three quarters of the enroled sample $(76 \% ; n=86)$ was comprised of females, $23 \%(n=26)$ was male, and $1 \%(n=1)$ was other. The majority of the participants $(89 \%, n=101)$ were Canadian citizens or Permanent Residents, and $11 \%(n=12)$ were International Students. Participants spanned all years of undergraduate enrolment, with 25\% $(n=28)$ in first year, 24\% $(n=27)$ in second year, $25 \%(n=28)$ in third year, and 19\% $(n=22)$ in fourth year, and 6\% $(n=7)$ in fifth year. Several Faculties from across campus were represented in the sample, with $30 \%$ ( $n=$ 34) from Social Science and Business Administration, 38\% $(n=43)$ from Science and 
Engineering, 19\% ( $n=21)$ from Health Science and Kinesiology, 9\% $(n=10)$ from Arts and Humanities and Music, and 4\% $(n=5)$ from Information and Media Studies.

The majority of participants $(53 \%, n=60)$ lived off campus in an apartment/house with at least one other person who was not a parent or spouse/partner, $25 \%(n=28)$ lived in residence, $12 \%(n=14)$ lived at home with parent(s), 4\% ( $n=4)$ lived off-campus in an apartment/house on his/her own, 4\% ( $n=$ 4) lived in a university-owned apartment/townhouse, $3 \%(n=3)$ lived at home with a spouse/partner, and none of the participants lived in a fraternity/sorority house. 23\% ( $n$ $=26)$ of participants had been diagnosed with a mental health problem, 13\% $(n=15)$ had been diagnosed with a chronic health problem, $46 \%(n=52)$ had sought professional help for school related difficulties, and $4 \%(n=4)$ had been on academic probation.

Finally, in terms of finances, participants were asked about how their tuition, living, and personal expenses were paid. The majority $(39 \%, n=89)$ had tuition expenses paid by their family, $23 \%(n=53)$ by loans, $22 \%(n=50)$ by scholarship, and $17 \%(n=38)$ were self-funded. For living expenses, $49 \%(n=92)$ were paid by family, $27 \%(n=51)$ were self-funded, $16 \%(n=31)$ by loans, and $8 \%(n=15)$ by scholarship. Lastly, for personal expenses, $47 \%(n=82)$ were self-funded, $36 \%(n=63)$ were paid by family, $11 \%(n=19)$ by loans, and $6 \%(n=10)$ by scholarship.

\subsubsection{Completers and Non-Completers}

When comparing the demographic differences between the participants who competed the study and the participants who did not complete the study, there are a few notable differences to report. In terms of program of study, there were more noncompleters enroled in Social Science/HBA (36\%, $n=23$ as compared to $22 \%, n=11$ of completers), and interestingly, given that this was a study about health, there were more completers in Health Science/Kinesiology (31\%, $n=25$ as compared to $9 \%, n=$ 6 of non-completers). 
When asked if they had ever been diagnosed with a mental health problem, a larger proportion $(28 \%, n=18)$ of non-completers responded that they had as compared to completers $(16 \%, n=8)$. Additionally, when asked if they had ever sought professional help for school related difficulties, a larger proportion $(55 \%, n=$ $35)$ of non-completers responded that they had compared to completers $(35 \%, n=$ 17).

Another important difference appeared when participants were asked about where they lived. A larger percentage of non-completers lived off campus in an apartment/house with at least one other person who is not a parent or spouse/partner $(59 \%, n=38)$, whereas more completers lived in residence $(31 \%, n=15)$.

\subsection{Happiness}

Five measures of self-reported happiness were used in this study: Authentic Happiness Inventory (AHI), Subjective Happiness Scale (SHS), Fordyce Emotions Questionnaire (FEQ), Oxford Happiness Inventory (OHI), and Flourishing Scale (FS). Table 13 and Table 14 present the happiness findings for these self-report happiness measures, and Figures 14-18 display the results as bar graphs. Additionally, participants were asked to report the percent of the time they felt happy, unhappy, and neutral each day. Figure 19 displays the percent of the time results as bar graphs. 
Table 13

Happiness scores

\begin{tabular}{|c|c|c|c|c|c|c|}
\hline & Happiness Measure & $\begin{array}{c}\text { Authentic } \\
\text { Happiness } \\
\text { Inventory } \\
(/ 5) \\
\end{array}$ & $\begin{array}{c}\text { Subjective } \\
\text { Happiness Scale } \\
\text { ( /7) }\end{array}$ & $\begin{array}{c}\text { Fordyce } \\
\text { Emotions } \\
\text { Questionnaire } \\
(/ 10) \\
\end{array}$ & $\begin{array}{c}\text { Oxford } \\
\text { Happiness } \\
\text { Inventory } \\
(/ 6) \\
\end{array}$ & $\begin{array}{l}\text { Flourishing Scale } \\
\qquad(/ 7)\end{array}$ \\
\hline M score & $\begin{array}{l}\text { All enroled pre } \\
\text { (N) } \\
\text { Non-completers pre } \\
\text { (N) } \\
\text { Completers pre } \\
\text { (N) } \\
\text { Completers } \\
\text { post } \\
\text { (N) }\end{array}$ & $\begin{array}{l}2.86 \\
(110) \\
2.69 \\
(61) \\
3.09 \\
(49) \\
3.32 \\
(48)\end{array}$ & $\begin{array}{l}4.22 \\
(109) \\
4.05 \\
(60) \\
4.46 \\
(49) \\
4.63 \\
(48)\end{array}$ & $\begin{array}{l}6.29 \\
(108) \\
5.75 \\
(59) \\
6.94 \\
(49) \\
7.33 \\
(48)\end{array}$ & $\begin{array}{l}3.93 \\
(99) \\
3.78 \\
(55) \\
4.16 \\
(44) \\
4.78 \\
(45)\end{array}$ & $\begin{array}{l}4.96 \\
(106) \\
4.93 \\
(57) \\
5.04 \\
(49) \\
5.43 \\
(46)\end{array}$ \\
\hline \multirow{5}{*}{$\begin{array}{l}\text { Completers } \\
\text { vs. } \\
\text { Non- } \\
\text { completers } \\
\text { pre } \\
\text { Completers } \\
\text { pre/post }\end{array}$} & (df) & $\begin{array}{c}3.11 \\
(94.47)\end{array}$ & $\begin{array}{c}1.92 \\
(101.50)\end{array}$ & $\begin{array}{c}2.80 \\
(105.11)\end{array}$ & $\begin{array}{c}2.02 \\
(79.78)\end{array}$ & $\begin{array}{c}0.32 \\
(75.67)\end{array}$ \\
\hline & $\begin{array}{l}\text { sig. } \\
\text { (2-tailed) }\end{array}$ & 0.00 & 0.06 & 0.01 & 0.04 & 0.75 \\
\hline & $\begin{array}{l}t \\
\text { (df) }\end{array}$ & $\begin{array}{l}4.85 \\
(47)\end{array}$ & $\begin{array}{l}1.35 \\
(47)\end{array}$ & $\begin{array}{l}2.32 \\
(48)\end{array}$ & $\begin{array}{c}11.58 \\
(39)\end{array}$ & $\begin{array}{l}1.93 \\
(44)\end{array}$ \\
\hline & $\begin{array}{l}\text { sig. } \\
\text { (1-tailed) }\end{array}$ & 0.00 & 0.09 & 0.01 & 0.00 & 0.03 \\
\hline & $\begin{array}{l}\text { Cronbach's Alpha } \\
\text { (N of items) } \\
\text { Cohen's } d\end{array}$ & $\begin{array}{l}0.94 \\
(24) \\
0.70\end{array}$ & $\begin{array}{c}0.41 \\
(4) \\
0.19 \\
\end{array}$ & $\begin{array}{l}-- \\
0.33 \\
\end{array}$ & $\begin{array}{l}0.94 \\
(29) \\
0.66 \\
\end{array}$ & $\begin{array}{c}0.91 \\
(8) \\
0.33 \\
\end{array}$ \\
\hline
\end{tabular}


Table 14

Percent of time spent feeling happy, unhappy, and neutral

\begin{tabular}{|c|c|c|c|c|c|c|c|c|}
\hline \multirow[b]{2}{*}{$\%$ of time } & \multicolumn{4}{|c|}{ M Score } & \multicolumn{2}{|c|}{$\begin{array}{c}\text { Non- } \\
\text { completers }\end{array}$} & \multicolumn{2}{|c|}{ Pre/Post } \\
\hline & $\begin{array}{c}\text { All } \\
\text { enroled } \\
\text { pre } \\
(\mathrm{N})\end{array}$ & $\begin{array}{c}\text { Non- } \\
\text { completers } \\
\text { pre } \\
\text { (N) }\end{array}$ & $\begin{array}{c}\text { Completers } \\
\text { pre } \\
(\mathrm{N})\end{array}$ & $\begin{array}{l}\text { Completers } \\
\text { post } \\
\text { (N) }\end{array}$ & $\begin{array}{c}t \\
\text { (df) }\end{array}$ & $\begin{array}{c}\text { sig. } \\
(2- \\
\text { tailed) }\end{array}$ & $\begin{array}{c}t \\
\text { (df) }\end{array}$ & $\begin{array}{c}\text { sig. } \\
\text { (2-tailed) }\end{array}$ \\
\hline you feel happy & $\begin{array}{r}46.06 \\
(108)\end{array}$ & $\begin{array}{c}41.08 \\
(59)\end{array}$ & $\begin{array}{c}52.80 \\
(49)\end{array}$ & $\begin{array}{c}60.44 \\
(45)\end{array}$ & $\begin{array}{c}2.53 \\
(99.51)\end{array}$ & 0.01 & $\begin{array}{c}2.53 \\
(99.51)\end{array}$ & 0.01 \\
\hline $\begin{array}{l}\text { you feel } \\
\text { unhappy }\end{array}$ & $\begin{array}{l}22.97 \\
(108)\end{array}$ & $\begin{array}{c}25.85 \\
(59)\end{array}$ & $\begin{array}{c}19.36 \\
(49)\end{array}$ & $\begin{array}{c}17.67 \\
(44)\end{array}$ & $\begin{array}{c}2.34 \\
(99.45)\end{array}$ & 0.02 & $\begin{array}{c}2.34 \\
(99.45)\end{array}$ & 0.02 \\
\hline you feel neutral & $\begin{array}{l}30.96 \\
(108)\end{array}$ & $\begin{array}{c}33.07 \\
(59)\end{array}$ & $\begin{array}{c}27.84 \\
(49)\end{array}$ & $\begin{array}{c}21.67 \\
(45)\end{array}$ & $\begin{array}{c}1.36 \\
(99.77)\end{array}$ & 0.17 & $\begin{array}{c}1.36 \\
(99.77)\end{array}$ & 0.17 \\
\hline
\end{tabular}




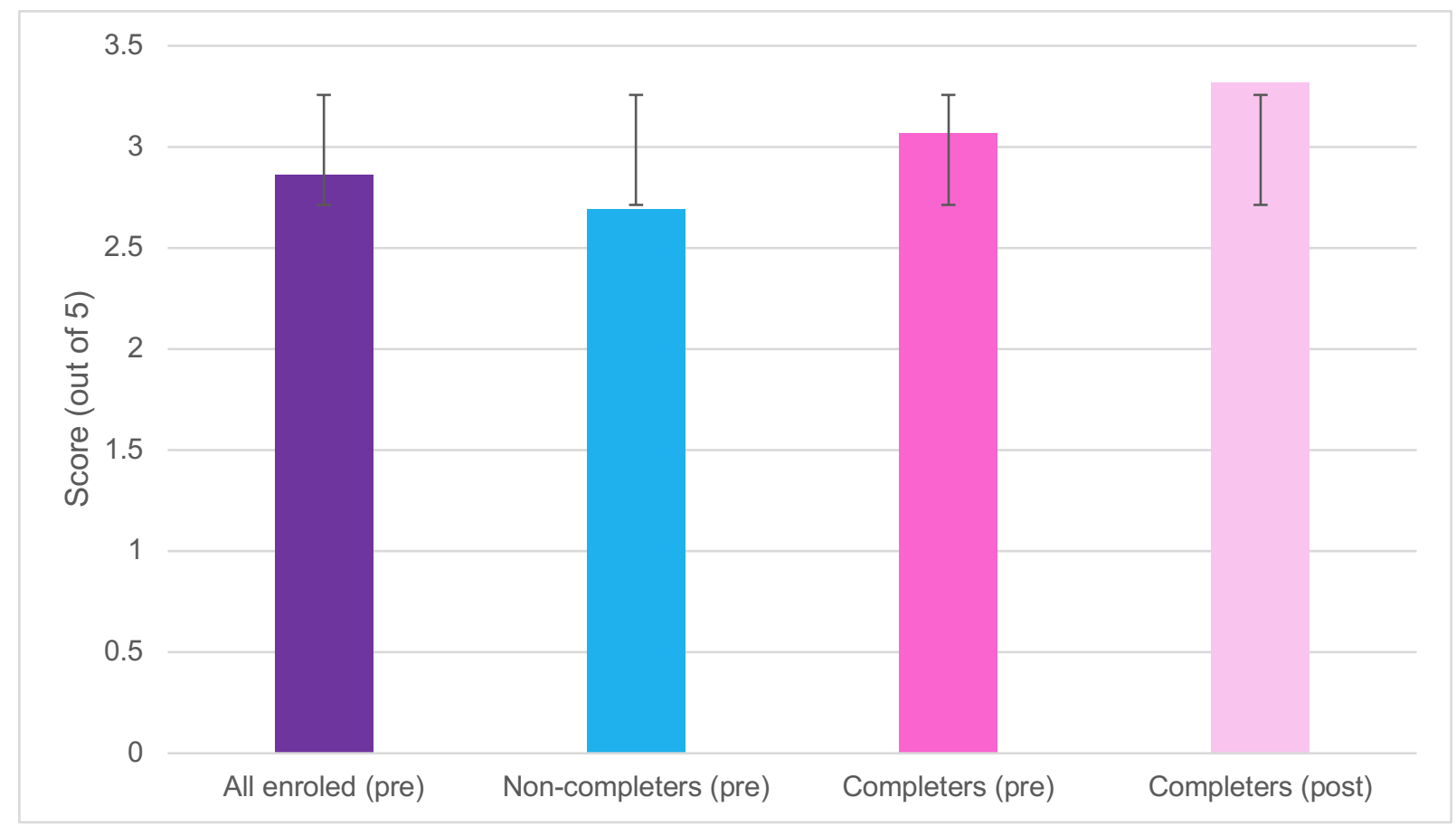

Figure 14. Authentic Happiness Inventory mean scores 


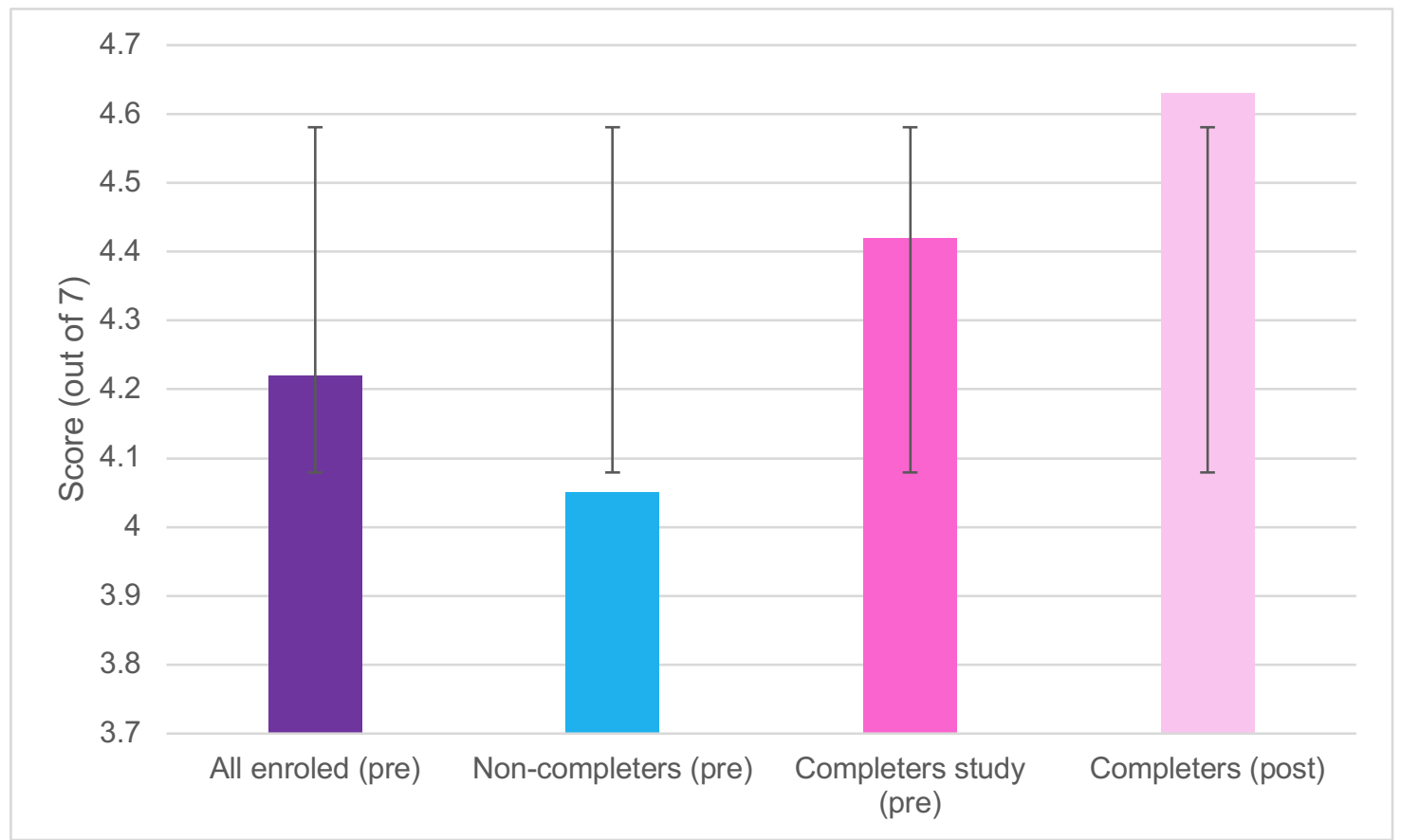

Figure 15. Subjective Happiness Scale mean scores 


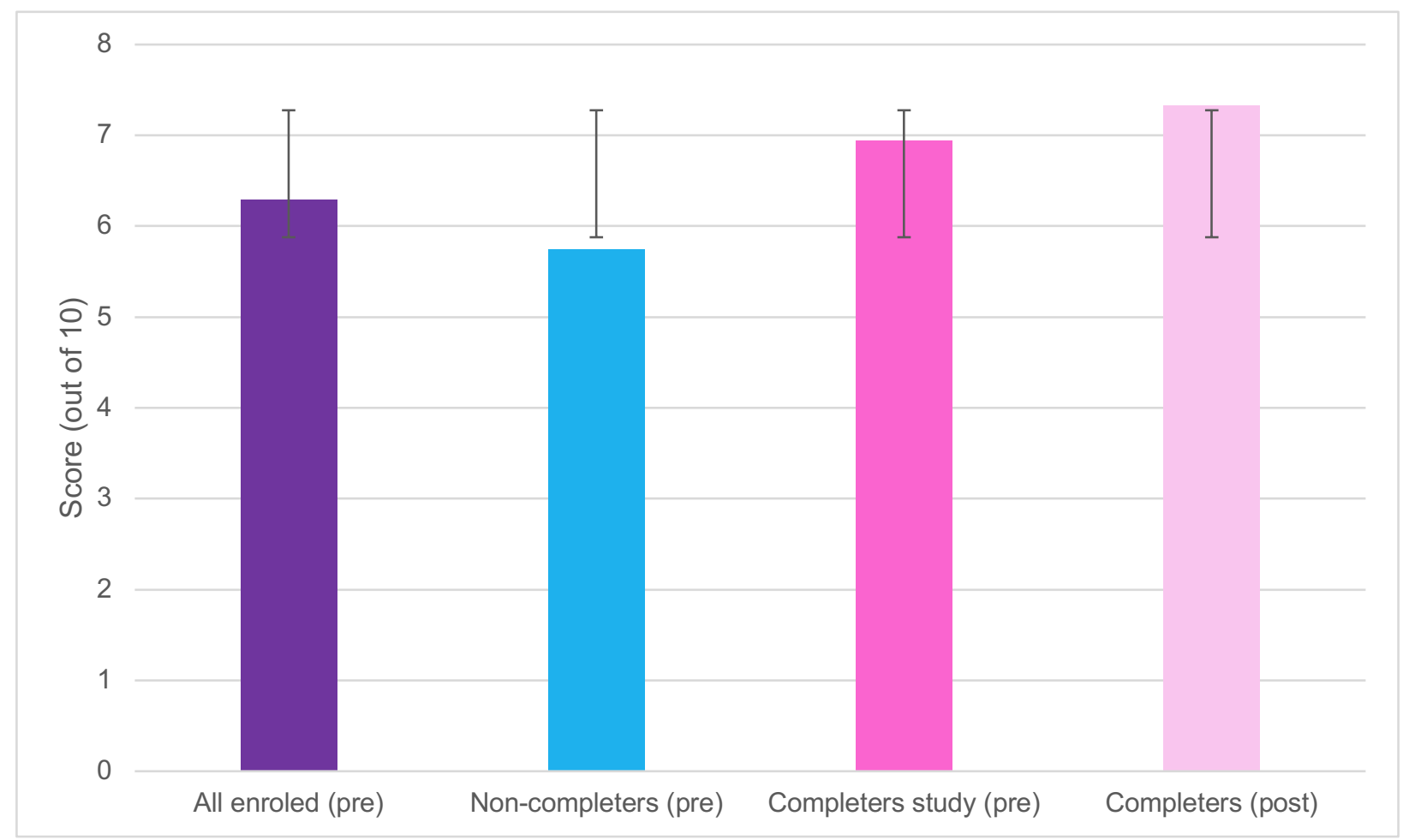

Figure 16. Fordyce Emotions Questionnaire mean scores 


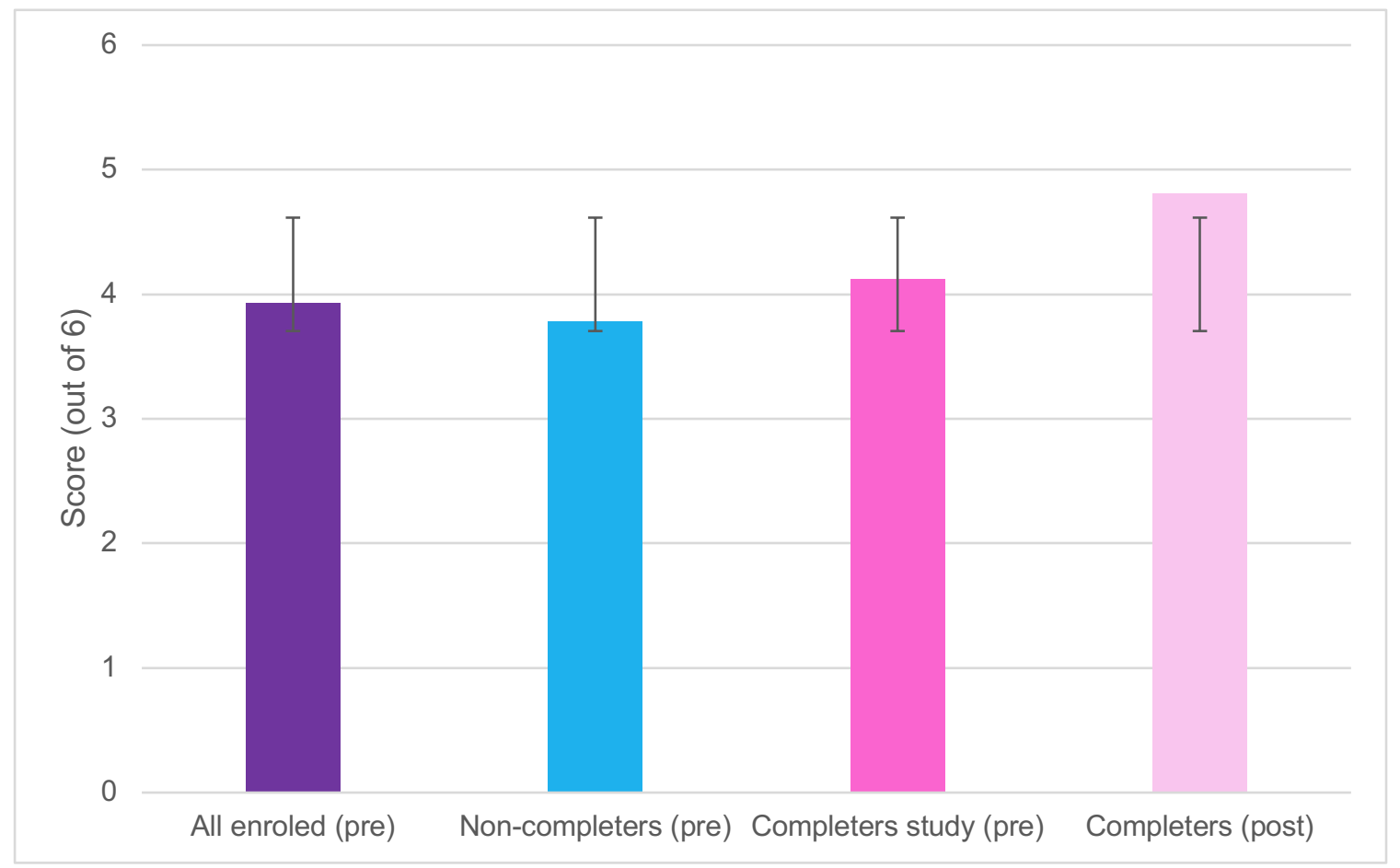

Figure 17. Oxford Happiness Inventory mean scores 


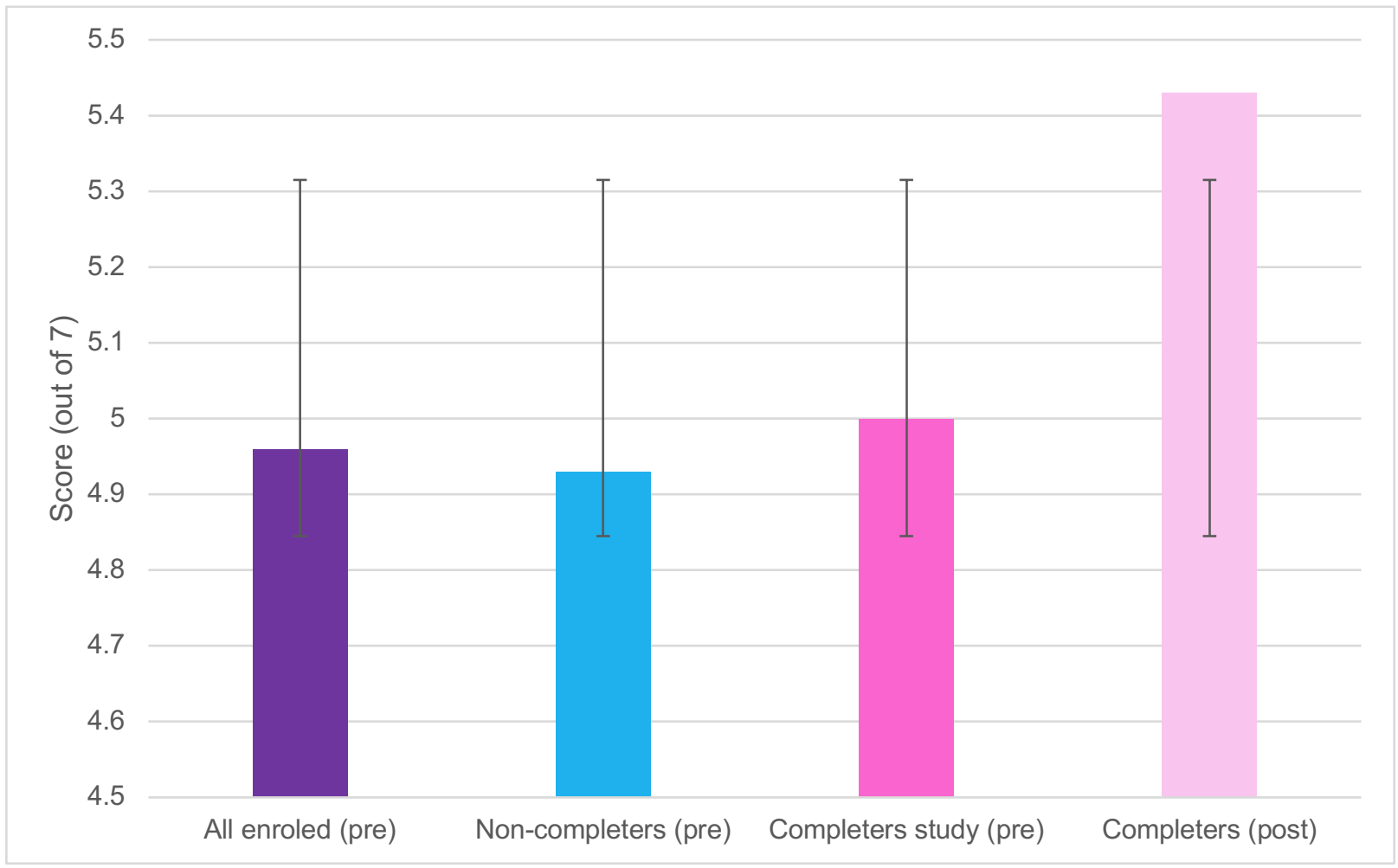

Figure 18. Flourishing Scale mean scores 


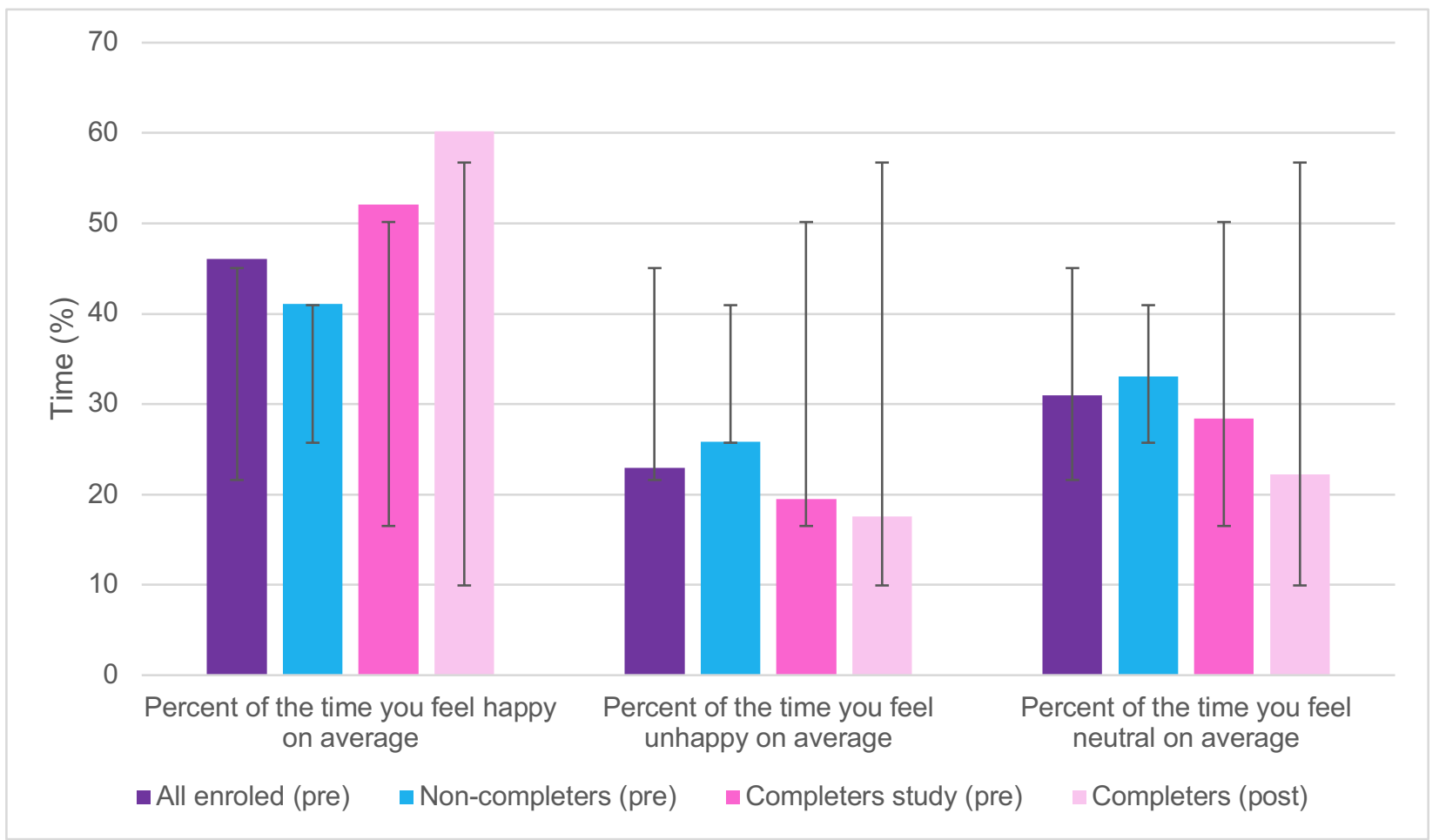

Figure 19. Percent of time spent happy, unhappy, and neutral 
A reliability analysis was completed for the four multi-item happiness indices. The Fordyce Emotions Questionnaire was not included because it only has one scaled item (the rest of the questionnaire asked participants to record the percentage of time they spent feeing happy, unhappy, and neutral). Out of the four measures for which Cronbach's alpha was calculated, three of the measures showed acceptable reliability (Authentic Happiness Inventory ( $\alpha=0.9$ ), Oxford Happiness Inventory $(\alpha=0.9$ ), and Flourishing Scale $(\alpha=0.9)$ ) and one, the Subjective Happiness Scale, did not $(\alpha=$ 0.41 .

In addition, effect sizes for the pre-post differences for the completers on all five self-reported happiness questionnaires were calculated using Cohen's $d$. A medium effect size was found for the Authentic Happiness Inventory $(d=0.9)$ and the Oxford Happiness Inventory $(d=0.7)$ whereas a small effect size was found for the Subjective Happiness Scale $(d=0.2)$, the Fordyce Emotions Questionnaire $(d=0.3)$, and the Flourishing Scale $(d=0.3)$.

\subsubsection{Pre vs. Post}

All five tools used to assess happiness saw an increase in scores from the beginning of the study to the end, and all of the five happiness measures except the Subjective Happiness Scale (SHS) revealed a statistically significant change at the completion of the study. Interestingly, the two longest questionnaires, the Authentic Happiness Inventory (AHI, 24 item questionnaire) and the Oxford Happiness Inventory (OHI, 29 item questionnaire) saw a statistically significant change: the mean score (out of 5) on the $\mathrm{AHI}$ increased from 3.09 ( $S D=0.7)$ pre to $3.3(S D=0.6)$ post, and the mean score (out of 6$)$ on the $\mathrm{OHI}$ increased from $4.2(S D=0.9)$ pre to $4.8(S D=0.9)$ post.

Participants completed a question that asked them what percent of the time they felt happy, unhappy, and neutral at the beginning and the end of the study. There was a significant increase in the percent of time participants reported feeling happy at the conclusion of the study $(60 \%, S D=22)$ as compared to the beginning of the study $(52 \%, S D=23)$ and a significant decrease in the percent of time participants reported 
feeling neutral at the end of the study $(28 \%, S D=18)$ as compared to the start $(22 \%$, $S D=16)$. The change in time spent unhappy approached significance although the decrease in time was small $(19 \%, S D=15$ pre to $18 \%, S D=15$ post).

\subsubsection{Completers vs. Non-completers}

In comparison to those who completed the study, those who did not complete the study had lower mean happiness scores on all five happiness questionnaires as compared to those who completed the study. Results were significant for three happiness measures: $\mathrm{AHI}(2.7, S D=0.6$ for non-completers and $3.1, S D=0.7$ for completers), $\mathrm{FEQ}$ (5.6, $S D=2.3$ for non-completers and 6.9, $S D=2.1$ for completers), and $\mathrm{OHI}(3.8, S D=0.7$ for non-completers and $4.2 S D=0.9$ for completers).

Similarly, the pattern of those who did not complete the study reporting lower happiness scores was again seen when participants were asked what percent of the time they felt happy, unhappy, and neutral. There was a significant difference in the percentage of time participants felt happy; those who did not complete the study reported feeling happy $41 \%$ of the time $(S D=22)$ and those who completed said they were happy $53 \%$ of the time $(S D=23)$.

In addition, those who did not complete the study felt unhappy significantly more often $(26 \%$ of the time, $S D=13)$ compared to those who completed the study who reported feeling unhappy only $19 \%$ of the time $(S D=15)$. There was no significant difference between the time spent feeling neutral between those who completed the study and those who did not complete the study.

\subsection{Lifestyle}

Lifestyle variables were assessed at the beginning and end of the study and included measures including weight, confidence in goal setting abilities, satisfaction with accomplishing daily tasks, exercise, sleep, stress, tobacco use, illicit drug use, alcohol consumption, social issues, number of close friends, and leisure activities. Results are provided in Table 15 for all participants enroled, those who completed the 
study (both pre and post results), and those participants who did not complete the study.

Table 15

Lifestyle information

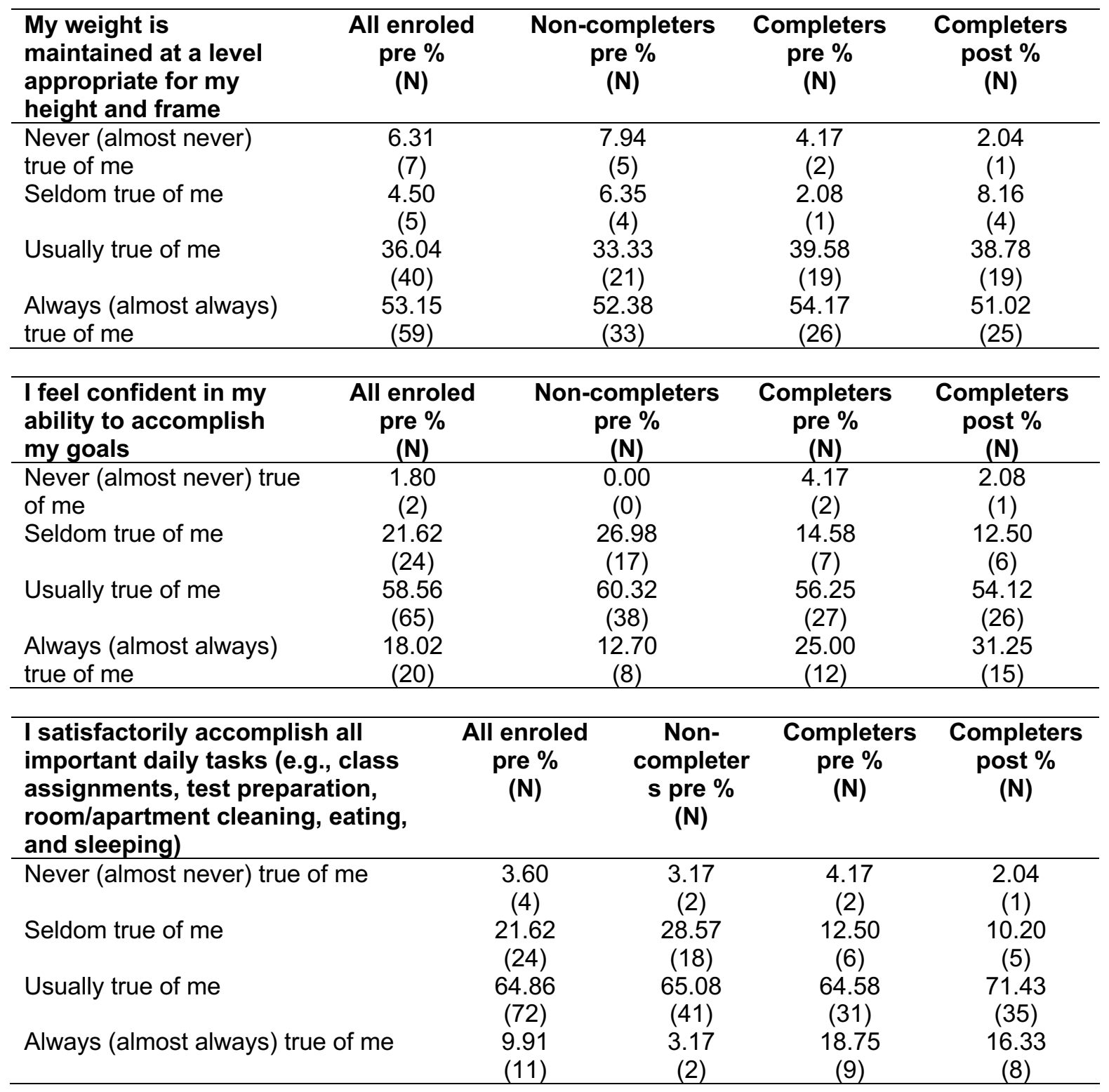




\begin{tabular}{|c|c|c|c|c|}
\hline $\begin{array}{l}\text { I exercise for } 30 \text { minutes } \\
\text { or more at least } 3 \text { times } \\
\text { per week }\end{array}$ & $\begin{array}{l}\text { All enroled } \\
\text { pre \% } \\
\text { (N) }\end{array}$ & $\begin{array}{l}\text { Non-completers } \\
\text { pre \% } \\
\text { (N) }\end{array}$ & $\begin{array}{l}\text { Completers } \\
\text { pre \% } \\
\text { (N) }\end{array}$ & $\begin{array}{l}\text { Completers } \\
\text { post \% } \\
\text { (N) }\end{array}$ \\
\hline $\begin{array}{l}\text { Never (almost never) true } \\
\text { of me }\end{array}$ & $\begin{array}{c}13.64 \\
(15)\end{array}$ & $\begin{array}{c}12.90 \\
(8)\end{array}$ & $\begin{array}{c}14.58 \\
(7)\end{array}$ & $\begin{array}{c}12.50 \\
(6)\end{array}$ \\
\hline Seldom true of me & $\begin{array}{c}30.00 \\
(33)\end{array}$ & $\begin{array}{c}35.48 \\
(22)\end{array}$ & $\begin{array}{c}20.83 \\
(10)\end{array}$ & $\begin{array}{c}27.08 \\
(13)\end{array}$ \\
\hline Usually true of me & $\begin{array}{c}31.82 \\
(35)\end{array}$ & $\begin{array}{c}29.03 \\
(18)\end{array}$ & $\begin{array}{c}35.42 \\
(17)\end{array}$ & $\begin{array}{c}29.17 \\
(14)\end{array}$ \\
\hline $\begin{array}{l}\text { Always (almost always) } \\
\text { true of me }\end{array}$ & $\begin{array}{c}24.55 \\
(27) \\
\end{array}$ & $\begin{array}{c}22.58 \\
(14) \\
\end{array}$ & $\begin{array}{c}29.17 \\
(14) \\
\end{array}$ & $\begin{array}{c}31.25 \\
(15) \\
\end{array}$ \\
\hline $\begin{array}{l}\text { I plan my activities to } \\
\text { make sure that I have } \\
\text { adequate time for sleep }\end{array}$ & $\begin{array}{l}\text { All enroled } \\
\text { pre \% } \\
\text { (N) }\end{array}$ & $\begin{array}{c}\text { Non-completers } \\
\text { pre \% } \\
(\mathrm{N}) \\
\end{array}$ & $\begin{array}{l}\text { Completers } \\
\text { pre \% } \\
\text { (N) }\end{array}$ & $\begin{array}{l}\text { Completers } \\
\text { post \% } \\
(\mathrm{N})\end{array}$ \\
\hline $\begin{array}{l}\text { Never (almost never) true } \\
\text { of me }\end{array}$ & $\begin{array}{c}7.21 \\
(8)\end{array}$ & $\begin{array}{c}4.76 \\
(3)\end{array}$ & $\begin{array}{l}10.42 \\
(5)\end{array}$ & $\begin{array}{l}6.12 \\
(3)\end{array}$ \\
\hline Seldom true of me & $\begin{array}{c}32.43 \\
(36)\end{array}$ & $\begin{array}{c}39.68 \\
(25)\end{array}$ & $\begin{array}{c}22.92 \\
(11)\end{array}$ & $\begin{array}{c}12.24 \\
(6)\end{array}$ \\
\hline Usually true of me & $\begin{array}{c}44.14 \\
(49)\end{array}$ & $\begin{array}{c}42.86 \\
(27)\end{array}$ & $\begin{array}{c}47.92 \\
(23)\end{array}$ & $\begin{array}{c}53.06 \\
(26)\end{array}$ \\
\hline $\begin{array}{l}\text { Always (almost always) } \\
\text { true of me }\end{array}$ & $\begin{array}{c}16.22 \\
(18) \\
\end{array}$ & $\begin{array}{c}12.70 \\
(8)\end{array}$ & $\begin{array}{c}18.75 \\
(9)\end{array}$ & $\begin{array}{c}28.57 \\
(14) \\
\end{array}$ \\
\hline $\begin{array}{l}\text { When I have experienced } \\
\text { stress or tension this } \\
\text { term... }\end{array}$ & $\begin{array}{c}\text { All enroled pre } \\
\% \\
(\mathrm{~N})\end{array}$ & $\begin{array}{l}\text { Non-completers } \\
\text { pre \% } \\
\text { (N) }\end{array}$ & $\begin{array}{l}\text { Completers } \\
\text { pre \% } \\
\text { (N) }\end{array}$ & $\begin{array}{l}\text { Completers } \\
\text { post \% } \\
\text { (N) }\end{array}$ \\
\hline $\begin{array}{l}\text { I have most often sought } \\
\text { relief by listening to music, } \\
\text { reading, or visiting friends }\end{array}$ & $\begin{array}{c}26.32 \\
(65)\end{array}$ & $\begin{array}{c}27.34 \\
(38)\end{array}$ & $\begin{array}{c}25.00 \\
(27)\end{array}$ & $\begin{array}{c}41.67 \\
(30)\end{array}$ \\
\hline $\begin{array}{l}\text { I have most often had a few } \\
\text { drinks or beers to relax }\end{array}$ & $\begin{array}{l}5.26 \\
(13)\end{array}$ & $\begin{array}{c}5.76 \\
(8)\end{array}$ & $\begin{array}{l}4.63 \\
(5)\end{array}$ & $\begin{array}{c}6.94 \\
(5)\end{array}$ \\
\hline $\begin{array}{l}\text { I have most often } \\
\text { exercised, worked out, or } \\
\text { played a sport }\end{array}$ & $\begin{array}{c}18.62 \\
(46)\end{array}$ & $\begin{array}{c}16.55 \\
(23)\end{array}$ & $\begin{array}{c}21.30 \\
(23)\end{array}$ & $\begin{array}{c}22.22 \\
(16)\end{array}$ \\
\hline $\begin{array}{l}\text { I have kept on going and } \\
\text { ignored the stress }\end{array}$ & $\begin{array}{c}23.48 \\
(58)\end{array}$ & $\begin{array}{c}23.02 \\
(32)\end{array}$ & $\begin{array}{c}24.07 \\
(26)\end{array}$ & $\begin{array}{c}19.44 \\
(14)\end{array}$ \\
\hline $\begin{array}{l}\text { I have had occasions when } \\
\text { it became too much to } \\
\text { handle and I had to take } \\
\text { days off to relax or } \\
\text { rest/sleep }\end{array}$ & $\begin{array}{c}26.32 \\
(65)\end{array}$ & $\begin{array}{c}27.34 \\
(38)\end{array}$ & $\begin{array}{c}25.00 \\
(27)\end{array}$ & $\begin{array}{c}9.72 \\
(7)\end{array}$ \\
\hline
\end{tabular}




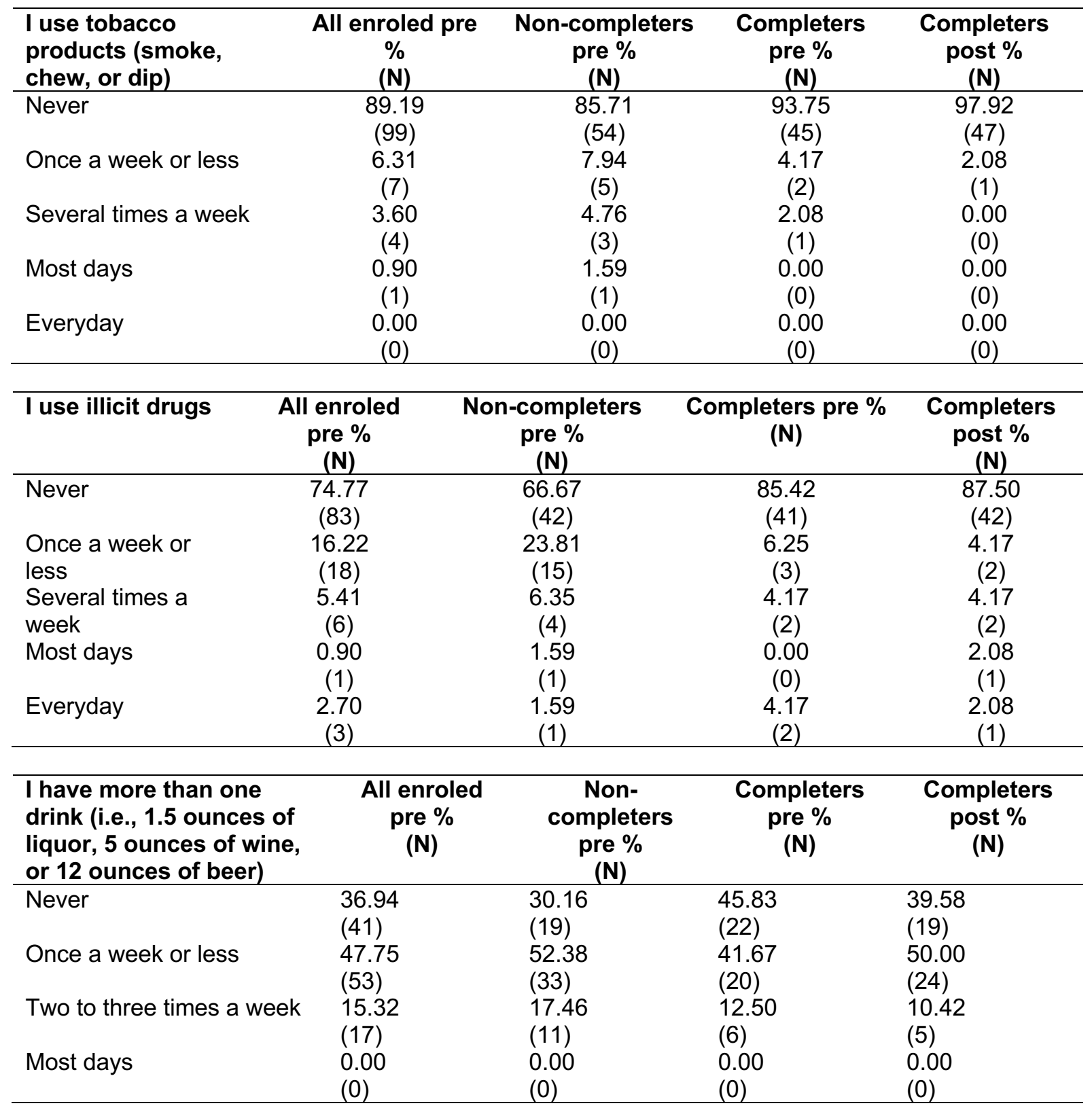




\begin{tabular}{|c|c|c|c|c|}
\hline $\begin{array}{l}\text { In regard to social issues } \\
\text { (e.g., homelessness, } \\
\text { environmental pollution, or } \\
\text { AIDS), }\end{array}$ & $\begin{array}{l}\text { All enroled } \\
\text { pre \% } \\
\text { (N) }\end{array}$ & $\begin{array}{c}\text { Non-completers } \\
\text { pre \% } \\
\text { (N) }\end{array}$ & $\begin{array}{l}\text { Completers } \\
\text { pre \% } \\
\text { (N) }\end{array}$ & $\begin{array}{l}\text { Completers } \\
\text { post \% } \\
\text { (N) }\end{array}$ \\
\hline I don't think much about them & $\begin{array}{c}8.11 \\
(9)\end{array}$ & $\begin{array}{c}7.94 \\
(5)\end{array}$ & $\begin{array}{c}8.33 \\
(4)\end{array}$ & $\begin{array}{c}6.38 \\
(3)\end{array}$ \\
\hline $\begin{array}{l}\text { I am concerned, but haven't } \\
\text { taken any specific actions }\end{array}$ & $\begin{array}{c}63.06 \\
(70)\end{array}$ & $\begin{array}{c}68.25 \\
(43)\end{array}$ & $\begin{array}{c}56.25 \\
(27)\end{array}$ & $\begin{array}{c}57.45 \\
(27)\end{array}$ \\
\hline $\begin{array}{l}\text { I contribute money to } \\
\text { organizations that address the } \\
\text { issue(s), but that is the extent } \\
\text { of my involvement }\end{array}$ & $\begin{array}{c}10.81 \\
(12)\end{array}$ & $\begin{array}{c}11.11 \\
(7)\end{array}$ & $\begin{array}{c}10.42 \\
(5)\end{array}$ & $\begin{array}{c}14.89 \\
(7)\end{array}$ \\
\hline $\begin{array}{l}\text { I am actively involved in } \\
\text { organizations that address the } \\
\text { issues(s) }\end{array}$ & $\begin{array}{c}18.02 \\
(20)\end{array}$ & $\begin{array}{c}12.70 \\
(8)\end{array}$ & $\begin{array}{c}25.00 \\
(12)\end{array}$ & $\begin{array}{c}21.28 \\
(10)\end{array}$ \\
\hline $\begin{array}{l}\text { How many close friends } \\
\text { do you feel you could go } \\
\text { to for support and to } \\
\text { confide in? }\end{array}$ & $\begin{array}{l}\text { All enroled } \\
\text { pre \% } \\
\text { (N) }\end{array}$ & $\begin{array}{l}\text { Non-completers } \\
\text { pre \% } \\
\text { (N) }\end{array}$ & $\begin{array}{l}\text { Completers } \\
\text { pre \%t } \\
\text { (N) }\end{array}$ & $\begin{array}{l}\text { Completers } \\
\text { post } \\
\% \\
(\mathrm{~N}) \\
\end{array}$ \\
\hline None & $\begin{array}{c}5.41 \\
(6)\end{array}$ & $\begin{array}{c}6.35 \\
(4)\end{array}$ & $\begin{array}{c}4.17 \\
(2)\end{array}$ & $\begin{array}{c}2.08 \\
(1)\end{array}$ \\
\hline $1-2$ & $\begin{array}{c}41.44 \\
(46)\end{array}$ & $\begin{array}{c}44.44 \\
(28)\end{array}$ & $\begin{array}{c}37.50 \\
(18)\end{array}$ & $\begin{array}{c}39.58 \\
(19)\end{array}$ \\
\hline $3-5$ & $\begin{array}{c}38.74 \\
(43)\end{array}$ & $\begin{array}{c}36.51 \\
(23)\end{array}$ & $\begin{array}{c}41.67 \\
(20)\end{array}$ & $\begin{array}{c}39.58 \\
(19)\end{array}$ \\
\hline $6-8$ & $\begin{array}{c}11.71 \\
(13)\end{array}$ & $\begin{array}{c}9.52 \\
(6)\end{array}$ & $\begin{array}{c}14.58 \\
(7)\end{array}$ & $\begin{array}{c}16.67 \\
(8)\end{array}$ \\
\hline More than 9 & $\begin{array}{c}2.70 \\
(3)\end{array}$ & $\begin{array}{c}3.17 \\
(2)\end{array}$ & $\begin{array}{c}2.08 \\
(1)\end{array}$ & $\begin{array}{c}2.08 \\
(1)\end{array}$ \\
\hline $\begin{array}{l}\text { Do you have } \\
\text { leisure activities } \\
\text { that you do just } \\
\text { for fun? }\end{array}$ & $\begin{array}{l}\text { oled pre } \\
\% \\
\text { (N) }\end{array}$ & $\begin{array}{l}\text {-completers } \\
\text { pre \% } \\
\text { (N) }\end{array}$ & $\begin{array}{l}\text { ppleters pre } \\
\% \\
\text { (N) }\end{array}$ & $\begin{array}{l}\text { Completers } \\
\text { post \% } \\
\text { (N) }\end{array}$ \\
\hline Yes & $\begin{array}{l}1.82 \\
90)\end{array}$ & $\begin{array}{c}79.03 \\
(49)\end{array}$ & $\begin{array}{c}85.42 \\
(41)\end{array}$ & $\begin{array}{c}89.36 \\
(42)\end{array}$ \\
\hline No & $\begin{array}{l}3.18 \\
20)\end{array}$ & $\begin{array}{c}20.97 \\
(13)\end{array}$ & $\begin{array}{c}14.58 \\
(7)\end{array}$ & $\begin{array}{c}10.64 \\
(5)\end{array}$ \\
\hline
\end{tabular}

\subsubsection{Pre vs. Post}

For the majority of lifestyle questions, there were very modest changes in participant responses from pre to post intervention. Approximately half of participants (545, $n=26$ pre; $51 \%, n=25$ post) responded with, "always (almost always) true of me" when asked if they felt their weight was maintained at a level appropriate for their height and frame, and $40 \%(n=19)$ said it was "usually true of me" pre and $39 \%$ ( $n=$ 19) post. 
In regard to goal setting, participants were asked about their confidence in their ability to accomplish their goals. Both pre and post the majority responded with, "usually true of me" ( $56 \%, n=27 ; 5 \%, n=26$; respectively). Interestingly, a larger percentage of participants responded with "always (almost always) true of me" after the intervention $(31 \%, n=15)$ as compared to before $(25 \%, n=12)$.

Participants were asked if they felt they satisfactorily accomplished all important daily tasks (e.g., class assignments, test preparation, room/apartment cleaning, eating, and sleeping), and the majority responded with, "usually true of me" $(65 \%, n=31$ pre; $71 \%, n=35$ post).

When asked if participants exercised for 30 minutes or more at least three times per week, the responses ranged from "never (almost never) true of me" 15\% $(n=7)$ pre and $13 \%(n=6)$ post, "seldom true of me" $21 \%(n=10)$ pre and $27 \%(n=13)$ post, "usually true of me" $35 \%(n=17)$ and $29 \%(n=14)$, and "always (almost always) true of me" $29 \%(n=14)$ pre and $31 \%(n=15)$ post.

In terms of sleep, participants were asked if they planned their activities to make sure that they had adequate time for sleep. Approximately half $(48 \%, n=23$ pre; $53 \%, n=26$ post) said that was usually true of them. There was a shift in the responses with less participants saying "seldom true of me" $(12 \%, n=6)$ after the intervention as compared to prior to the intervention ( $23 \%, n=11)$. More participants also responded with "always (almost always) true of me" $(29 \%, n=14)$ after the intervention while only $19 \%(n=9)$ gave that response at the beginning.

When asked about stress management, participants were told to select as many stress management possibilities from the available options that they engaged in. Interestingly, the difference in number of participants who selected, "I have had occasions when it became too much to handle and I had to take days off to relax or rest/sleep" decreased from $25 \%(n=27)$ at the start of the study to $10 \%(n=7)$ at the end of the study. The other noteworthy stress-related finding was that when asked about stress at the beginning of the study $25 \%(n=27)$ selected the response, "I have 
most often sought relief by listening to music, reading, or visiting friends" and this percentage increased to $42 \%(n=30)$ at the conclusion of the study.

When asked about tobacco, the vast majority of participants reported never using tobacco (smoke, chew, or dip) both before $(94 \%, n=45)$ and after $(98 \%, n=47)$ the study. A similar pattern was observed for illicit drugs: $85 \%(n=41)$ reported they never use illicit drugs prior to the study and $88 \%(n=42)$ at the completion of the study.

Regarding alcohol consumption, participants were asked about how many times per week they have more than one drink (i.e., 1.5 ounces of liquor, 5 ounces of wine, or 12 ounces of beer). At pre and post no participants reported having more than one drink on most days, and the majority had one drink per week or less $(42 \%, n=20$ pre; $50 \%, n=24$ post) or no drinks per week (46\%, $n=22$ pre; $40 \%, n=19$ post).

When asked about social issues such as homelessness, environmental pollution, or AIDS, over half of participants answered, “I am concerned, but haven't taken any specific actions" (56\%, $n=27$ pre; $57 \%, n=27$ post).

The majority of participants reported having three to five close friends that they felt they could go to for support and could confide in (42\%, $n=20$ pre; 40\%, $n=19$ post). An additional $38 \%(n=18)$ pre and $40 \%(n=19)$ post reported having one to two friends, and 15\% $(n=7)$ pre and $17 \%(n=8)$ post reported having six to eight. Very few participants had no close friends ( $4 \%, n=2$ pre; $2 \%, n=1$ post) or more than nine friends ( $2 \%, n=1$ pre; $2 \%, n=1$ post).

Lastly, participants were asked if they had leisure activities that they did just for fun. The majority said yes $(85 \%, n=41)$ before and after $(89 \%, n=42)$ the study.

\subsubsection{Completers vs. Non-completers}

When comparing the lifestyle differences at pretest between those participants who competed the study and those who did not complete the study, there are few major differences to report. For example, participants who completed the study and 
participants who did not complete the study responded in a similar proportion to the answers to the question, "my weight is maintained at a level appropriate for my height and frame".

One important difference appeared when participants were asked if they felt confident in their ability to accomplish their goals. More non-completers answered, "seldom true of me" $(27 \%, n=17)$ as compared to those who completed the study $(15 \%, n=7)$. A similar pattern was observed when participants were asked if they satisfactorily accomplished all important daily tasks (e.g., class assignments, test preparation, room/apartment cleaning, eating, and sleeping) where a larger proportion of non-completers answered, "seldom true of me" $(29 \%, n=18)$ as compared to only $13 \%(n=6)$ of those who completed the study. Among those that completed the study, a larger proportion $(19 \%, n=9)$ stated that they always accomplished important daily tasks by responding, "always (almost always) true of me" whereas only $3 \%(n=2)$ of non-completers gave the same response. Furthermore, when asked about exercise and sleep, a larger percentage of those who did not complete the study answered, "seldom true of me" when asked if they exercised for 30 minutes or more at least 3 times per week ( $35 \%, n=22$ non-completers; $21 \%, n=10$ of completers) and if they planned their activities to make sure that they have adequate time for sleep $(40 \%, n=$ 25 non-completers; $23 \%, n=11$ of completers).

The pattern of less reported physical activity among those who did not complete the study was also found when participants were asked if they exercised, worked out, or played a sport when they experienced stress or tension (17\%, $n=23$ noncompleters; $21 \%, n=23$ of those who completed the study). When asked about stress, all other potential response options had a similar percentage of responses between those who completed and those who did not complete the study.

While the difference was small, in terms of tobacco products (smoke, chew, or dip), illicit drugs, and alcohol, a larger percentage of participants who completed the study were more likely to say they never engaged in use of these products. For example, among those who completed the study, a greater percentage reported that 
they never used tobacco products $(94 \%, n=45$ of completers versus $86 \%, n=54$ of non-completers), never used illicit drugs $(85 \%, n=41$ of completers versus $67 \%, n=$ 42 of non-completers), and never had more than one drink ( $46 \%, n=22$ of completers versus $30 \%, n=19$ of non-completers).

A difference between those who completed the study and those that did not complete the study emerged when asked about social issues such as homelessness, environmental pollution, or AIDS. While both groups were concerned about social issues, those who completed the study more frequently stated that they were talking action to address them ( $25 \%, n=12$ of completers compared to $13 \%, n=8$ of noncompleters). Similarly, a larger proportion of those who did not complete the study were more likely to report that although they were concerned, they had not taken any specific actions in regard to social issues $(68 \%, n=43$ of non-completers compared to $56 \%, n=27$ of completers).

Lastly, when asked about the number of close friends participants felt they could go for support and could confide, and if they had leisure activities that they did just for fun, there were no noteworthy differences between those who completed the study and those who did not complete the study.

\subsection{Gratitude}

Three questions were used to assess gratitude, including the extent to which participants felt grateful, appreciative, and thankful. Cronbach's alpha was calculated with all of the pre responses to determine the internal consistency of this brief scale. Reliability was found to be 0.9 , which indicates a high level of internal consistency. Table 16, 17, and 18 present the gratitude findings numerically and Figures 20, 21, and 22 present them as bar graphs. 
Table 16

Gratitude results

\begin{tabular}{|c|c|c|c|c|}
\hline $\begin{array}{l}\text { To what extent do } \\
\text { you feel grateful right } \\
\text { now, at the present } \\
\text { moment? }\end{array}$ & $\begin{array}{c}\text { All enroled pre } \\
\% \\
\text { (N) }\end{array}$ & $\begin{array}{l}\text { Non-completers } \\
\text { pre \% } \\
\text { (N) }\end{array}$ & $\begin{array}{l}\text { Completers } \\
\text { pre \% } \\
\text { (N) }\end{array}$ & $\begin{array}{l}\text { Completers } \\
\text { post \% } \\
\text { (N) }\end{array}$ \\
\hline Very Slightly/Not at All & $\begin{array}{c}5.41 \\
(6)\end{array}$ & $\begin{array}{c}4.76 \\
(3)\end{array}$ & $\begin{array}{c}6.25 \\
(3)\end{array}$ & $\begin{array}{c}4.17 \\
(2)\end{array}$ \\
\hline A Little & $\begin{array}{c}8.11 \\
(9)\end{array}$ & $\begin{array}{c}9.52 \\
(6)\end{array}$ & $\begin{array}{c}6.25 \\
(3)\end{array}$ & $\begin{array}{c}2.08 \\
(1)\end{array}$ \\
\hline Moderately & $\begin{array}{c}27.93 \\
(31)\end{array}$ & $\begin{array}{c}33.33 \\
(21)\end{array}$ & $\begin{array}{c}20.83 \\
(10)\end{array}$ & $\begin{array}{c}14.58 \\
(7)\end{array}$ \\
\hline Quite a Bit & $\begin{array}{c}37.84 \\
(42)\end{array}$ & $\begin{array}{c}38.10 \\
(24)\end{array}$ & $\begin{array}{c}37.50 \\
(18)\end{array}$ & $\begin{array}{c}43.75 \\
(21)\end{array}$ \\
\hline Extremely & $\begin{array}{c}20.72 \\
(23)\end{array}$ & $\begin{array}{c}14.29 \\
(9)\end{array}$ & $\begin{array}{c}29.17 \\
(14)\end{array}$ & $\begin{array}{c}35.42 \\
(17)\end{array}$ \\
\hline
\end{tabular}

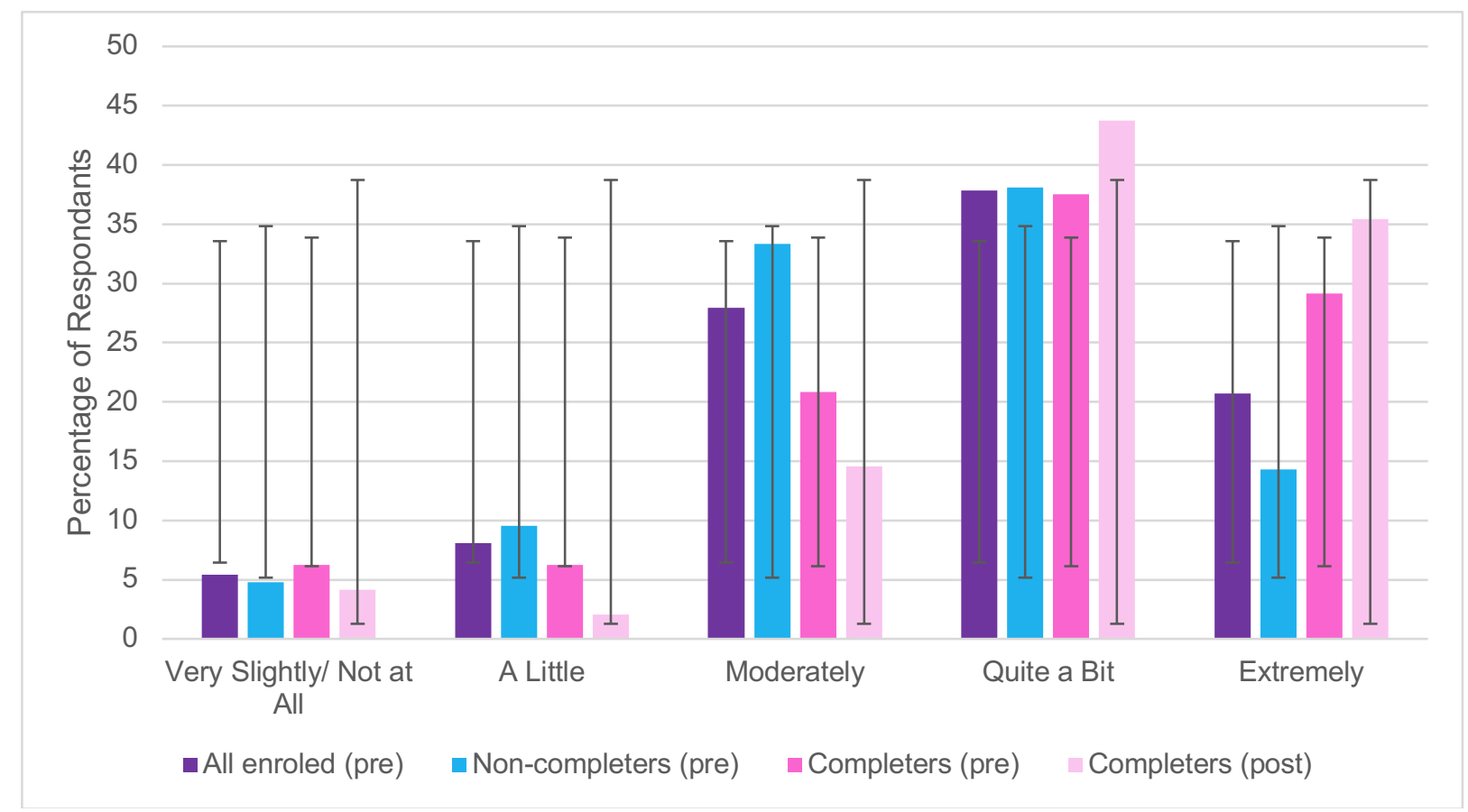

Figure 20. Participants by the extent they feel grateful right now, at the present moment 
Table 17

Appreciation results

\begin{tabular}{|c|c|c|c|c|}
\hline $\begin{array}{l}\text { To what extent do you } \\
\text { feel appreciative right } \\
\text { now, at the present } \\
\text { moment? }\end{array}$ & $\begin{array}{l}\text { All enroled } \\
\text { pre \% } \\
\text { (N) }\end{array}$ & $\begin{array}{c}\text { Non-completers } \\
\text { pre \% } \\
\text { (N) }\end{array}$ & $\begin{array}{l}\text { Completers } \\
\text { pre \% } \\
\text { (N) }\end{array}$ & $\begin{array}{l}\text { Completers } \\
\text { post \% } \\
\text { (N) }\end{array}$ \\
\hline Very Slightly/Not at All & $\begin{array}{c}6.31 \\
(7)\end{array}$ & $\begin{array}{c}4.84 \\
(3)\end{array}$ & $\begin{array}{c}8.16 \\
(4)\end{array}$ & $\begin{array}{c}4.17 \\
(2)\end{array}$ \\
\hline A Little & $\begin{array}{c}15.32 \\
(17)\end{array}$ & $\begin{array}{c}19.35 \\
(12)\end{array}$ & $\begin{array}{c}10.20 \\
(5)\end{array}$ & $\begin{array}{c}2.08 \\
(1)\end{array}$ \\
\hline Moderately & $\begin{array}{c}31.53 \\
(35)\end{array}$ & $\begin{array}{c}35.48 \\
(22)\end{array}$ & $\begin{array}{c}26.53 \\
(13)\end{array}$ & $\begin{array}{c}18.75 \\
(9)\end{array}$ \\
\hline Quite a Bit & $\begin{array}{c}28.83 \\
(32)\end{array}$ & $\begin{array}{c}30.65 \\
(19)\end{array}$ & $\begin{array}{c}26.53 \\
(13)\end{array}$ & $\begin{array}{c}37.50 \\
(18)\end{array}$ \\
\hline Extremely & $\begin{array}{c}18.02 \\
(20)\end{array}$ & $\begin{array}{c}9.68 \\
(6)\end{array}$ & $\begin{array}{c}28.57 \\
(14)\end{array}$ & $\begin{array}{c}37.50 \\
(18)\end{array}$ \\
\hline
\end{tabular}

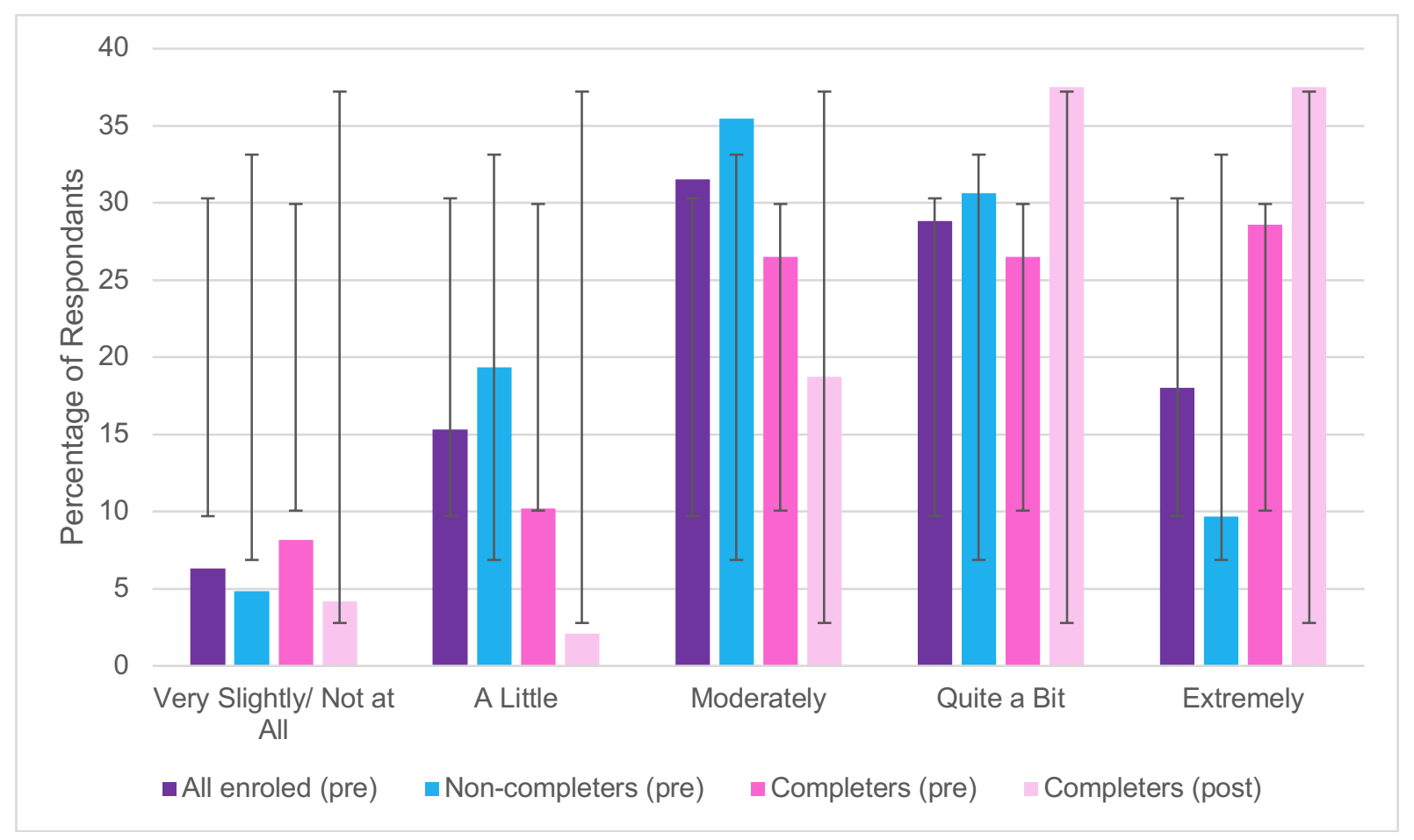

Figure 21. Participants by the extent they feel appreciative right now, at the present moment 
Table 18

Thankful results

\begin{tabular}{lcccc}
\hline $\begin{array}{l}\text { To what extent do } \\
\text { you feel thankful right } \\
\text { now, at the present } \\
\text { moment? }\end{array}$ & $\begin{array}{c}\text { All enroled pre } \\
\%\end{array}$ & $\begin{array}{c}\text { Non-completers } \\
\text { pre \% } \\
\mathbf{( N )}\end{array}$ & $\begin{array}{c}\text { Completers } \\
\text { pre \% } \\
(\mathbf{N})\end{array}$ & $\begin{array}{c}\text { Completers } \\
\text { post \% } \\
\text { (N) }\end{array}$ \\
\hline Very Slightly/Not at All & 3.57 & 3.17 & 4.08 & 4.17 \\
& $(4)$ & $(2)$ & $(2)$ & $(2)$ \\
A Little & 12.50 & 12.70 & 12.24 & 2.08 \\
& $(14)$ & $(8)$ & $(6)$ & $(1)$ \\
Moderately & 25.89 & 33.33 & 16.33 & 20.83 \\
& $(29)$ & $(21)$ & $(8)$ & $(10)$ \\
Quite a Bit & 33.04 & 31.75 & 34.69 & 33.33 \\
& $(37)$ & $(20)$ & $(17)$ & $(16)$ \\
Extremely & 25.00 & 19.05 & 32.65 & 39.58 \\
& $(28)$ & $(12)$ & $(16)$ & $(19)$ \\
\hline
\end{tabular}

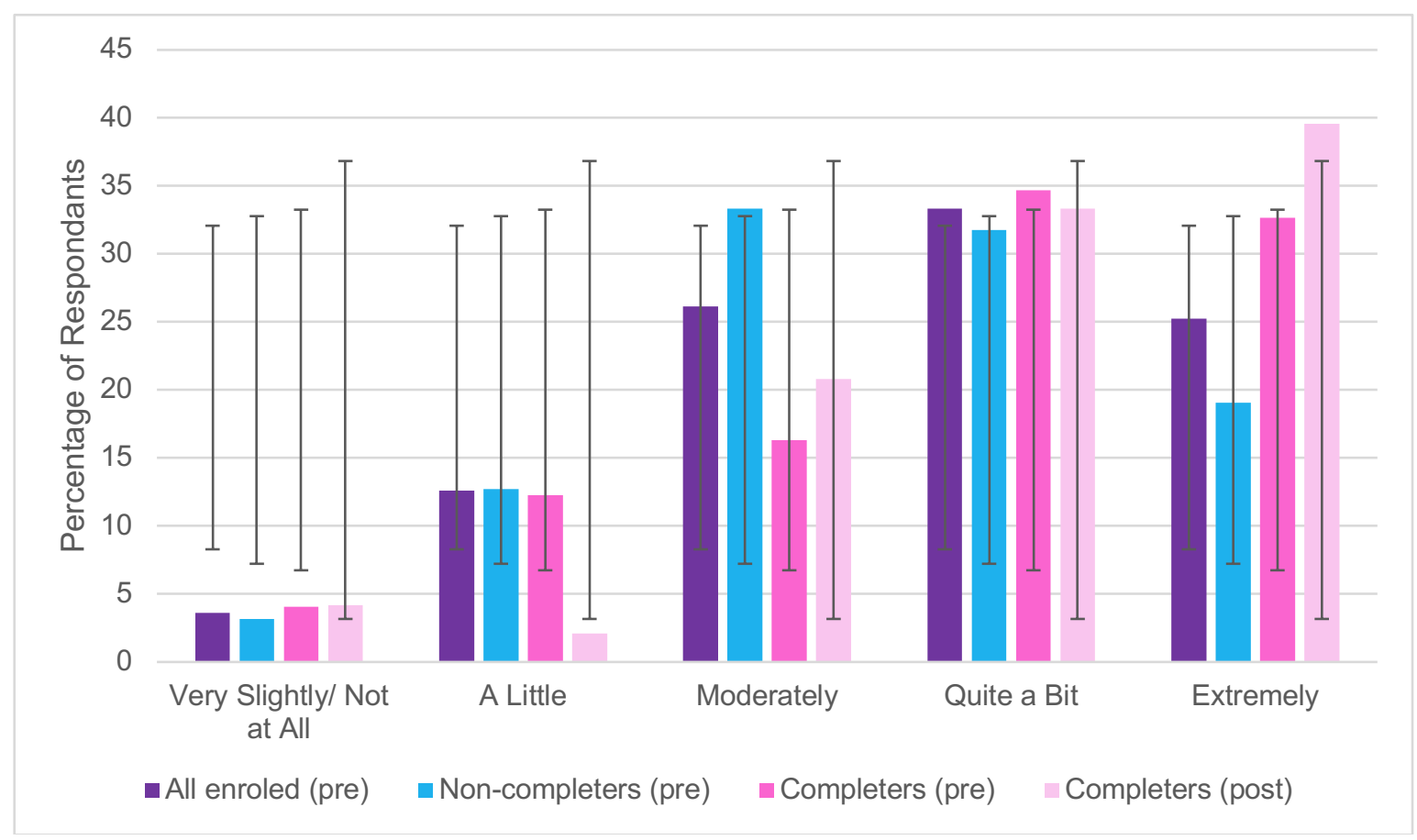

Figure 22. Participants by the extent they feel thankful right now, at the present moment

\subsubsection{Pre vs. Post}

The majority of participants who completed the study responded that they felt "quite a bit" grateful right now, at the present moment (38\%, $n=18$ pre; $44 \%, n=21$ 
post). When asked about the extent participants felt appreciative right now, at the present moment, responses were split mostly between "extremely" with 29\% $(n=14)$ at pre and $38 \%(n=18)$ at post, "quite a bit" with $27 \%(n=13)$ at pre and $38 \%(n=18)$ at post, and "moderately" with $27 \%(n=13)$ at pre and $19 \%(n=9)$ at post. Finally, participants were asked to what extent they felt thankful right now, at the present moment. The majority of participants responded with "quite a bit" $(35 \%, n=17$ pre; $33 \%, n=16$ post) and "extremely" (33\%, $n=16$ pre; $40 \%, n=19$ post). Interestingly, across all three indicators, the number of participants who responded with "extremely" increased at the end of the study and the number of participants who responded with "very slightly/not at all" and "a little" decreased.

\subsubsection{Completers vs. Non-completers}

When asked about gratitude, a difference emerged in the proportion of responses among those who completed the study and those who did not complete the study. Those who finished the study more frequently responded with, "extremely" when asked about the extent they felt grateful $(29 \%, n=14$ completers; $14 \%, n=9$ of non-completers), appreciative ( $29 \%, n=14$ completers; $10 \%, n=6$ of noncompleters), and thankful (33\%, $n=16$ completers; $19 \%, n=12$ of non-completers) right now, at the present moment.

Those who did not complete the study more frequently cited "moderately" when asked about the extent they felt grateful (33\%, $n=21$ of non-completers; $21 \%, n=10$ completers), appreciative (35\%,n=22 of non-completers; $27 \%, n=13$ completers), and thankful ( $33 \%, n=21$ of non-completers; $16 \%, n=13$ completers;) right now, at the present moment.

\subsection{Post-program feedback}

Thirteen participants completed the online post-program feedback questionnaire which consisted of a series of six optional, open-ended questions about happiness and eight optional, open-ended questions soliciting feedback about the video modules. The timing of the administration of this feedback form coincided with 
the spring exam period, which likely contributed to the low response rate (49 participants completed the post program questionnaire). Results are provided in Table 19 and Table 20.

Table 19

Program feedback questionnaire happiness results

What does happiness mean to you? $(n=11)$

- Happiness to me means being happy in all aspects of my life - school, work, health, family, friends, etc.

- Happiness is an emotion that accompanies certain phenomenon that bring joy to one's life. It is a mental state in which the individual enjoys their life.

- A choice to think about things and do things that please you individually

- To me, happiness is recognizing and appreciating things, moments, actions, people, etc. around you.

- Choosing to make the best of a situation and be positive even when it may be difficult.

- To me, happiness means a feeling of excitement when you are surrounded by the people you love. You always create something to look forward to in your mind, and are aware of your feeling of elation.

- Being content with what you have

- My family member can happy and I can reach my goal at the last period of time.

- Being healthy and having good relationships with people around you and especially your family and the people you love

- Happiness means being physically and emotionally invested in life and all activities going on around me while having a positive attitude and a smile on my face

- Being grateful for all the life experiences I have, good or bad, and being able to respond to people in a positive way regardless of how they act. Also, having a sense of fulfillment and belonging 
What makes you happy?

\section{Family/Relationships $(n=12)$}

- My family makes me happy, school makes me happy, and exercising and relaxing makes me happy.

- I also get happiness from being around friends and family. And puppies.

- Interpersonal relationships

- If I have a meaningful conversation with someone, I'm happy because I, and the person I've spoken with, have successfully established a connection or agreement.

- Family, friends, love

- Socializing, being able to talk to someone about issues, meeting goals, warm weather, the ocean, Muskoka, vacations, etc.

- My friends, and my family

- Spending time with family

- Spending time with my friends, spending time with my girlfriend

- Being with my Boyfriend.

- Spending time with my family and/or friends.

- Positive social interactions (knowing that people care), laughter, spending time with family

Food $(n=5)$

- Delicious food

- Food

- Having delicious food

- Eating tasty food

- Eating good food

Success $(n=4)$

- I get happiness from success, and that applies to all areas of life. If I play well in band practice, I'm happy because I played well.

- Achieving my goals

- Major accomplishments, believing in oneself

- Finishing a To-do list.

Exercise $(n=4)$

- Sports, exercise

- Going to the gym

- Play sports, exercising, hiking,

- Active lifestyle

Other $(n=4)$

- My wish can come true 
- Travelling, reading, watching movies, watching a good TV show, going to concerts, spending time outside, driving on back roads, playing video games with my roommates, playing with my dog.

- Being creative. Waking up after having the chance to sleep in. Writing in my planner.

- Literature, imagination, having time for myself to let my mind wander and being hopeful for the future.

Gratitude $(n=3)$

- Seeing everything that I have at my fingertips

- Being grateful

- Thanking my blessings

What makes you feel unhappy? $(n=12)$

- I feel unhappy when it is caused by other people - when people are rude, talk behind your back, etc.

- Seeing other people hurt or in distress, physical pain, getting a bad mark on an assignment.

- Fighting with people, negative people, failed at goals

- Failure. Feeling like I'm incompetent, or I haven't worked hard enough, or that I've let other people down.

- Being alone for too long. Not accomplishing my goals. Lack of sleep.

- When people around me are unhappy, when my friends hide things from me or lie to me, when people are pessimistic instead of optimistic or even neutral, when people are mad at me, when I feel like I have let other down, etc.

- Unfortunate events

- The terrible weather and bad mark.

- When I fight with my close friends or my family

- Getting bad marks back, doing things I do not enjoy, driving in traffic, having a bad race (swimming), having things that restrict me from exercise (blisters, injuries), fighting with my girlfriend.

- A bad grade, bullying, seeing others unhappy

- Negative social interactions (no response), other people's negative behaviour, failure. 
How often do you feel happy?

Most of the time $(n=8)$

- Most of the time - it is something I prioritize in my life and I'm quite good at having a positive outlook on life.

- $80 \%$ of the time

- I feel happy most of the time.

- Every day, almost all the time.

- Most of the time

- Most of the time

- Most of the time. l'd say almost $80 \%$ of the time.

- I feel happy probably $95 \%$ of the time

Sometimes $(n=3)$

- I feel happy about $45 \%$ of the time.

- 3 times per week.

- $30-40 \%$ time

Unsure $(n=1)$

- I'm not sure. I feel like I have a few moments of happiness everyday, surrounded by neutral feelings, and sometimes marked by unhappy feelings.

\section{How important is it to you to feel happy?}

Extremely/very important $(n=7)$

- It is of the utmost importance to me to feel happy

- It's my number one priority. Everything else in life is temporary and fleeting but if you can "be good at happiness" it'll make all the difference. I put feeling happy above anything else, including doing well in school.

- VERY important. I try my best to always think on the bright side of things and be aware of my happiness, to live a healthy life.

- Very important, without it both my body and mind will fall in chaos.

- Extremely important.

- It is very important to feel happy, I believe you can make others happy if they see you are happy. A smile goes a long way.

- Very important

Moderately/somewhat important $(n=4)$

- Moderately important

- It's not the most important thing to me. My daily goals don't usually include "be happy," but feeling happy after or throughout the day is sort of like a bonus.

- It is not my main priority. I am usually more focused on the tasks I need to complete.

- Somewhat important 
Are your friends happy?

Yes $(n=6)$

- My friends are happy - they have everything they want, and they are good at not worrying about what others think or say

- My friends are very happy people. When I'm with them they keep my laughing and smiling, even when times get rough.

- Yes they are, because their happiness is easy to achieve.

- Yes I suppose they are because they are living a well-balanced life, doing things they love and enjoy and are surrounded by people who care for them

- Yes I would say my friends are happy because they have good situations at home (with family), and have good friends at school, as well as getting good grades

- Yes they are. They all have goals which they have mostly accomplished by the end of the school year. They are also all able to talk to one another to discuss any issues if they arise.

\section{Most of the time $(n=5)$}

- Most of them, some are unhappy due to mental illness

- Most of the time. Unless assignment deadlines are approaching. But in general, they are happy people.

- Most seem happy. I try to distance myself from friends who are rubbing their unhappiness off on me. I believe my friends who are unhappy are this way when they are alone and not socializing, or when they don't talk to me about things/lie to me.

- Not all the time but some of the time

- Generally, l'd say people around me are happy most of the time, if stressed, which I can empathize with (a lot of my friends are working or in university; high stress environments). 
Table 20

Program feedback questionnaire video module results

Did the video content impact your concept of happiness?

Yes/positive response (a sample from the total responses, $n=11$ )

"They made me think about happiness much more and what it was and what it meant to me. It also gave me ideas for how to incorporate more happiness into my life."

"It did, I got a better idea of what happiness truly means and how important it is to be happy on a daily basis, and how our happiness can affect others' happiness too"

"Yes, they made me consciously aware of many terms or concepts that I would not normally think of, rather than just do."

\section{Not sure/neutral $(n=1)$}

"I'm not sure how much the content impacted my concept of happiness. That is to say, my understanding of happiness hasn't been drastically altered."

No $(n=1)$

"No"

\section{Did your view of happiness change after watching the videos?}

No (a sample from the total responses, $n=6$ )

"Not really, it mostly strengthened my pre-existing ideas about it."

"No, I think a lot of the concepts were a bit familiar (this is not my first encounter with mindfulness), but some things are important to be reminded of (the importance of gratefulness), and understanding the additional scientific support behind some of these ideas is good."

Yes (a sample from the total responses, $n=3$ )

"Yes, I learned that happiness isn't about a constant feeling of joy, but being aware, mindful and present in the happy moment in your life."

"Yes, being social more important."

Stayed the same $(n=1)$

"It relatively stayed the same. I did learn new things but I started out as a very happy person." 
Did you continue to think about the videos after you watched them?

Yes (a sample from the total responses, $n=8$ )

"They definitely stayed in my mind for a while after. They also gave me something to think about throughout the day in my social encounters and experiences."

"Yes, I sometimes think of the exercises when I am feeling down in order to increase my happiness."

"I did think about the videos after watching them, especially when I was having a rough day."

No (a sample from the total responses, $n=3$ )

"No, I found them to be very fleeting."

"Not really."

Did certain videos have more of an impact than others?

Yes (a sample from the total responses, $n=6$ )

"The most impactful videos for me were ones that gave me ideas to apply to my actual life."

"The videos in the week about friendship."

"The videos that had exercises that I could physically try at home."

"Some did when they talked about having gratitude, they left more of an impact."

No (a sample from the total responses, $n=5$ )

"No, I found them to be all equally impactful."

"No." 
Did you learn anything from the videos that impacted your life?

\section{Yes (a sample from the total responses, $n=8$ )}

"How to take a positive outlook on things no matter what and to always look at the big picture - things are never as bad as they seem."

"I did, some examples they used I could easily relate them to my life."

"Yes, I am going to try to cultivate stronger friendships to support people around me."

No (a sample from the total responses, $n=4$ )

"I don't know if I necessarily learned anything new, but the videos definitely gave me a greater understanding of things l'd been aware of before (i.e. mindfulness), and gave me greater awareness of how certain things can increase happiness (i.e. gratefulness)."

"Not really."

Have you learned anything from the videos that you have or plan to incorporate into your life?

Yes (a sample from the total responses, $n=7$ )

"Just that happiness comes in many forms."

"Yes, I am going to try to cultivate stronger friendships to support people around me."

"The exercises, such as 3 great things."

"Taking a couple minutes to count your blessings."

No (a sample from the total responses, $n=5$ )

"Nothing I did not already know to be happy."

"No. I am already a pretty happy person."

"No, nothing new."

Did you share anything you learned in the videos with your friends?

No (a sample from the total responses, $n=10$ )

"Not really. Just my smile!"

"No."

Yes $(n=2)$

"I shared a couple of videos with my family."

"Yes, with my boyfriend! I explained the parts that lead to a happy relationship, so we could focus on them in our relationship." 
Was there anything about the videos you would change, improve, or remove? Yes (a sample from the total responses, $n=7$ )

"More graphics and animations would be nice! Helps people stay engaged. If they were a little shorter and more energetic that would be good too."

"The videos were to the point which was nice. However the format of just having someone sit in front of a camera and talk in a lecturer voice did not make the videos very engaging."

"Having it seem like they are lecturing at you was not enjoyable. a more interactive style of video would be better"

"Have more exercises for viewers to do and have more enthusiasm in the presenters' voices."

No (a sample from the total responses, $n=5$ )

"No, I thought they were appropriate for the task at hand."

"I really liked all the videos."

"No, I thought they were very informative."

\subsubsection{Qualitative Happiness Data}

Participants were asked to describe what happiness meant to them. Eleven participants responded, and a sample of answers included:

Happiness is an emotion that accompanies certain phenomenon that bring joy to one's life. It is a mental state in which the individual enjoys their life.

To me, happiness is recognizing and appreciating things, moments, actions, people, etc. around you.

Happiness means being physically and emotionally invested in life and all activities going on around me while having a positive attitude and a smile on my face.

When asked, "what makes you happy?", participants' responses emerged in six categories: family/relationships $(n=12)$, food $(n=5)$, success $(n=4)$, exercise $(n=4)$, other $(n=4)$, and gratitude $(n=3)$. And when asked, "what makes you unhappy?", participants cited a number of things such as seeing other people hurt, unfortunate events, terrible weather, bad marks, bullying, and lack of sleep. 
In terms of frequency, most participants $(n=8)$ described feeling happy most of the time, three said they were sometimes happy, and one was unsure.

All of the responding participants placed happiness as a priority: seven described it as extremely/very important and four as moderately/somewhat important.

When asked if their friends were happy, six participants responded yes. Five participants said their friends were happy most of the time.

\subsubsection{Video Module Feedback}

The majority of participants $(n=11)$ said that they video they watched during the study impacted their concept of happiness or gave a positive response, one was not sure/neutral, and one said that the videos did not impact their concept of happiness.

The majority $(60 \%, n=6)$ of respondents said no to the question, "did your view of happiness change after watching the videos?"; however, their responses suggested that they already knew about happiness and the videos had content that they were already familiar with. Three participants $(30 \%)$ stated that their views about happiness did change, and one participant (10\%) said that they stayed the same.

$73 \%$ of participants $(n=8)$ continued to think about the videos after they watched them, $67 \%(n=8)$ learned something from the videos that impacted their life, $58 \%(n=7)$ learned something from the videos that they have or plan to incorporate into their life, and $55 \%(n=6)$ stated certain videos had more of an impact than others ( $46 \%, n=5$ found the videos to be equally impactful).

Finally, participants were asked if there was anything about the videos that they would change, improve, or remove. Of those who said yes $(58 \%, n=7)$, suggestions included better graphics and animations, shorter video length, a more engaging format, and an increased number of weekly exercises. 


\subsection{Summary of Findings}

This chapter presented the results of the study. Recruitment and demographic information were first described. Happiness, lifestyle, and gratitude results were presented in ways, firstly for participants who completed the study (comparing pre and post results) and secondly, an analysis of completers versus non-completers to examine characteristics that may differentiate those who completed from those who did not. Finally, qualitative data (about happiness and video module feedback) from an open-ended, post-program questionnaire were described. 


\section{Chapter 5. Discussion of Results}

The purpose of this chapter is to interpret and discuss the research findings from the current study investigating whether a four-week intervention to test if online videos that teach strategies to enhance happiness (e.g. gratitude, empathy, and mindfulness) can increase self-reported happiness among university students. The primary outcome was self-reported happiness, and secondary outcomes included self-reported lifestyle measures (weight, confidence in goal setting abilities, satisfaction with accomplishing daily tasks, exercise, sleep, stress, tobacco use, illicit drug use, alcohol consumption, social issues, number of close friends, and leisure activities) and self-reported gratitude.

Relevant literature is utilised to interpret and discuss the research findings, which are divided into three sections. First, an interpretation of the results for participants who both started and completed the study are discussed in terms of self-reported happiness, lifestyle, and gratitude findings. Second, the analysis of non-completers regarding the characteristics that distinguished them from those that completed the study are discussed based on self-reported happiness, lifestyle, and gratitude results. Third, post-program feedback is considered and examined based on self-reported happiness and video module feedback.

Seligman et al. (2005) have described that happiness, in a theoretical sense, can encompass overall positive affect, mood, and well-being. Given that there is a large variability among the definitions and uses of the words happiness, subjective wellbeing, well-being, and positive affect, for the purpose of this section, the word happiness will be considered synonymous with all of those terms.

\subsection{Representativeness of the Study Sample}

A total of 114 participants completed the pre-program questionnaire ( $76 \%$ female, $23 \%$ male, $0 \%$ other), 49 participants completed the post-program questionnaire $(78 \%$ female, $22 \%$ male), and 13 participants ( $77 \%$ female, $23 \%$ males), completed the program feedback questionnaire. Western's undergraduate population is comprised of 
10\% International Students (Universities Canada, 2016), which is similar to the sample in this study $(11 \%)$. While the proportion of females was higher in the study sample (Western is $56 \%$ female, $44 \%$ male), participants spanned all years of undergraduate enrolment, and a saw a similar percentage of students in first year $(25 \%)$ as Western University (22\% Universities Canada, 2016). Several Faculties from across campus were represented in the sample, and when comparing the current sample to the fulltime undergraduate students at Western (Universities Canada, 2016), a similar proportion of student enrolment was seen across various Faculties: Social Science/HBA (30\% study participants, 38\% Western), Science/Engineering (38\% study participants, 30\% Western), Health Science/ Kinesiology (19\% study participants, 21\% Western), Arts and Humanities/Music (9\% study participants, 6\% Western), and Information and Media Studies (4\% study participants, 4\%Western).

\subsection{Pre vs. Post Results}

The study's primary outcome was self-reported happiness as measured by five happiness scales. On all five tools used to assess self-reported happiness there was an increase in scores from pre-test to post-test; for four of the scales, the increases were statistically significant. In addition to the increase in happiness, there were noteworthy observations in some of the secondary outcomes, including self-reported lifestyle measures (confidence in goal setting and accomplishing daily tasks, sleep, and stress) and self-reported gratitude.

\subsubsection{Happiness}

In the current study, an increase in self-reported happiness from pre-test to post-test was observed based on all five measures of happiness. The significant prepost changes indicated that a relatively brief intervention based on the use of online modules can significantly increase self-reported happiness. Interestingly, the two longest questionnaires, the Authentic Happiness Inventory (AHI, 24 item questionnaire) and the Oxford Happiness Inventory ( $\mathrm{OHI}, 29$ item questionnaire) saw a statistically significant change, as well as high scores of internal consistency. 
Although four of the measures saw a statistically significant change, the Subjective Happiness Scale (SHS) did not. In other studies the SHS has been found to have good to excellent internal consistency (Lyubomirsky \& Lepper, 1999; McCullough et al., 2002; Schiffrin \& Nelson, 2010), and Howell et al. (2010) have tested it for use on the Internet using both a college student sample. When examining the internal consistency of the SHS in the current study, it was the only questionnaire that had a low internal consistency. Notably, this was the shortest of the five happiness tools used in the current study, which may account for why this measure showed the smallest pre-post effect.

A meta-analysis conducted by Sin and Lyubomksky (2009), which included 51 interventions with a total of 4,266 participants, examined several studies to investigate if interventions aimed at increasing positive feelings, behaviours, or thoughts can enhance well-being. The authors found that in the majority of the studies ( 49 of the 51 studies) there was a significant increase in well-being demonstrated by a medium effect size (Mr=0.29)]. When examining interventions that involve a student population, similar results are seen; interventions boosted happiness in an undergraduate population. For example, a study by Van Zyl and Rothmann (2012) designed to increase happiness involved 20 students who completed a program that included an initial orientation, a three-day personal and group development program, and six sessions of individual coaching. The study found that the program increased the levels of perceived happiness of the participants. Another study, a randomized control trial by Ouweneel, Le Blanc, and Schaufeli (2014) with 50 undergraduate students, asked participants to evaluate their happiness both before and after a oneweek online happiness intervention where participants assigned to the experimental condition received an email every morning, from Monday to Friday, with short activities and a mood questionnaire. Relative to scores prior to the study, participants scored higher on positive emotions after the study. The level of positive emotions of participants were monitored on a daily basis, and interestingly, the experimental group scored significantly higher on positive emotion compared to the control group starting after the second day of the intervention. 
In addition to interventions that were similar to the current study (in that they focused on an undergraduate student population), there are also other interventions that were administered online that have similar findings to the current study. Interestingly, while the administration of online programs is increasing, as is the number of people online (Buzwell et al., 2016), a study published by Manthey, Vehreschild, and Renner (2016) noted that to the best of their knowledge, theirs was the first intervention that was Internet-based and used video instructions to increase well-being. Their study included 666 participants, and they found that the intervention conditions were effective in increasing well-being when compared to a control group. Although the effect sizes were small $(r=0.09-0.13)$, the results from a four-week follow-up showed that the improvements were still maintained. More recently, a sixweek, self-paced online program for increasing self-compassion and happiness (in which participants completed one online module per week for six weeks) conducted in Australia by Finlay-Jones et al. (2017) was published. Results described how participants not only reported significant increases in happiness from pretest to posttest, but the majority of changes were still maintained at a three-month follow up.

In the current study, participants were asked to complete a question that asked them what percent of the time they felt happy, unhappy, and neutral at the beginning and the end of the study. There was a significant increase in the mean percent of time participants reported feeling happy at the conclusion of the study as compared to the beginning of the study, and a significant decrease in the mean percent of time participants reported feeling neutral at the end of the study as compared to the start. This finding from the current study is noteworthy for two reasons. First, overall in terms of the mean total percentage of time that participants spent feeling happy, unhappy, and neutral, the current study had rates that were very similar to rates reported by Liaghatdar, Jafari, Abedi, and Samiee (2008). Specifically, in Liaghatdar et al.'s (2008) college sample of 3,050 students, the authors found that the average total percentage of time participants spent happy was $54 \%$ ( $S D=22$, Liaghatdar et al., 2008). In the current study the mean total percentage of time participants spent happy was very similar, $53 \%(S D=23)$. When examining mean time spent unhappy, Liaghatdar et al. (2008)'s sample reported spending an average of $20 \%(S D=15)$ of their time 
unhappy, and similarly, the sample in the current study reported an mean of $22 \%$ (SD $=16$ ) of their time was spent unhappy. Finally, Liaghatdar et al.'s (2008) sample reported that $25 \%$ ( $S D=17$ ) of the day they felt neutral feeling neutral, and the current study's sample spent $19 \%(S D=15)$ of their day feeling neutral. Second, there was a statistically significant increase in happiness post-intervention, as the mean percent of time participants reported feeling happy at the conclusion of the study increased compared to the beginning of the study. This finding is not surprising given that the primary purpose of the intervention was to increase happiness; however, what is noteworthy is that there was a significant decrease in the mean percentage of time participants reported feeling neutral at the end of the study as compared to the start. This change may be related to the content of the video modules in the first week of the intervention because in the first week of videos, participants were taught some misconceptions about happiness, one of which was the difference between happiness and sadness. They were taught that it is okay to feel sad sometimes. They were told that instead of focusing on getting rid of sad feelings all together, they should notice times in their life when they feel fairly neutral and focus on how they can change their mood to feel happier especially during those times. Given that content in week one, it is not surprising to see that there was a significant reduction in the mean percentage of time participants reported feeling neutral at the conclusion of the study.

\subsubsection{Lifestyle}

For the lifestyle questions, a few responses were noteworthy and will be discussed, including pre/post changes in goal setting and daily task accomplishment, sleep, and stress.

In the current study, when asked about their ability to accomplish goals, a larger percentage of participants responded with "always (almost always) true of me" after the intervention as compared to before. In addition, in terms of accomplishing all important daily tasks there was an increase in the percentage of participants who responded with "usually true of me" from the beginning to at the end of the study which suggests that over the course of the study, participants perceived an increase in their ability to achieve their goals and to accomplish daily tasks. In the video modules used 
in this study, participants were taught about the importance of goal setting. One of the activities, three good things, promoted goal setting because it required them to set a goal to list three things they were grateful for each day. The positive effects of goal setting and self-efficacy on performance and mood have been well documented (Mathew \& Hicks, 2010). A 2014 correlational analysis conducted by Kiaei and Reio (2014) with 513 university students $(M$ age $=25, S D=7$ ) found that goal-striving ability and task accomplishment positively and significantly impacted well-being. These findings were also seen by Schultheiss, Jones, Davis, and Kley (2008) in a crosssectional study with 101 undergraduate students. The authors found that individuals experienced greater feelings of happiness when they reported high levels of goal progress. In addition, a study by Sheldon and Marko (2001) with 139 first year students from the University of Missouri, Columbia found that one can increase their level of well-being by doing well at personal initiatives, such as goal setting and task accomplishment. Sheldon and Marko (2001) suggested that one way to help students to better pursue happiness may be to help them to better identify and accomplish personal goals. They also noted, "these findings carry an inspirational but also a realistic message: You can hope to make yourself happier, but it will take hard work to get there and more hard work to stay there" (p. 161).

When asked if participants planned their activities to make sure that they had adequate time for sleep, there was a decrease in the percentage of participants who answered, "seldom true of me" as well as an increase in the parentage who responded with, "always (almost always) true of me" at the end of the study. That is to say, that the percent of participants who always or almost always made time for sleep increased over the course of the study. There has been a growing amount of literature looking at sleep, mood, and well-being, and it has been well documented that quality sleep is essential for physical and emotional health (Mushtaq et al., 2014). When specifically looking at university students, a similar finding is seen in work by Gray and Watson (2002). The authors found that high self-reported sleep quality was associated with positive affect among a sample of 334 undergraduate students from the University of lowa. In 2016, a systematic review was conducted by Ong, Kim, Young, and Steptoe that included 44 studies and a total of 14,844 respondents ranging from 8 to 97 years 
of age. It provided growing support for a relationship between positive affect (a more general term used to refer to positive mood); Ong et al. (2016) and sleep; however, the authors note that there is still a lot to understand about this association. Overall, findings indicated that higher levels of positive affect were associated with better sleep. Additionally, the inclusion criteria for Ong et al.'s (2016) systematic review encompassed any studies that included an assessment of positive affect; however, two of the studies included in the systematic review specifically examined happiness. First, a study by Jackowska, Dockray, Hendrickx, and Steptoe (2011) was included. The authors conducted a study at University College London (UCL) and neighboring institutions with 199 participants, and after adjusting for factors that had been previously found to be related to the sleep experience, including age, having children, personal income, marital status, and Body Mass Index, greater sleep efficiency (the proportion of total time spent sleeping) was found among happier participants. Second, Fuligni and Hardway (2006) asked 750 high school students to complete a daily sleep diary for two weeks in addition to completing information about mood and happiness on a daily basis. The authors found that there was a positive association between sleep quantity and happiness; more sleep (7-8 hours per night) was associated with more happy feelings (Fuligni \& Hardway, 2006).

In the current study, when asked about stress, participants were given a list of stress management possibilities and were asked to select all of the available options in which they engaged. Interestingly, the difference in the number of participants who selected, "I have had occasions when it became too much to handle and I had to take days off to relax or rest/sleep" decreased after the program. This finding is important because in addition to happiness scores rising during the intervention, the number of participants who found their stress levels to be overwhelming decreased. It has been well documented that perceived stress is negatively related to happiness (Mohammadkhani, 2013; Papageorgiou, 2004; Wells, 2009). A 2015 study by Saricam with 290 university students examined the relationships between perceived stress and happiness using correlation analysis. Perceived stress was found to be negatively associated with happiness $(r=-0.6, p<0.01)$, and reductions in stress corresponded with increases in happiness (Saricam, 2015). Those who perceived higher levels of 
stress were less happy than those with lower levels of stress (Saricam, 2015). The results from the current study are consistent with other research, such as a 2010 study by Schiffrin and Nelson (2010) that included 100 full-time undergraduate students. Using two of the same tools to assess happiness as used the current study, the SHS and the $\mathrm{AHI}$, the authors found a negative, linear correlation with stress, that is, higher perceived stress was found to be related to lower self-reported happiness scores (Schiffrin \& Nelson, 2010). Another study with students and stress was conducted by Denovan and Macaskill (2017) with 306 undergraduate students. Participants completed questionnaires about stress and mental health at the beginning of the semester and again at the end of the semester. The authors observed that on average, students became less happy across the semester; they suggested this may be, in part, due to the increasing stress from university requirements, increasing coursework demands, and students' perspectives that their performance in the semester did not meet their personal expectations. As the semester progresses, students' workload and academic pressures increase, (Hjeltnes, Binder, Moltu, \& Dundas, 2015; Misra \& Mckean, 2000; Robotham \& Julian, 2006), growing academic workload and examinations are commonly cited by students as sources of stress (Beck \& Srivastava, 1991; Evans \& Kelly, 2004). This pattern of increasing stress as the semester advances is particularly noteworthy when considering the timing of the current study; participants in the current study completed their post-test questionnaire during the final exam period, a time when their stress levels were likely at their peak. Notably, even with this timing, there was a decrease in the percentage of participants who felt their stress was too much to handle.

In addition to the negative relationship between happiness and stress, the role of happiness as a buffer against stress has also been examined (Schiffrin \& Nelson, 2010). In the current study, there were increases in both happiness scores and the percentage of participants who selected, "I have most often sought relief by listening to music, reading, or visiting friends". The rise in the percentage of participants who sought out coping mechanisms to help buffer their stress has also been documented by Misra and Mckean (2000) and Robotham and Julian (2006). In terms of coping mechanisms, interventions targeting both stress and happiness have found that 
activities such as exercise, meditation, and written expression have been shown to decrease stress while increasing happiness (Compton, 2005; King, 2001; Lyubomirsky et al., 2006; Lyubomksky et al., 2005). Activities similar to those identified in the current study were also noted by Murdock, Naber, and Perlow (2010) when the authors administered a questionnaire to 95 undergraduate Nursing students who asked about stress and stress management skills. The top identified stress management skills that were cited by participants included exercise (33\%), socializing $(19 \%)$, and listening to music $(13 \%)$.

\subsubsection{Gratitude}

According to Emmons and McCullough (2015), experiences of gratitude are positively associated with happiness and well-being, and research has shown that gratitude is linked to happiness (Davis et al., 2016; Emmons \& McCullough, 2015; Nelson, 2009). Interestingly, in the current study, in addition to the increased happiness scores at the completion of the study, the percentage of participants who responded with "extremely" to all three gratitude indicators (the extent to which participants feel grateful, appreciative, and thankful right now, at the present moment) also increased (participants were asked to select a response on a scale from 1 [very slightly/not at all grateful] to 5 [extremely grateful]). Lyubomirsky et al. (2005) suggested that gratitude may lead to emotional benefits, a finding that was further supported in a 2015 study with 157 undergraduate participants by Emmons and McCullough (2015). The authors found that the participants who completed the selfguided gratitude exercises reported significantly more positive affect during the 13-day study period.

Gratitude and other positive feelings may overlap and share commonalities; however, gratitude also possesses unique characteristics that distinguish it from happiness (Emmons \& McCullough, 2015; Weiner, 1985). A meta-analyses by Davis and colleauges (2016) evaluated the efficacy of gratitude interventions and found that gratitude interventions outperformed controls on all measures of psychological wellbeing. Additionally, Seligman et al.'s (2005) randomized controlled trial suggested that the gratitude activity in their intervention had the most pronounced positive changes in 
happiness among participants. Given these findings, gratitude-focused activity/(ies)in a happiness intervention may further improve well-being outcomes. Additionally, work by Emmons and McCullough (2003) suggested that gratitude may be an important topic to include in a happiness intervention. Sin and Lyubomksky (2009) suggested that positive psychology interventions could combine different topics (e.g gratitude and happiness) into a larger, comprehensive positive psychology program to strengthen their effects. They, along with Seligman et al. (2005) concluded that having an intervention that requires participants to engage in multiple different activities during an intervention may be more effective than engaging in only one activity.

The idea of including gratitude as part of a happiness intervention is further supported by the findings of this study because not only did gratitude increase at the end of the study, but many participants also provided written feedback that expressed their enjoyment of the gratitude exercises during the study. This may suggest that not only could gratitude be a key element of a happiness intervention to enhance psychological well-being, it may also be a particular aspect of the intervention that participants genuinely enjoy, perhaps encouraging continued practice beyond the intervention.

In addition to its correlation with happiness, gratitude also shows additional promise for a student population specifically. A 2018 study by Froiland examined the effects of a positive psychology course on gratitude and emotions toward studying in 26 undergraduate students. Using a retrospective pretest-posttest design, the authors found that students experienced an increase in positive emotions toward studying, homework, and gratitude. Given that the participants in the current study both enjoyed the gratitude activities and reported an increase in their self-reported gratitude, it is possible that the positive benefits of gratitude may have also extended to students' attitudes toward homework and study habits.

\subsection{Completer vs. Non-completers Results}

The non-completer rate for the current study was $57 \%$ from pre-test to post-test. Although this seems high, it is comparable to the non-completer rate observed in 
similar studies. For example, Finlay-Jones et al. (2017) reported that $54 \%$ of their participants completed the post-test measures during their 6-week online study with university students.

Given the non-completer rate (57\%) observed in the current study, an analysis comparing those who did not complete the study to those who completed the study was conducted. Several noteworthy differences were observed, including happiness, lifestyle behaviours, and gratitude; however, due to the exploratory nature of the study, and the limited scope of the self-report lifestyle information that was collected from participants, differences between those who competed the study and those did not complete the study should be interpreted with caution. Additionally, given the limited number of participants who completed the program, a comparison of demographic information (such as year of study, program enrolment, etc.) was not possible.

An analysis comparing the participants who did not complete the study to those who completed the study is also justified because both anecdotal and empirical evidence suggest that characteristically happy and unhappy individuals seem to differ in the ways in which they respond to life events and daily situations (Lyubomirsky \& Tucker, 1998). It has been documented that individuals who have a "talent" (Lyubomirsky \& Tucker, 1998, p. 156) for happiness, or have a naturally happier disposition tend to perceive, interpret, think about, and experience life events in a way that further supports and enhances their happy disposition (Myers \& Diener, 2010; Ryff, Singer, Love, \& Essex, 1998). For example, Lyubomirsky and Tucker (1998) conducted a study with students and found that happy people tend to perceive, interpret, and think about events in more positive ways. Further support for the idea that happier people are different than those who are less happy can be seen in results from a study with 410 adolescents $(M$ age $=19 ; S D=1)$, where Proctor, Linley, and Maltby (2010) found that those who reported higher positive affect, gratitude, and happiness experienced significantly less self-reported depression, negative affect, and stress when compared to those who were less happy. Finally, work by Abbe, Tkach, and Lyubomirsky (2003) showed that happier people tend to avoid engaging in 
negative self-reflection and are able to perform subsequent tasks without dwelling on previous failure.

Given that predispositions toward happiness and lifestyle behaviours vary across individuals, interventions to promote happiness may be differentially effective across various individual characteristics. Thus, when designing a happinessenhancing intervention, instead of a one-size-fits-all approach, a model that considers baseline happiness prior to the beginning of a happiness program may be more efficacious. If it were possible to filter participants based on their baseline level of happiness at the start of the intervention, and then have customized programs that meet the different needs of each group, it may be possible to not only increase the happiness levels of those who complete the study, but also to reduce attrition if the additional, unique needs of participants who are less happy are addressed.

\subsubsection{Happiness}

In comparison to those who completed the study, those who did not complete the study had lower mean self-reported happiness scores at pre-test. The differences were significant for three of the happiness questionnaires, the AHI, FEQ, and the $\mathrm{OHI}$. When examining the pre/post changes for those who completed the study, all three of these questionnaires saw a significant increase as well.

The current study results suggest that those who did not complete the study reported lower self-reported happiness scores (as compared to those who completed the study), and yet some evidence suggests that happiness activities may be most effective for those individuals who are the least happy (Lyubomirsky \& Layous, 2013; Parks et al., 2012; Sin \& Lyubomksky, 2009). In other words, those for whom the intervention may have been most effective did not complete the intervention. Although the reason(s) for which the non-completers reported lower levels of self-reported happiness is currently unknown, work by Manthey et al. (2016) may provide some insight. Manthey et al. (2016) found that participants in their happiness intervention who perceived the intervention as interesting or meaningful showed higher increases in well-being. Consistently, Sheldon and Elliot (1999) also showed that interest 
moderated the effectiveness of their happiness intervention. Given these findings, perhaps designing a future intervention that includes meaningful information about happiness and its value at the very beginning may help to engage those who are less happy. This may then, in turn, increase their likelihood of completing the intervention.

In addition to interest level, Lyubomirsky et al. (2011) also found that happiness interventions are most successful when participants know about, endorse, and commit to the intervention. Stated more specifically, although the intentional pursuit of increased happiness can be successful and happiness gains are possible, maximal benefits are only found when one has both a will (i.e., appropriate expectations, motivation, or perhaps social/cultural support) and a way (i.e., an effective happinessenhancing strategy; Lyubomirsky et al., 2011).

\subsubsection{Lifestyle}

For the majority of lifestyle questions there were very few differences between those who completed the study and those who did not. One particularly noteworthy finding that warrants discussion is the difference that appeared when participants were asked if they felt confident in their ability to accomplish their goals and daily tasks. While the specific relationship between happiness and goal setting and task accomplishment is still unclear (Ouweneel et al., 2014), Pekrun, Goetz, Titz, and Perry, (2002) have stated that positive experiences and emotions can help people envision and complete goals and challenges. In the current study, those who did not complete the study were less happy at pre-test and were also less likely to report accomplishing their goals as compared to those who completed the study (i.e., more non-completers answered, "seldom true of me"). A similar pattern was observed when participants were asked if they satisfactorily accomplished all important daily tasks; more non-completers answered, "seldom true of me" in contrast to a larger proportion of those who completed the study who stated that they always (or almost always) accomplished important daily tasks. These findings are in line with Brunstein, Schultheiss, and Grässmann's (1998) findings. The authors used self-report mood adjective scales to assess university students' personal goals and emotional wellbeing. They found that higher rates of goal progress predicted elevated well-being, 
and lower rates of goal progress predicted lower well-being among a sample of university students (Brunstein, Schultheiss, \& Grässmann, 1998). Additionally, a 2012 study by Haase et al. found that when individuals experience positive affect they become more motivated to invest time, increase effort, and overcome obstacles while pursuing their goals. Another study published the same year by Parks et al. (2012) found that $74 \%$ of adult participants identified pursuing goals as a happinessincreasing activity.

\subsubsection{Gratitude}

Similar to the lifestyle outcomes, there were few differences in terms of selfreported gratitude between those who completed the study and those who did not. At pre-test, participants who did not complete the study reported feeling less grateful, appreciative, and thankful than those who completed the study. Gratitude has been shown to be a strong predictor of happiness; however, further investigation is needed because the nature of the relationship between happiness and gratitude is not fully understood (McCullough et al., 2002; Wood et al., 2008). While the connection between gratitude and happiness is complex (Emmons \& McCullough, 2015), a study by Senf and Liau (2013) with 122 college students $(M=20 ; S D=2)$ examined the effects of gratitude on happiness. The authors also explored personality traits as moderator variables of the potential effectiveness of the interventions, and they found that participants with higher levels of extraversion and higher levels of openness benefitted more from the gratitude intervention compared to those with lower levels.

\subsection{Post-Program Feedback Results}

Upon completion of the study, participants were asked to complete a postprogram feedback questionnaire. Given that this study was exploratory in nature, these questions were intended to gain more detailed feedback and insight about the participant's experiences during the program. Although 49 participants completed the study, only 13 participants completed the post-program feedback questionnaire. The

post-program feedback questionnaire timing coincided with the spring exam period, which likely contributed to its low response rate. 
Overall, in addition to changes in happiness scores on all five questionnaires, the majority of participants who completed the program feedback questionnaire said that the videos they watched during the study had a positive impact on their happiness.

During the first week of the study, the video modules included information that asked participants to reflect on what makes them happy. In the program feedback questionnaire, participants were asked to describe what makes them happy, and the most frequently cited response was family/relationships. This finding was not surprising given that during week two the information in the videos focused on the importance of having strong social connection to increase happiness. The videos discussed how healthy relationships, both friendships and romantic relationships, could increase happiness, and so it was not surprising that the majority of participants identified social relationships when reflecting on what makes them happy.

In addition, when asked what makes participants feel happy, another frequently cited response was gratitude. This response was explicable because the fourth week of the study included a video that defined gratitude and participants were taught how being grateful can increase happiness. Other responses when asked what makes participants feel happy included food, success, and exercise. These responses from the current study are similar to findings from Parks et al. (2012) who found that the most commonly cited happiness-increasing activities in their study were nurturing social relationships, expressing gratitude, practicing acts of kindness towards others, pursuing important goals, doing physical exercise or sports, and doing activities that make the respondent feel "in the moment", and practicing meditation.

Given that this was an exploratory study, the feedback received from participants about how to change or improve the videos is relevant. Although the videos were well received by participants, suggestions such as improved graphics and animations and a more engaging format, are valuable, particularly in terms of efforts to increase retention and video viewership. Some participants noted that they would like videos that were shorter in duration. While the length of an average attention span 
while watching videos has not been determined (Wilson \& Korn, 2007), researchers have noticed a pattern of attention: students' attention declines over time. The pattern of diminishing attention as time elapses was also observed by Bunce, Flens, and Neiles (2010) when the authors evaluated the attention span of 196 university students in three courses by asking participants to report attention lapses by pressing a button on an assigned clicker after they became aware that they had experienced a period of inattention. The authors saw a consistent spike in reported attention lapses between four to five minutes into a lecture, followed by another spike at seven to nine minutes, and another at 10 minutes. As the lecture progressed, this waxing-and-waning pattern continued; however, as time passed the attention lapses occurred more frequently. Given that students' attention decreases as time elapses, creating videos that are long enough to effectively deliver the content, but no longer than necessary, will minimize the number of attention lapses. In addition to video length, Bunce et al. (2010) also noted that incorporating active learning into a lecture resulted in fewer attention lapses as compared to a strict lecture format. They suggested that active learning helped to better engage student attention. Given that another piece of feedback from participants was to increase the exercises, and so perhaps incorporating new activities (taught via the videos) may be beneficial to help increase engagement.

Time was also cited as a challenge in a 2017 study by Finlay-Jones et al. (2017). The authors required participants to watch online video modules, with approximately one hour of content each, at their own pace over a period of six weeks. In the current study, one of the main difficulties reported was participants felt that they had very busy schedules and consequently, did not have enough time to complete the program. Given the limited amount of time students have, these results highlight the need for future videos to be only as long as necessary to increase not only attention during the videos, but also to increase the likelihood that participants will be able to watch all the videos. 


\section{Chapter 6. Implications}

\subsection{Strengths and Limitations of this Study}

Mentioning happiness in many academic and policy circles is still sometimes met with scepticism (O'Brien, 2008), and so this study adds to the body of work that suggests that happiness interventions may improve the self-reported happiness of undergraduate university students. This study also provides some empirical evaluation of online tools that aim to boost the mental health of Western students specifically.

While this was an exploratory study, the overwhelming response from students interested in participating evidences their interest to learn more about happiness. Additionally, this study demonstrated that it is also possible to increase the selfreported happiness of university students via online videos.

Limitations to this study must also be acknowledged. Due to the ethics amendment delay at the start of the study, the conclusion of the study coincided with the spring exam period at Western. It is anticipated that if the end of study had not fallen during the examination period, the non-completer rate would have been lower, contributing to a higher completion rate, larger study sample, increased statistical power, and greater confidence in the results. The sample had larger female representation as compared to the undergraduate student population at Western, the sample size did not allow for evaluation of differences across groups of students (e.g., by year in program, major, citizenship/immigration status), and measurements were only taken before and after the intervention. Additionally, there was no random selection because participants self-selected to participate in the study and there was no matched control group in the current study; thus, it cannot be conclusively stated that outcome improvements were in fact due to participation in the intervention rather than other, uncontrolled variables. Since self-reported happiness increased (along with secondary outcomes) in the current study, it offers additional support that such activities do have a positive impact on the self-reported mental health of Western students. 


\subsection{What this Research Adds to the Literature}

The aim of this study was to investigate if online videos that teach happiness can increase self-reported happiness among university students. The study's primary outcome was self-reported happiness, and all five measures used to assess happiness revealed an increase in scores over the duration of the study; the increase was statistically significant for four of the five measures.

This study demonstrated that not only are students interested in participating in online programs to boost happiness (as evidenced by the overwhelmingly large response of students interested in participating in the study), but it is also possible to increase the self-reported happiness of university student via online videos.

In addition, this study adds additional support to the evidence that screening and sub-categorizing participants prior to an intervention in an effort to increase engagement and to meet the unique needs of individuals with particularly characteristics, may be efficacious and may increase retention. Sheldon and Lyubomirsky, 2007 found that increases in happiness are highest when the activity fits the person's interests and values. In the current study, sub group analysis of those who completed the study compared to those who did not complete the study found that participants who completed the study were happier prior to the intervention. Given that happy people may benefit more from happiness interventions (Parks et al., 2012) and are more likely to complete them, this study highlights a gap in that those who most need happiness interventions need special programs designed to address the unique challenges that hinder their completion of a program.

\subsection{Implications for Policy and Practice}

Similar to other universities, Western University recently developed a Student Mental Health and Wellness Strategic Plan to further support the mental health of their students (Doerksen et al., 2018). The vision for this Strategic Plan is to, "create a university campus that is resilient and cares about mental health and wellness, where students receive support as needed, where talking and learning about mental health 
reduces and eliminates the stigma surrounding mental health issues, and where we build a more supportive and inclusive campus environment to enhance all students' potential for success" (Doerksen et al, 2018, p. 2). Its directions, goals, and recommendations were developed from the examination of several national frameworks, best practice recommendations, and extensive consultation. Within the plan, one of the highlighted priorities is to, "ensure that students receive mental health and wellness education through course curricula and/or co-curricular content during their studies at Western" (Doerksen et al., 2018, p. 3). Given that the current study involved happiness education delivered to Western student participants and included content that is aligned and supports some of the priorities described in this Strategic Plan, it could be used as a complementary resource to help improve the health of Western undergraduate students.

Additionally, the Wellness Education Centre at Western University tracks analytics on visits to their website. From January until April 2018, the top downloaded item on their site was a self-care toolkit for students. The Psychological Services area of their website also had very high usage, and the top three most accessed pages (with over 10,000 total views) were the Psychological Services home page, Individual Counselling, and crisis counselling (Western University Student Experience, 2018). Given the information from the Western University Student Experience (2018), it is clear that Western students are not only seeking psychological services, they are also looking for tools and resources (e.g the self-care toolkit for students). This information is significant because the majority of students consider institutional or official websites as the most credible sources for health information (Montagni et al., 2018). Given that the content of the video modules in the current study is similar to the content that is popular on The Wellness Education Centre at Western University's website, the fact that students were very interested in participating in the current study, and that selfreported happiness scores increased over the duration of the study, the content from the current study (or similar content specifically designed for Western students) may be beneficial to incorporate in The Wellness Education Centre's online resources. Additionally, a non-credit course could be developed that included the content from the videos. The course could be available online for students, hosted by the Western 
Student Experience, and could be considered for inclusion on student's co-curricular record.

\subsection{Future Research}

While this study was exploratory in nature, the promising results warrant further investigation. Specifically, some additional insights that are suggested for future research include incorporating academic performance and structural/systemic factors (such as race, ethnicity, and socioeconomic status) data; assessment via smartphones; using an Experience Sampling Method (ESM); measuring program login, video viewing time, and view counts; including a larger sample and a control group; including a brief assessment of each module's content immediately following its completion; assessing the full eight-week version of the course; including content specifically aimed at undergraduate students; and collecting data at different times throughout the year.

Given the link between happiness and academic performance (Wong et al., 2013), if future studies included collecting students' marks in addition to assessing happiness, it could provide further understanding to determine if an intervention that aimed to increase happiness also had an impact on academic performance. Such a link has been found in other studies (Heizomi et al., 2015), and it could be an important element to substantiate and validate for university administration and students how increasing happiness may have benefits that extend beyond improving psychological well-being. Additionally, in the current study no structural/systemic factors such as race, ethnicity, socioeconomic status were assessed. Future research could include collecting data on structural/systemic factors to help determine if study participation, study completion, or happiness scores were related to these factors.

Smartphones are increasingly being used as a tool to collect information in a variety of studies because they can provide a record of the number, duration, and type of communications with social contacts (Lane et al., 2010). Preliminary studies have demonstrated that mood can be classified using smartphone data collected via smartphone apps (Bogomolov, Lepri, Ferron, Pianesi, \& Pentland, 2014; Li, Liu, Lane, 
\& Zhong, 2013). Given that smartphones are increasingly being used by university students (Howells, Ivtzan, \& Jose, 2016), they may be a tool to include in future interventions to help collect more detailed happiness data. Smartphones have applications that can send notifications and reminders; consequently, they may be able to improve attrition and may help gain additional insight into an individual's happiness, as well as related variables such as social support, stress, sleep, physical activity levels, and more.

In addition to smartphones, other new and innovative ways to measure happiness are continually emerging. One particular technique, ESM, collects participants' responses at random times during the waking hours of the day from an electronic pager and yields several measures of happiness throughout a week. Each time the pager signals, participants are prompted to rate their experiential states, including happiness. ESM has been used (Csikszentmihalyi \& Hunter, 2003) because it not only accounts for momentary states, but also because it can yield trait-like patterns by observing separate, momentary responses. Given that reported happiness can vary by day of week, time of day, type of activity, and life events (Schwartz \& Strack, 2009), adding ESM may be beneficial to gain further insights into happiness levels throughout an intervention. Additionally, a similar technique to ESM that could be administered via an application on a smartphone may be another possibility to obtain frequent, in the moment assessments of happiness.

While the number of total video views was tracked in the current study, it was not possible to assess which participants watched each video, whether participants watched the videos in their entirety, whether videos were watched in a single session, or if participants watched the same video more than once. Additionally, the current study did not measure frequency or duration of the online program log-in time. In accordance with the Consolidated Standards of Reporting Trials of Electronic and Mobile HEalth Applications and onLine TeleHealth (CONSORT-EHEALTH) guidelines (Eysenbach \& CONSORT-EHEALTH Group, 2011), future evaluation would benefit from including the assessment of metrics such as the total session time spent on each video for individual participants, as well as the time of day participants are viewing the 
videos, because it would help give additional insight into the patterns and behaviours of the participants. First, assessing the total session time spent watching each video would provide more detailed information about video views, and would allow researchers to know how much of the video is actually being watched. For example, a video view is counted by YouTube once someone has watched 30 seconds of a video (Buffer, 2017), and so when looking at a video's total views it is impossible to know if a video was watched in its entirely because some of the views are from people who did not watch the entire video, but did watch a minimum of 30 seconds. Determining the total session viewing time for each participant would show which videos participants watched, and it would also ensure that all participants were spending enough time on each video to account for the total video duration, providing evidence that they watched the videos in their entirety. Secondly, assessing the time of day the videos were viewed could provide insight into the daily viewing habits of participants. This information could be used to determine the most popular and unpopular times participants watched the videos, which could help to determine the best time to post the videos each week and the most effective time to send participation reminder messages to participants.

Given that the current study had a sample size of 49 participants who completed the full study, future interventions that include not only a larger sample, but also a control group is suggested. To assess comprehension and retention of the program's content, future work could include a brief test of each module's content immediately following its completion. Not only would this ensure that participants were successfully learning the material, it would also help to track information such as when during the study participants dropped out.

The current study used four of the eight weeks of videos from the Greater Good Science Center's Science of Happiness Course. Only four weeks of videos were included because the Greater Good Science Center was considering the potential evaluation and use of a shorter version. Future work could also include the full eightweek course to test the differences in effectiveness between the four- and eight-week versions and to evaluate the value of extending the study beyond four weeks. 
Qualitative feedback from participants reveled that they would prefer videos that were more engaging and included improved graphics and animations. To increase retention and video viewership, as well as to better engage students, future videos could include improved video editing and graphics, as well as content specifically aimed at undergraduate students.

Finally, in the current study, happiness was initially assessed during the winter, while the final happiness assessment occurred during the spring. Future research could take place throughout the year to account for potential seasonality and/or temporal differences in happiness. 


\section{References}

Abbe, A., Tkach, C., \& Lyubomirsky, S. (2003). The Art of Living by Dispositionally Happy People. Journal of Happiness Studies, 4(4), 385-404. http://doi.org/10.1023/B:JOHS.0000005769.54611.3c

Abu-Moghli, F. A., Khalaf, I. A., \& Barghoti, F. F. (2010). The influence of a health education programme on healthy lifestyles and practices among university students. International Journal of Nursing Practice, 16(1), 35-42. http://doi.org/10.1111/j.1440-172X.2009.01801.x

Akhtar, M., \& Boniwell, I. (2010). Applying positive psychology to alcohol-misusing adolescents. Groupwork, 20(3), 6-31. http://doi.org/10.1921/095182410X576831

Alam, F., Boet, S., Piquette, D., Lai, A., Perkes, C. P., \& LeBlanc, V. R. (2016). Elearning optimization: the relative and combined effects of mental practice and modeling on enhanced podcast-based learning - a randomized controlled trial. Advances in Health Sciences Education, 21(4), 789-802.

http://doi.org/10.1007/s10459-016-9666-9

Allen, I. E., \& Seaman, J. (2013). Changing course: ten years of tracking online education in the United States. Nursing Standard (Royal College of Nursing (Great Britain) : 1987), 26, 47. http://doi.org/10.1177/0165551508095781

American College Health Association. (2016). ACHA-National College Health Assessment. Retrieved from http://oucha.ca/pdf/2016_NCHAII_WEB_SPRING_2016_ONTARIO_CANADA_REFERENCE_GROUP_EXECUTI VE_SUMMARY.pdf

Argyle, M. (1999). Causes and correlates of happiness. In Well-being: The foundations of hedonic psychology (pp. 353-373). New York, New York: Russell Sage Foundation.

Argyle, M., \& Lu, L. (1990). Happiness and social skills. Personality and Individual 
Differences, 11, 1255-1261.

Argyle, M., Martin, M., \& Crossland, J. (1989). Happiness a function of personality and social encounters. In Recent advances in social psychology: An international perspective (pp. 189-203). Amsterdam: Elsevier Science.

Ataeiasl, M., Sarbakhsh, P., Dadashzadeh, H., Augner, C., Anbarlouei, M., \& Mohammadpoorasl, A. (2018). Relationship between happiness and tobacco smoking among high school students. Epidemiology and Health, 40, 1-7. http://doi.org/10.4178/epih.e2018009

Bahrami, S., Rajaeepour, S., Rizi, H. A., Zahmatkesh, M., \& Nematolahi, Z. (2011). The relationship between students' study habits, happiness and depression. Iranian Journal of Nursing and Midwifery Research, 16(3), 217-221. Retrieved from

http://ovidsp.ovid.com/ovidweb.cgi?T=JS\&PAGE=reference\&D=prem\&NEWS=N\& $\mathrm{AN}=22224110$

Bayram, N., \& Bilgel, N. (2008). The prevalence and socio-demographic correlations of depression, anxiety and stress among a group of university students. Social Psychiatry and Psychiatric Epidemiology, 43(8), 667-672. http://doi.org/10.1007/s00127-008-0345-x

Beck, D. L., \& Srivastava, R. (1991). Perceived level and sources of stress in baccalaureate nursing students. The Journal of Nursing Education, 30(3), 127133. http://doi.org/10.3928/0148-4834-19910301-08

Beck, T., Ward, C., Mendelson, M., Hock, J., \& Erbaugh, J. (1961). An inventory for measuring depression. Archives of General Psychiatry, 7, 158-216.

Bogomolov, A., Lepri, B., Ferron, M., Pianesi, F., \& Pentland, A. (Sandy). (2014). Daily Stress Recognition from Mobile Phone Data, Weather Conditions and Individual Traits. Proceedings of the ACM International Conference on Multimedia - MM '14, 477-486. http://doi.org/10.1145/2647868.2654933 
Braungart, J. M., Plomin, R., DeFries, J. C., \& Fulker, D. W. (1992). Genetic Influence on Tester-Rated Infant Temperament as Assessed by Bayley's Infant Behavior Record: Nonadoptive and Adoptive Siblings and Twins. Developmental Psychology, 28(1), 40-47. http://doi.org/10.1037/0012-1649.28.1.40

Brunstein, J., Schultheiss, C., \& Grässmann, R. (1998). Personal goals and emotional well-being: the moderating role of motive dispositions. J Pers Soc Psychol, 75(2), 494-508.

Buffer. (2017). What Counts As a Video View on Facebook, Instagram, Twitter, and Snapchat? The Buffer Guide to Video Metrics.

Bunce, D., Flens, E., \& Neiles, K. (2010). How Long Can Students Pay Attention in Class? Journal of Chemical Education, 87(12), 1438-1443.

http://doi.org/10.1021/ed100409p

Buzwell, S., Farrugia, M., \& Williams, J. (2016). Students' voice regarding important characteristics of online and face-to-face higher education. Sensoria: A Journal of Mind, Brain \& Culture, 12(1), 38-49. Retrieved from http://ovidsp.ovid.com/ovidweb.cgi?T=JS\&PAGE=reference\&D=psyc13\&NEWS= $N \& A N=2016-28512-006$

Caunt, B. S., Franklin, J., Brodaty, N. E., \& Brodaty, H. (2013). Exploring the Causes of Subjective Well-Being: A Content Analysis of Peoples' Recipes for Long-Term Happiness. Journal of Happiness Studies, 14(2), 475-499. http://doi.org/10.1007/s10902-012-9339-1

Cavus, N., \& Ibrahim, D. (2009). M-Learning: An experiment in using SMS to support learning new English language words. British Journal of Educational Technology, 40(1), 78-91. http://doi.org/10.1111/j.1467-8535.2007.00801.x

Chang, H. H., \& Nayga, R. M. (2010). Childhood obesity and unhappiness: The influence of soft drinks and fast food consumption. Journal of Happiness Studies, 11(3), 261-275. http://doi.org/10.1007/s10902-009-9139-4 
Chen, L. H., \& Kee, Y. H. (2008). Gratitude and adolescent athletes' well-being. Social Indicators Research, 89(2), 361-373. http://doi.org/10.1007/s11205-008-9237-4

Cigularov, K., Chen, P. Y., Thurber, B. W., \& Stallones, L. (2008). What Prevents Adolescents from Seeking Help After a Suicide Education Program? Suicide and Life-Threatening Behavior, 38(1), 74-86. http://doi.org/10.1521/suli.2008.38.1.74

Clegg-Kraynok, M. M., McBean, A. L., \& Montgomery-Downs, H. E. (2011). Sleep quality and characteristics of college students who use prescription psychostimulants nonmedically. Sleep Medicine, 12(6), 598-602. http://doi.org/10.1016/j.sleep.2011.01.012

Collingridge, D. S., \& Gantt, E. E. (2008). The quality of qualitative research. American Journal of Medical Quality, 23(5), 389-395. http://doi.org/10.1177/1062860608320646

Compton, W. C. (2005). An introduction to positive psychology. Belmont, CA:

Thomson/Wadsworth. Retrieved from https://cmc.marmot.org/Record/.b31182392

Cooke, R., Bewick, B. M., Barkham, M., Bradley, M., \& Audin, K. (2006). Measuring, monitoring and managing the psychological well-being of first year university students. British Journal of Guidance and Counselling, 34(4), 505-517. http://doi.org/10.1080/03069880600942624

Craig, C., Marshall, A., Sjöström, M., Bauman, A., Booth, M., Ainsworth, B., \& Oja, P. (2003). International Physical Activity Questionnaire: 12-Country reliability and validity. Medicine and Science in Sports \& Exercise, (35), 1381-1395.

Crane, M. M., Lutes, L. D., Ward, D. S., Bowling, J. M., \& Tate, D. F. (2015). A randomized trial testing the efficacy of a novel approach to weight loss among men with overweight and obesity. Obesity, 23(12), 2398-2405. http://doi.org/10.1002/oby.21265

Csikszentmihalyi, M., \& Hunter, J. (2003). Happiness in everyday life: The use of experience sampling. Journal of Happiness Studies, 4(February), 185-199. 
http://doi.org/10.1023/a:1024409732742

Culjak, G., Kowalenko, N., \& Tennant, C. (2016). Awareness , Access and Use of Inter net Self-Help Websites for Depression by Univ ersity Students. JMIR Ment Health, 3(4), 1-7. http://doi.org/10.2196/mental.5311

Davis, D. E., Choe, E., Meyers, J., Wade, N., Varjas, K., Gifford, A., ... Worthington, E. L. (2016). Thankful for the little things: A meta-analysis of gratitude interventions. Journal of Counseling Psychology, 63(1), 20-31.

http://doi.org/10.1037/cou0000107

De Araujo Guerra Grangeia, T., De Jorge, B., Franci, D., Santos, T. M., Setubal, M. S. V., Schweller, M., \& De Carvalho-Filho, M. A. (2016). Cognitive load and selfdetermination theories applied to e-learning: Impact on students' participation and academic performance. PLOS ONE, 11(3), 1-22.

http://doi.org/10.1371/journal.pone.0152462

Deasy, C., Coughlan, B., Pironom, J., Jourdan, D., \& Mcnamara, P. M. (2015).

Psychological distress and lifestyle of students: Implications for health promotion. Health Promotion International, 30(1), 77-87.

http://doi.org/10.1093/heapro/dau086

Denovan, A., \& Macaskill, A. (2017). Stress and Subjective Well-Being Among First Year UK Undergraduate Students. Journal of Happiness Studies, 18(2), 505-525. http://doi.org/10.1007/s10902-016-9736-y

Diener, E. (1984). Subjective well-being. Psychological Bulletin, 95(3), 542-575. http://doi.org/10.1037/0033-2909.95.3.542

Diener, E. (2000). Subjective well-being: The science of happiness and a proposal for a national index. American Psychologist, 55(1), 34-43.

http://doi.org/10.1037//0003-066X.55.1.34

Diener, E., Oishi, S., \& Lucas, R. E. (2015). National accounts of subjective well-being. American Psychologist, 70(3), 234-242. http://doi.org/10.1037/a0038899 
Diener, E., Suh, E. M., Lucas, R. E., \& Smith, H. L. (1999). Subjective Weil-Being : Three Decades of Progress. Psychological Bulletin, 125(2), 276-302. http://doi.org/10.1037/0033-2909.125.2.276

Diener, E., \& Tay, L. (2012). A Scientific Review of the Remarkable Benefits of Happiness for Successful and Healthy Living. Happiness: Transforming the Development Landscape, 90-117.

Diener, E., Wirtz, D., Tov, W., Kim-Prieto, C., Choi, D., Oishi, S., \& Biswas-Diener, R. (2009). Flourishing Scale. Social Indicators Research, 39(January), 247-266. http://doi.org/10.1037/t03126-000

Diug, B., Kendal, E., \& Ilic, D. (2016). Evaluating the use of Twitter as a tool to increase engagement in medical education. Education for Health: Change in Learning \& Practice, 29(3), 223-230. Retrieved from https://www.lib.uwo.ca/cgibin/ezpauthn.cgi?url=http://search.proquest.com/docview/1960444242?accountid $=15115$

Doerksen, J., Ezekiel, R., Chiodo, D., \& The Student Mental Health and Wellness Advisory Committee. (2018). Western 's Student Mental Health and Wellness Strategic Plan.

eCampus Ontario. (2017a). Drivers and Barriers to Online Learning in Ontario.

eCampus Ontario. (2017b). eCampus Ontario Annual Report 2016 - 2017.

eCampus Ontario. (2018). Western University Online Courses \& Programs. Retrieved from https://learnonline.ecampusontario.ca/Online-CollegesUniversities/427/western-university

Educase Center For Applied Research. (2012). ECAR Study of Undergraduate Students and Information Technology. Educause.

Eisenberg, D., Golberstein, E., \& Gollust, S. E. (2007). Help-seeking and access to mental health care in a university student population. Medical Care, 45(7), 594- 
601. http://doi.org/10.1097/MLR.0b013e31803bb4c1

Emmons, \& McCullough, M. E. (2015). Counting Blessings Versus Burdens: An Experimental Investigation of Gratitude and Subjective Well-Being in Daily Life. Journal of Personality and Social Psychology, 84(2), 3. http://doi.org/10.1037/0022-3514.84.2.377

Emmons, R. A., \& Shelton. (2002, January 1). Gratitude and the science of positive psychology. Handbook of Positive Psychology.

Emmons, R., \& McCullough, M. E. (2003). Counting Blessings Versus Burdens: An Experimental Investigation of Gratitude and Subjective Well-Being in Daily Life. American Psychological Assoication, 84(2), 377-389. http://doi.org/10.1037/00223514.84.2.377

Emmons, R., \& McCullough, M. E. (2003). Counting Blessings Versus Burdens: An Experimental Investigation of Gratitude and Subjective Well-Being in Daily Life. Journal of Happiness Studies, 84(2), 377-389. http://doi.org/10.1037/00223514.84.2.377

Eşkisu, M., Hoşoğlu, R., \& Rasmussen, K. (2017). An investigation of the relationship between Facebook usage, Big Five, self-esteem and narcissism. Computers in Human Behavior, 69, 294-301. http://doi.org/10.1016/j.chb.2016.12.036

Estrada, C., Young, M. J., \& Isen, A. M. (1994). Positive affect influences creative problem solving and reported source of practice satisfaction in physicians. Motivation and Emotion, 18(4), 285-299. http://doi.org/10.1007/BF02856470

Evans, W., \& Kelly, B. (2004). Pre-registration diploma student nurse stress and coping measures. Nurse Education Today, 24(6), 473-482. http://doi.org/10.1016/j.nedt.2004.05.004

Eysenbach, G., \& CONSORT-EHEALTH Group. (2011). CONSORT-EHEALTH: improving and standardizing evaluation reports of Web-based and mobile health interventions. Journal of Medical Internet Research, 13(4). 
http://doi.org/10.2196/jmir.1923

Fielder, R. L., Walsh, J. L., Carey, K. B., \& Carey, M. P. (2013). Predictors of sexual hookups: A theory-based, prospective study of first-year college women. Archives of Sexual Behavior, 42(8), 1425-1441. http://doi.org/10.1007/s10508-013-0106-0

Finlay-Jones, A., Kane, R., \& Rees, C. (2017). Self-Compassion Online: A Pilot Study of an Internet-Based Self-Compassion Cultivation Program for Psychology Trainees. Journal of Clinical Psychology, 73(7), 797-816. http://doi.org/10.1002/jclp.22375

Fischer, J. (2015). Cannabis use and quality of life of adolescents and young adults: findings from an Australian birth cohort. Journal of Psychoactive Drugs, 47(2), 107-116.

Fordyce, M. W. (1972). Happiness, its daily variation and its relation to values. Dissertation Abstracts International, 33(1266B).

Fordyce, M. W. (1977). Development of a program to increase happiness. Journal of Counseling Psychology, 24(6), 511-521.

Fordyce, M. W. (1987). the Happiness Measures : a Sixty Second. Social Indicators Research, 20(1988), 373-399.

Fordyce, M. W. (1988). A review of research on The Happiness Measures: A sixty second index of happiness and mental health. Social Indicators Research, 63-89.

Fox, K. R. (1999). The influence of physical activity on mental well-being. Public Health Nutrition, 2(3a), 411-418. http://doi.org/10.1017/S1368980099000567

Francis, L., Brown, L., Lester, D., \& Philipchalk, R. (1998). Happiness as a Stable Extraversion: A Cross-Cultural Examination of the Reliability and Validity of the Oxford Happiess Inventory Among Students in the U.K., U.S.A., Australia, and Canada. 
Froiland, J. M. (2018). Promoting Gratitude and Positive Feelings About Learning Among Young Adults. Journal of Adult Development, 0(0), 1-8. http://doi.org/10.1007/s10804-018-9294-0

Fuligni, A. J., \& Hardway, C. (2006). Daily variation in adolescents' sleep, activities, and psychological well-being. Journal of Research on Adolescence, 16(3), 353378. http://doi.org/10.1111/j.1532-7795.2006.00498.x

Furnham, a, \& Christoforou, I. (2008). Personality traits, emotional intelligence and multiple happiness. North, 9(3), 439-462. Retrieved from http://discovery.ucl.ac.uk/45280/

Garaigordobil, M. (2015). Predictor variables of happiness and its connection with risk and protective factors for health. Frontiers in Psychology, 6(August), 1-10. http://doi.org/10.3389/fpsyg.2015.01176

Geiger, B. B., \& MacKerron, G. (2016). Can alcohol make you happy? A subjective wellbeing approach. Social Science and Medicine, 156, 184-191. http://doi.org/10.1016/j.socscimed.2016.03.034

Gikas, J., \& Grant, M. M. (2013). Mobile computing devices in higher education: Student perspectives on learning with cellphones, smartphones \& social media. Internet and Higher Education, 19, 18-26. http://doi.org/10.1016/j.iheduc.2013.06.002

Gomes, A. A., Tavares, J., \& De Azevedo, M. H. P. (2011). Sleep and academic performance in undergraduates: A multi-measure, multi-predictor approach. Chronobiology International, 28(9), 786-801. http://doi.org/10.3109/07420528.2011.606518

Gordon, C. F., Juang, L. P. (Linda P., \& Syed, M. (2007). Internet Use and Well-Being Among College Students: Beyond Frequency of Use. Journal of College Student Development, 48(6), 674-688. http://doi.org/10.1353/csd.2007.0065

Gray, E. K., \& Watson, D. (2002). General and specific traits of personality and their 
relationship to sleep and academic performance. Journal of Personality, 70(2).

Griffiths, K., Farrer, L., \& Christensen, H. (2007). Clickety-click: E-mental health train on track. Australasian Psychiatry, 15(2), 100-108.

http://doi.org/10.1080/10398560601123716

Grim, M., Hortz, B., \& Petosa, R. (2011). Impact evaluation of a pilot web-based intervention to increase physical activity. American Journal of Health Promotion, 25(4), 227-230. http://doi.org/10.4278/ajhp.081216-ARB-307

Grossoehme, D. (2015). Research Methodology Overview of Qualitative Research. J Health Care Chaplain, 20(3).

http://doi.org/10.1080/08854726.2014.925660.Research

Grummon, P. (2005). Trends in Higher Education. Planning for Higher Education, 6(1), 1-9. Retrieved from

http://proquest.umi.com/pqdweb?did=1980865781\&Fmt=7\&clientld=8429\&RQT=3 09\&VName $=P Q D$

Haase, A., Steptoe, A., Sallis, J. F., \& Wardle, J. (2004). Leisure-time physical activity in university students from 23 countries: Associations with health beliefs, risk awareness, and national economic development. Preventive Medicine, 39(1), 182-190. http://doi.org/10.1016/j.ypmed.2004.01.028

Haase, C. M., Poulin, M. J., \& Heckhausen, J. (2012). Happiness as a Motivator: Positive Affect Predicts Primary Control Striving for Career and Educational Goals. Personality and Social Psychology Bulletin, 38(8), 1093-1104. http://doi.org/10.1177/0146167212444906

Hallal, P. C. (2006). Adolescent physical activity and health: a systematic review. Sports Medicine (Auckland), 36(12), 1019-1030.

Hanauer, D., \& Dibble, E. (2004). Internet use among community college students: Implications in designing healthcare interventions. Journal of American .... Retrieved from http://www.tandfonline.com/doi/abs/10.3200/JACH.52.5.197-202 
Harker, L. A., \& Keltner, D. (2001). Expressions of positive emotion in women's college yearbook pictures and their relationship to personality and life outcomes across adulthood. Journal of Personality and Social Psychology, 80(1), 112-124. http://doi.org/10.1037//0022-3514.80.1.112

Hasemeyer, M. D. (2013). The Relationship between Gratitude and Psychological, Social, and Academic Functioning in Middle Adolescence.

Hathaway, D. M. (2009). Assessing Quality Dimensions and Elements of Online Learning Enacted in a Higher Education Setting A dissertation submitted in partial fulfillment of the requirements for the degree of Doctor of Philosophy at George Mason University By Dawn M. Hathaway M. Dimension Contemporary German Arts And Letters.

Heizomi, H., Allahverdipour, H., Asghari Jafarabadi, M., \& Safaian, A. (2015). Happiness and its relation to psychological well-being of adolescents. Asian Journal of Psychiatry, 16, 55-60. http://doi.org/10.1016/j.ajp.2015.05.037

Heller, D., llies, R., \& Watson, D. (2004). The role of person versus situation in life satisfaction: A critical examination. Psychological Bulletin, 130(4), 574-600. http://doi.org/10.1037/0033-2909.130.4.574

Hjeltnes, A., Binder, P., Moltu, C., \& Dundas, I. (2015). Facing the fear of failure: An explorative qualitative study of client experiences in a mindfulness-based stress reduction program for university students with academic evaluation anxiety, 2631(November 2017), 1-14. http://doi.org/10.3402/qhw.v10.27990

Hodges, C. A., O'brien, M. S., \& Mcgorry, P. D. (2007). headspace: National Youth Mental Health Foundation: Making headway with rural young people and their mental health. Australian Journal of Rural Health, 15(2), 77-80. http://doi.org/10.1111/j.1440-1584.2007.00868.x

Horgan, Á., \& Sweeney, J. (2012). University students' online habits and their use of the internet for health information. CIN - Computers Informatics Nursing, 30(8), 
402-408. http://doi.org/10.1097/NXN.0b013e3182510703

Howell, R. T., Rodzon, K. S., Kurai, M., \& Sanchez, A. H. (2010). A validation of wellbeing and happiness surveys for administration via the internet. Behavior Research Methods, 42(3), 775-784. http://doi.org/10.3758/BRM.42.3.775

Howells, A., Ivtzan, I., \& Jose, F. (2016). Putting the 'app' in Happiness : A Randomised Controlled Trial of a Smartphone-Based Mindfulness Intervention to Enhance Wellbeing. Journal of Happiness Studies, 163-185.

http://doi.org/10.1007/s10902-014-9589-1

Hyland, A., Ambrose, B. K., Conway, K. P., Borek, N., Lambert, E., Carusi, C., ... Compton, W. M. (2017). Design and methods of the Population Assessment of Tobacco and Health (PATH) Study. Tobacco Control, 26(4), 371-378. http://doi.org/10.1136/tobaccocontrol-2016-052934

Irwin, J. D. (2004). Prevalence of university students' sufficient physical activity: a systematic review. Perceptual and Motor Skills, 98(3 Pt 1), 927-943. http://doi.org/10.2466/pms.98.3.927-943

Jackowska, M., Dockray, S., Hendrickx, H., \& Steptoe, A. (2011a). Psychosocial factors and sleep efficiency: Discrepancies between subjective and objective evaluations of sleep. Psychosomatic Medicine, 73(9), 810-816. http://doi.org/10.1097/PSY.0b013e3182359e77

Jackowska, M., Dockray, S., Hendrickx, H., \& Steptoe, A. (2011b). Psychosocial factors and sleep efficiency: Discrepancies between subjective and objective evaluations of sleep. Psychosomatic Medicine, 73(9), 810-816.

http://doi.org/10.1097/PSY.0b013e3182359e77

Jackson, L., Mark Pancer, S., Pratt, M. W., \& Hunsberger, B. E. (2000). Great Expectations: The Relation Between Expectancies and Adjustment During the Transition to University'. Journal of Applied Social Psychology, 30(10), 21002125. http://doi.org/10.1111/j.1559-1816.2000.tb02427.x 
Jarden, A. (2011). Positive Psychological Assessment: A practical introduction to empirically validated research tools for measuring wellbeing. Emotion, (September), 1-48.

Jha, P., \& Peto, R. (2015). Global Effects of Smoking, of Quitting, and of Taxing Tobacco - NEJM. New England Journal of Medicine, 370(1), 60-68. http://doi.org/10.1056/NEJMra1308383

Jou, M., Tennyson, R. D., Wang, J., \& Huang, S. Y. (2016). A study on the usability of E-books and APP in engineering courses: A case study on mechanical drawing. Computers and Education, 92-93, 181-193. http://doi.org/10.1016/j.compedu.2015.10.004

Kasser, T., \& Ryan. (1996). Further Examining the American Dream: Differential Correlates of Intrinsic and Extrinsic Goals. Personality \& Social Psychology Bulletin, 22(3), 280-287. http://doi.org/10.1177/0146167296223006

Kawada, T., Kuratomi, Y., \& Kanai, T. (2009). Lifestyle determinants of depressive feeling and a feeling of unhappiness. Work, 33(3), 255-260. http://doi.org/10.3233/WOR-2009-0873

Kelly, C. M., Jorm, A. F., \& Wright, A. (2007). Improving mental health literacy as a strategy to facilitate early intervention for mental disorders. The Medical Journal of Australia, 187(7 Suppl), 1-5. http://doi.org/kel10278_fm [pii]

Kelly, W., Kelly, K., \& Clanton, R. (2001). The relationship between sleep length and grade-point average among college students, 1(35).

Kemp, N., \& Grieve, R. (2014). Face-to-face or face-to-screen? Undergraduates' opinions and test performance in classroom vs. Online learning. Frontiers in Psychology, 5(NOV), 1-11. http://doi.org/10.3389/fpsyg.2014.01278

Kiaei, Y. A., \& Reio Jr., T. G. (2014). Goal pursuit and eudaimonic well-being among university students: Metacognition as the mediator. Behavioral Development Bulletin, 19(4), 91-104. http://doi.org/10.1037/h0101085 
King, L. A. (2001). The health benefits of writing about life goals. Personality and Social Psychology Bulletin, 27(7), 798-807. http://doi.org/10.1177/0146167201277003

King, L. a., \& Pennebaker, J. W. (1998). What's So Great About Feeling Good? Psychological Inquiry, 9(1), 53-56. http://doi.org/10.1207/s15327965pli0901_8

Koopmans, T. A., Geleijnse, J. M., Zitman, F. G., \& Giltay, E. J. (2010). Effects of happiness on all-cause mortality during 15 years of follow-up: The Arnhem Elderly Study. Journal of Happiness Studies, 11(1), 113-124.

http://doi.org/10.1007/s10902-008-9127-0

Kukulska-Hulme, A., \& Shield, L. (2008). An overview of mobile assisted language learning: From content delivery to supported collaboration and interaction. ReCALL, 20(03), 271-289. http://doi.org/10.1017/S0958344008000335

Kushlev, K., Heintzelman, S. J., Lutes, L. D., Wirtz, D., Oishi, S., \& Diener, E. (2017). ENHANCE: Design and rationale of a randomized controlled trial for promoting enduring happiness \& well-being. Contemporary Clinical Trials, 52, 62-74. http://doi.org/10.1016/j.cct.2016.11.003

Kye, S. Y., Kwon, J. H., \& Park, K. (2016). Happiness and health behaviors in South Korean adolescents: a cross-sectional study. Epidemiology and Health, 38, e2016022. http://doi.org/10.4178/epih.e2016022

Lambert, M., Fleming, T., Ameratunga, S., Robinson, E., Crengle, S., Sheridan, J., ... Merry, S. (2014). Looking on the bright side: An assessment of factors associated with adolescents' happiness. Advances in Mental Health, 12(2), 101-109. http://doi.org/10.1080/18374905.2014.11081888

Lane, N. D., Miluzzo, E., Lu, H., Peebles, D., Choudhury, T., Campbell, A. T., \& College, D. (2010). A Survey of Mobile Phone Sensing, (September), 140-150.

Lauder, S., Chester, A., \& Berk, M. (2007). Net-effect? Online psychological interventions. Acta Neuropsychiatrica, 19(6), 386-388. http://doi.org/DOI: 
10.1111/j.1601-5215.2007.00261.x

Lee Duckworth, A., Steen, T. A., \& Seligman, M. E. P. (2005). Positive Psychology in Clinical Practice. Annual Review of Clinical Psychology, 1(1), 629-651. http://doi.org/10.1146/annurev.clinpsy.1.102803.144154

Lewis, M. A., Atkins, D. C., Blayney, J. A., Dent, D. V, \& Kaysen, D. L. (2013). What Is Hooking Up? Examining Definitions of Hooking Up in Relation to Behavior and Normative Perceptions. The Journal of Sex Research, 50(8), 757-766. http://doi.org/10.1080/00224499.2012.706333

Liaghatdar, M. J., Jafari, E., Abedi, M. R., \& Samiee, F. (2008). Reliability and Validity of the Oxford Happiness Inventory among University Students in Iran. The Spanish Journal of Psychology, 11(01), 310-313.

http://doi.org/10.1017/S1138741600004340

LiKamWa, R., Liu, Y., Lane, N. D., \& Zhong, L. (2013). MoodScope. Proceeding of the 11th Annual International Conference on Mobile Systems, Applications, and Services - MobiSys '13, 465. http://doi.org/10.1145/2462456.2483967

Luo, Z., \& Inoué, S. (2000). A short daytime nap modulates levels of emotions objectively evaluated by the emotion spectrum analysis method. Psychiatry and Clinical Neurosciences, 54(2), 207-212. http://doi.org/10.1046/j.14401819.2000.00660.x

Lykken, D. (1999). Happiness: what studies on twins show us about nature, nurture and the happiness set-point. New York, New York: Golden Books.

Lykken, D., \& Tellegen, A. (1996). Happiness is a stochastic phenomenon. Psychological Science, 7(3), 186-189. http://doi.org/10.1111/j.14679280.1996.tb00355.x

Lyubomirsky, S. (2008). The how of happiness: A scientific approach to getting the life you want. New York, New York: Penguin Press. 
Lyubomirsky, S., Dickerhoof, R., Boehm, J. K., \& Sheldon, K. M. (2011). Becoming happier takes both a will and a proper way: An experimental longitudinal intervention to boost well-being. Emotion, 11(2), 391-402. http://doi.org/10.1037/a0022575

Lyubomirsky, S., King, L., \& Diener, E. (2005). The benefits of frequent positive affect: Does happiness lead to success? Psychological Bulletin, 131(6), 803-855. http://doi.org/10.1037/0033-2909.131.6.803

Lyubomirsky, S., \& Layous, K. (2013). How Do Simple Positive Activities Increase Well-Being? Current Directions in Psychological Science, 22(1), 57-62. http://doi.org/10.1177/0963721412469809

Lyubomirsky, S., \& Lepper, H. (1999). A Measure of Subjective Happiness :

Preliminary Reliability and Construct Validation Author ( s ): Sonja Lyubomirsky and Heidi S . Lepper Published by : Springer Stable URL:

http://www.jstor.org/stable/27522363 Your use of the JSTOR archive indicates you, 46(2), 137-155.

Lyubomirsky, S., Sousa, L., \& Dickerhoof, R. (2006). The costs and benefits of writing, talking, and thinking about life's triumphs and defeats. Journal of Personality and Social Psychology, 90(4), 692-708. http://doi.org/10.1037/0022-3514.90.4.692

Lyubomirsky, S., \& Tucker, K. L. K. (1998). Implications of Individual Differences in Subjective Happiness for Perceiving, Interpreting, and Thinking About Life Events 1. Motivation and Emotion, 22(2), 155-186.

http://doi.org/10.1023/A:1021396422190

Lyubomksky, S., Sheldon, K. M., \& Schkade, D. (2005). Pursuing happiness: The architecture of sustainable change. Review of General Psychology, 9(2), 111131. http://doi.org/10.1037/1089-2680.9.2.111

MacLeod, A. K., Coates, E., \& Hetherton, J. (2008). Increasing well-being through teaching goal-setting and planning skills: Results of a brief intervention. Journal of 
Happiness Studies, 9(2), 185-196. http://doi.org/10.1007/s10902-007-9057-2

Manthey, L., Vehreschild, V., \& Renner, K. H. (2016). Effectiveness of Two Cognitive Interventions Promoting Happiness with Video-Based Online Instructions. Journal of Happiness Studies, 17(1), 319-339. http://doi.org/10.1007/s10902-014-9596-2

Marks, G. N., \& Fleming, N. (1999). Influences and consequences of well-being among Australian young people: 1980-1995. Social Indicators Research, 46(3), 301-323. http://doi.org/10.1023/A:1006928507272

Mathew, T., \& Hicks, R. E. (2010). Personality and task performance. (R. E. Hicks, Ed.)Personality and individual differences: Current directions BT - Personality and individual differences: Current directions. Australian Academic Press, Bowen Hills, QLD. Retrieved from https://www.lib.uwo.ca/cgibin/ezpauthn.cgi?url=http://search. proquest.com/docview/916528651?accountid= 15115

McCullough, M. E., Emmons, R. A., \& Tsang, J. A. (2002). The grateful disposition: A conceptual and empirical topography. Journal of Personality and Social Psychology, 82(1), 112-127. http://doi.org/10.1037//0022-3514.82.1.112

Misra, R., \& Mckean, M. (2000). College students'academic stress and its relation to their anxiety, time management, and leisure satisfaction. American journal of health studies (Vol. 16).

Mohammadkhani, S. (2013). The Role of Fusion Beliefs and Metacognitions in Obsessive - Compulsive Symptoms in General Population, 1(2), 97-104.

Montagni, I., Cariou, T., Feuillet, T., Langlois, E., \& Tzourio, C. (2018). Exploring Digital Health Use and Opinions of University Students: Field Survey Study. JMIR MHealth and UHealth, 6(3), e65. http://doi.org/10.2196/mhealth.9131

Mouw, J. T., \& Khanna. (1993). Prediction of academic success: A review of the literature and some recommendations. College Student Journal, 27(3). 
Murdock, C., Naber, J., \& Perlow, M. (2010). Stress level and stress management skills of admitted baccalaureate nursing students. Kentucky Nurse, 58(2), 8.

Mushtaq, Z., Ghayas, S., \& Niazi, S. (2014). Happiness, quality of sleep and academic achievement among university undergraduates. Journal of the Indian Academy of Applied Psychology, 40(1), 62-69. Retrieved from http://jiaap.org/Listing_Detail/Logo/3a0a0dff-0e1e-4707-ad60fb849cf947ff.pdf\%0Ahttp://ezproxy.lib.uh.edu/login?url=http://search.ebscohost.co $\mathrm{m} /$ login. aspx?direct=true \&db=psyh\&AN=2014-22567-007\&site=ehost-live

Myers, B. D. G., \& Diener, E. (2010). Who Is Happy?, 6(1), 10-19.

Nelson, C. (2009). Appreciating gratitude: Can gratitude be used as a psychological intervention to improve individual well-being? Counselling Psychology Review, 24(3-4), 38-50. Retrieved from http://search.ebscohost.com/login.aspx?direct=true\&db=psyh\&AN=2010-04367005\&site=ehost-live\%5Cnhttp://Nelson.home@btopenworld.com

Nes, R. B. (2010). Happiness in behaviour genetics: Findings and implications. Journal of Happiness Studies, 11(3), 369-381. http://doi.org/10.1007/s10902-009-9145-6

Norrish, J. M., \& Vella-Brodrick, D. A. (2008). Is the study of happiness a worthy scientific pursuit? Social Indicators Research, 87(3), 393-407. http://doi.org/10.1007/s11205-007-9147-x

O'Brien, C. (2008). Sustainable happiness: How happiness studies can contribute to a more sustainable future. Canadian Psychology, 49(4), 289-295. http://doi.org/10.1037/a0013235

Office of the Provost and Vice-President. (2017). Report on the Survey of Graduating Students: 2016-17. Retrieved from http://www.ipb.uwo.ca/documents/201415_Survey_of_Graduating_Students.pdf

Okun, M. A., Levy, R., Karoly, P., \& Ruehlman, L. (2009). Dispositional happiness and college student GPA: Unpacking a null relation. Journal of Research in 
Personality, 43(4), 711-715. http://doi.org/10.1016/j.jrp.2009.03.010

Ong, A. D., Kim, S., Young, S., \& Steptoe, A. (2016). Positive affect and sleep: A systematic review. Sleep Medicine Reviews, 35, 21-32. http://doi.org/10.1016/j.smrv.2016.07.006

Otter, R. R., Seipel, S., Graeff, T., Alexander, B., Boraiko, C., Gray, J., ... Sadler, K. (2013). Comparing student and faculty perceptions of online and traditional courses. Internet and Higher Education, 19, 27-35. http://doi.org/10.1016/j.iheduc.2013.08.001

Ouweneel, E., Le Blanc, P. M., \& Schaufeli, W. B. (2014). On being grateful and kind: Results of two randomized controlled trials on study-related emotions and academic engagement. Journal of Psychology: Interdisciplinary and Applied, 148(1), 37-60. http://doi.org/10.1080/00223980.2012.742854

Papageorgiou, C. P. (2004, January 1). An empirical test of clinical metacognitive model of rumination and depression. Depression, rumination and metacognition: empirical tests of an information-processing model.

Parks, A. C., Della Porta, M. D., Pierce, R. S., Zilca, R., \& Lyubomirsky, S. (2012). Pursuing happiness in everyday life: The characteristics and behaviors of online happiness seekers. Emotion, 12(6), 1222-1234. http://doi.org/10.1037/a0028587

Parks, K. A., Frone, M. R., Muraven, M., \& Boyd, C. (2017). Nonmedical use of prescription drugs and related negative sexual events: Prevalence estimates and correlates in college students. Addictive Behaviors, 65, 258-263. http://doi.org/10.1016/j.addbeh.2016.08.018

Pekrun, R., Goetz, T., Titz, W., \& Perry, R. (2002). Positive emotions in education. Oxford: University Press.

Peltzer, K., \& Pengpid, S. (2013). Subjective Happiness and Health Behavior Among a Sample of University Students in India. Social Behavior and Personality, 41(6), 1045-1056. http://doi.org/10.2224/sbp.2013.41.6.1045 
Pierceall, E. A., \& Keim, M. C. (2007). Stress and Coping Strategies Among Community College Students. Community College Journal of Research and Practice, 31(9), 703-712. http://doi.org/10.1080/10668920600866579

Piqueras, J. A., Kuhne, W., Vera-Villarroel, P., Van Straten, A., \& Cuijpers, P. (2011a). Happiness and health behaviours in Chilean college students: A cross-sectional survey. BMC Public Health, 11(1), 443. http://doi.org/10.1186/1471-2458-11-443

Piqueras, J. A., Kuhne, W., Vera-Villarroel, P., Van Straten, A., \& Cuijpers, P. (2011b). Happiness and health behaviours in Chilean college students: A cross-sectional survey. BMC Public Health, 11. http://doi.org/10.1186/1471-2458-11-443

Plotnikoff, R. C., Costigan, S. A., Williams, R. L., Hutchesson, M. J., Kennedy, S. G., Robards, S. L., ... Germov, J. (2015). Effectiveness of interventions targeting physical activity, nutrition and healthy weight for university and college students: A systematic review and meta-analysis. International Journal of Behavioral Nutrition and Physical Activity, 12(1), 1-10. http://doi.org/10.1186/s12966-015-0203-7

Proctor, C., Linley, P. A., \& Maltby, J. (2010). Very Happy Youths: Benefits of Very High Life Satisfaction Among Adolescents. Social Indicators Research, 98(3), 519-532. http://doi.org/10.1007/s11205-009-9562-2

Quick, V., Byrd-Bredbenner, C., White, A. A., Brown, O., Colby, S., Shoff, S., ... Greene, G. (2014). Eat, Sleep, Work, Play: Associations of Weight Status and Health-Related Behaviors among Young Adult College Students. American Journal of Health Promotion, 29(2), e64-e72. http://doi.org/10.4278/ajhp.130327QUAN-130

Rasmussen, M., \& Laumann, K. (2014). The role of exercise during adolescence on adult happiness and mood. Leisure Studies, 33(4), 341-356. http://doi.org/10.1080/02614367.2013.798347

Regehr, C., Glancy, D., \& Pitts, A. (2013). Interventions to reduce stress in university students: A review and meta-analysis. Journal of Affective Disorders, 148(1), 1- 
11. http://doi.org/10.1016/j.jad.2012.11.026

Reiner, M., Niermann, C., Jekauc, D., \& Woll, A. (2013). Long-term health benefits of physical activity--a systematic review of longitudinal studies. BMC Public Health, 13(1), 813. http://doi.org/10.1186/1471-2458-13-813

Rennis, L., McNamara, G., Seidel, E., \& Shneyderman, Y. (2015). Google it! Urban community college students' use of the Internet to obtain self-care and personal health information. College Student Journal, 49(3), 414-426.

Renuka, S., \& Gurunathan, D. (2017). Usage of internet for academic purposes by undergraduate students, 7(December 2016), 18-21.

Rickwood, D., Deane, F. P., Wilson, C. J., \& Ciarrochi, J. (2005). Young people's helpseeking for mental health problems. Australian E-Journal for the Advancement of Mental Health (AeJAMH), 4(3), 1-34. http://doi.org/10.5172/jamh.4.3.218

Robbins, M., Francis, L. J., \& Edwards, B. (2010). Happiness as stable extraversion: Internal consistency reliability and construct validity of the oxford happiness questionnaire among undergraduate students. Current Psychology, 29(2), 89-94. http://doi.org/10.1007/s12144-010-9076-8

Robotham, D., \& Julian, C. (2006). Stress and the higher education student: a critical review of the literature. Journal of Further and Higher Education, 30(2), 107-117. http://doi.org/10.1080/03098770600617513

Roditis, M., Delucchi, K., Cash, D., \& Halpern-Felsher, B. (2016). Adolescents' Perceptions of Health Risks, Social Risks, and Benefits Differ Across Tobacco Products. Journal of Adolescent Health, 58(5), 558-566.

http://doi.org/10.1016/j.jadohealth.2016.01.012

Royal College of Psychiatrists. (2011). 8 Mental health of students in higher education Royal College of Psychiatrists. College Report CR166 Royal College of Psychiatrists, 1-97. 
Ryan, M., Shochet, I. M., \& Stallman, H. M. (2010). Universal online interventions might engage psychologically distressed university students who are unlikely to seek formal help. Advances in Mental Health, 9(1), 73-83.

http://doi.org/10.5172/jamh.9.1.73

Ryff, C. D., Singer, B., Love, G. D., \& Essex, M. J. (1998). Resilience in adulthood and later life: Defining features and dynamic processes. In J. Lomranz (Ed.), Handbook of aging and mental health: An integrative approach (p. 69-96, Chapter xix, 539 Pages). Plenum Press, New York, NY. http://doi.org/http://dx.doi.org/10.1007/978-1-4899-0098-2_4

Sagiv, L., \& Roccas. (2004, January 1). Value Pathways to Well-Being: Healthy Values, Valued Goal Attainment, and Environmental Congruence. Positive Psychology in Practice.

Saricam, H. (2015). METACOGNITION AND HAPPINESS: THE MEDIATING ROLE OF PERCEIVED STRESS. Studia Psychologica, 57(4), 271-283. http://doi.org/10.21909/sp.2015.03.699

Saricam, H. (2015). METACOGNITION AND HAPPINESS: THE MEDIATING ROLE OF PERCEIVED STRESS. Studia Psychologica, 57(4), 271-283. http://doi.org/10.21909/sp.2015.03.699

Schiffrin, H. H., \& Nelson, S. K. (2010). Stressed and happy? Investigating the relationship between happiness and perceived stress. Journal of Happiness Studies, 11(1), 33-39. http://doi.org/10.1007/s10902-008-9104-7

Schueller, S. M., \& Seligman, M. E. P. (2010). Pursuit of pleasure, engagement, and meaning: Relationships to subjective and objective measures of well-being. Journal of Positive Psychology, 5(4), 253-263. http://doi.org/10.1080/17439761003794130

Schultheiss, O. C., Jones, N. M., Davis, A. Q., \& Kley, C. (2008). The role of implicit motivation in hot and cold goal pursuit: Effects on goal progress, goal rumination, 
and emotional well-being. Journal of Research in Personality, 42(4), 971-987. http://doi.org/10.1016/j.jrp.2007.12.009

Schwartz, N., \& Strack, F. (2009). Well-Being: The Foundations of Hedonic Psychology. New York, New York: Russell Sage.

Seligman, M. E., \& Csikszentmihalyi, M. (2000). Positive psychology. An introduction. The American Psychologist, 55(1), 5-14. http://doi.org/10.1037/0003-066X.55.1.5

Seligman, M. E. P. (2002). Authentic Happiness: Using the New Positive Psychology to Realize Your Potential for Lasting Fulfillment. New York, New York: Simon \& Shuster Inc.

Seligman, M. E. P., Steen, T. A., Park, N., \& Peterson, C. (2005). Positive psychology progress: empirical validation of interventions. The American Psychologist, 60(5), 410-421. http://doi.org/10.1037/0003-066X.60.5.410

Senf, K., \& Liau, A. K. (2013). The Effects of Positive Interventions on Happiness and Depressive Symptoms, with an Examination of Personality as a Moderator. Journal of Happiness Studies, 14(2), 591-612. http://doi.org/10.1007/s10902-0129344-4

Sheldon, K., \& Lyubomirsky, S. (2007). Is It Possible to Become Happier? (And If So, How?). Social and Personality Psychology Compass, 1(1), 129-145. http://doi.org/10.1111/j.1751-9004.2007.00002.x

Sheldon, K. M., \& Elliot, A. J. (1999). Goal striving, need satisfaction, and longitudinal well-being: The self-concordance model. Journal of Personality and Social Psychology, 76(3), 482-497. http://doi.org/10.1037/0022-3514.76.3.482

Sheldon, K. M., \& Lyubomirsky. (2004, January 1). Achieving Sustainable New Happiness: Prospects, Practices, and Prescriptions. Positive Psychology in Practice.

Sheldon, K. M., \& Lyubomirsky, S. (2006a). Achieving sustainable gains in happiness: 
Change your actions, not your circumstances. Journal of Happiness Studies, 7(1), 55-86. http://doi.org/10.1007/s10902-005-0868-8

Sheldon, K. M., \& Lyubomirsky, S. (2006b). How to increase and sustain positive emotion: The effects of expressing gratitude and visualizing best possible selves. Journal of Positive Psychology, 1(2), 73-82. http://doi.org/10.1080/17439760500510676

Sheldon, K. M., \& Lyubomirsky, S. (2012). Achieving Sustainable New Happiness: Prospects, Practices, and Prescriptions. Positive Psychology in Practice, 127145. http://doi.org/10.1002/9780470939338.ch8

Sheldon, K. M., \& Marko, L. H. (2001). Self - Concordance, Goal Attianment and the Pursuit of Happiness: Can There be an Upward Spiral? Journal of Personality and Social Psychology, 80(1), 152-165.

Sheldon, P. (2016). Facebook friend request: Applying the theory of reasoned action to student-teacher relationships on Facebook. Journal of Broadcasting \& Electronic Media, 60(2), 269-285.

http://doi.org/http://dx.doi.org/10.1080/08838151.2016.1164167

Shopland, D. R. (1995). Tobacco use and its contribution to early cancer mortality with a special emphasis on cigarette smoking. Environmental Health Perspectives, 103(SUPPL. 8), 131-142. http://doi.org/10.1289/ehp.95103s8131

Siegrist, J. (2008). Chronic psychosocial stress at work and risk of depression: Evidence from prospective studies. European Archives of Psychiatry and Clinical Neuroscience, 258(SUPPL. 5), 115-119. http://doi.org/10.1007/s00406-008-50240

Sin, N., \& Lyubomksky, S. (2009). Enhancing Well-Being and Alleviating Depressive Symptoms With Positive Psychology Interventions: A Practice-Friendly MetaAnalysis. Journal of Clinical Psychology, 65(5), 467-487. http://doi.org/10.1002/jclp 
Solcova, L., \& Magdin, M. (2016). Interactive textbook—A new tool in off-line and online education. TOJET: The Turkish Online Journal of Educational Technology, 15(3), 111-125. Retrieved from https://www.lib.uwo.ca/cgibin/ezpauthn.cgi?url=http://search.proquest.com/docview/1928290461?accountid $=15115$

Statistics Canada. (2009). National Longitudinal Survey of Children and Youth Survey Overview. Retrieved from http://www23.statcan.gc.ca/imdbbmdi/document/4450_D2_T9_V4-eng.pdf

Staw, B. M., Sutton, R. I., \& Pelled, L. H. (1994). Employee Positive Emotion and Favorable Outcomes at the Workplace. Organization Science, 5(1), 51-71. http://doi.org/10.1287/orsc.5.1.51

Stickley, A., Koyanagi, A., Roberts, B., Leinsalu, M., Goryakin, Y., \& McKee, M. (2015). Smoking status, nicotine dependence and happiness in nine countries of the former soviet union. Tobacco Control, 24(2), 190-197. http://doi.org/10.1136/tobaccocontrol-2014-052092

Stubbe, J. H., Posthuma, D., Boomsma, D. I., De Geus, E. J. C., \& Versaevel, L. N. (2005). Heritability of life satisfaction in adults: A twin-family study. Psychological Medicine, 35(11), 1581-1588. http://doi.org/10.1017/S0033291705005374

Suh, E., Diener, E., \& Fujita, F. (1996). Events and subjective well-being: Only recent events matter: Erratum. Journal of Personality and Social Psychology, 71(5), 842. http://doi.org/http://dx.doi.org/10.1037/0022-3514.71.5.842

Tate, D. F., Jackvony, E. H., \& Wing, R. R. (2003). Effects of Internet Behavioral Counseling on Weight Loss in Adults at Risk for Type 2 Diabetes. Jama, 289(14), 1833. http://doi.org/10.1001/jama.289.14.1833

Telama, R., Yang, X., Viikari, J., Valimaki, I., Wanne, O., \& Raitakari, O. (2005). Physical Activity from Childhood to Adulthood. Journal of Sports Medicine and Physical Fitness, 28(3), 267-273. http://doi.org/10.1016/j.amepre.2004.12.003 
Thoits, P. A., \& Hewitt, L. N. (2016). Volunteer Work and Well-Being. Journal of Health and Social Behavior, 42(2), 115-131.

Toumbourou, J., Stockwell, T., Neighbors, C., Marlatt, G., Sturge, J., \& Rehm, J. (2007). Interventions to reduce harm associated with adolescent substance use. Lancet, 369(9570), 1391-1401. http://doi.org/10.1016/S0140-6736(07)60369-9

Truesdale, K. P., Stevens, J., Lewis, C. E., Schreiner, P. J., Loria, C. M., \& Cai, J. (2006). Changes in risk factors for cardiovascular disease by baseline weight status in young adults who maintain or gain weight over 15 years: The CARDIA study. International Journal of Obesity, 30(9), 1397-1407. http://doi.org/10.1038/sj.ijo.0803307

Universities Canada. (2016). 2017 Full-Time and Part-Time Fall Enrolment at Canadian Universities: Ontario Canada Reference Group. Retrieved from https://www.univcan.ca/universities/facts-and-stats/enrolment-by-university/

Vaez, M.; Laflamme, L. (2008). Experienced stress, psychological symptoms, selfrated health and academic achievement. Social Behavior and Personality, 36(2), 183196.

Van Zyl, L. E., \& Rothmann, S. (2012). Beyond smiling: The evaluation of a positive psychological intervention aimed at student happiness. Journal of Psychology in Africa, 22(3), 369-384. http://doi.org/10.1080/14330237.2012.10820541

Veenhoven, R. (2003). Hedonism and Happiness. Journal of Happiness Studies, 4(4), 437-457. http://doi.org/10.1023/B:JOHS.0000005719.56211.fd

Veenhoven, R. (2008). Healthy happiness: Effects of happiness on physical health and the consequences for preventive health care. Journal of Happiness Studies, 9(3), 449-469. http://doi.org/10.1007/s10902-006-9042-1

Veenhoven, R. (2015). Social conditions for human happiness: A review of research. International Journal of Psychology, 50(5), 379-391. http://doi.org/10.1002/ijop.12161 
Ventegodt, S. (1995). Quality of Life in Denmark. Copenhagen, Denmark: Forskningscentrets Forlag.

Viner, R. M., \& Taylor, B. (2007). Adult outcomes of binge drinking in adolescence: findings from a UK national birth cohort. Journal of Epidemiology \&amp; Community Health, 61(10), 902-907. http://doi.org/10.1136/jech.2005.038117

Wachs, P., \& Cooper, D. (2002). Validating the Student Developmental Task and Lifestyle Assessment: A longitudinal study. Journal of College Student Development, 43(1), 124-129. Retrieved from http://www.eric.ed.gov/ERICWebPortal/recordDetail?accno=EJ642673

Watkins, P. C., Woodward, K., Stone, T., \& Kolts, R. L. (2003). Gratitude and Happiness: Development of a Measure of Gratitude, and Relationships With Subjective Well-Being. Social Behavior and Personality: An International Journal, 31(5), 431-451. http://doi.org/10.2224/sbp.2003.31.5.431

Weiner, B. (1985). An attributional theory of motivation and emotion. Psychological Review, 92(4), 548-573.

http://doi.org/http://dx.doi.org.library.smu.ca:2048/10.1037/0033-295X.92.4.548

Wells, A. (2009). Metacognitive therapy for anxiety and depression. Anxiety, Stress \& Coping (Vol. 22). http://doi.org/10.1080/10615800902833770

Wessman, A., \& Ricks, D. (1966). Mood and Personality. New York, New York: Holt, Rinehart, and Winston.

Western Office of Institutional Planning. (2017). Common University Data Ontario 2017 Western University. Retrieved from http://www.ipb.uwo.ca/documents/cudo2014.pdf

Williams, S., \& Shiaw, W. T. (1999). Mood and organizational citizenship behavior: The effects of positive affect on employee organizational citizenship behavior intentions. The Journal of Psychology, 133(6), 656-68. http://doi.org/10.1080/00223989909599771 
Wilson, K., \& Korn, J. (2007). Attention During Lectures: Beyong Ten Minutes.

Teaching of Psychology, 34(2), 85-89.

http://doi.org/10.1080/00986280701291291

Winston, R. B. (1990). The Student Developmental Task and Lifestyle Inventory: An approach to measuring students' psychosocial development. Journal of College Student Development, 31(2), 108-120. Retrieved from https://www.lib.uwo.ca/cgibin/ezpauthn.cgi?url=http://search. . roquest.com/docview/617756132?accountid= 15115

Winston, R., Miller, T., \& Cooper, D. (1999). Student Developmental Task and Lifestyle Assessment. Boone, NC: Appalachian State University.

Wolkowitz, O. W., Epel, E. S., Reus, V. I., \& Mellon, S. H. (2010). Depression gets old fast: Do stress and depression accelerate cell aging? Depression and Anxiety, 27(4), 327-338. http://doi.org/10.1002/da.20686

Wong, M. L., Lau, E. Y. Y., Wan, J. H. Y., Cheung, S. F., Hui, C. H., \& Mok, D. S. Y. (2013). The interplay between sleep and mood in predicting academic functioning, physical health and psychological health: A longitudinal study. Journal of Psychosomatic Research, 74(4), 271-277.

http://doi.org/10.1016/j.jpsychores.2012.08.014

Wood, A. M., Froh, J. J., \& Geraghty, A. W. A. (2010). Gratitude and well-being: A review and theoretical integration. Clinical Psychology Review, 30(7), 890-905. http://doi.org/10.1016/j.cpr.2010.03.005

Wood, A. M., Maltby, J., Gillett, R., Linley, P. A., \& Joseph, S. (2008). The role of gratitude in the development of social support, stress, and depression: Two longitudinal studies. Journal of Research in Personality, 42(4), 854-871. http://doi.org/10.1016/j.jrp.2007.11.003

Wrench, A., Garrett, R., \& King, S. (2013). Guessing where the goal posts are: Managing health and well-being during the transition to university studies. Journal 
of Youth Studies, 16(6), 730-746. http://doi.org/10.1080/13676261.2012.744814

Wyn, J. (2009). Young people's wellbeing: Contradictions in managing the healthy self. ACHPER Healthy Lifestyles Journal (Vol. 56).

Zare, M., Sarikhani, R., Salari, M., \& Mansouri, V. (2016). The impact of E-learning on university students' academic achievement and creativity. Journal of Technical Education and Training, 8(1), 25-33. Retrieved from https://www.scopus.com/inward/record.uri?eid=2-s2.084976561256\&partnerID=40\&md5=60573201a335ada0ebbfb2b9f0ce3b8d

Zaremohzzabieh, Z., Samah, B. A., Omar, S. Z., Bolong, J., Akhtar, N., \& Kamarudin, N. A. (2014). Addictive Facebook use among university students. Asian Social Science, 10(6), 107-116. http://doi.org/10.5539/ass.v10n6p107

Zhang, Z., \& Chen, W. (2018). A Systematic Review of the Relationship Between Physical Activity and Happiness. Journal of Happiness Studies, 1-18. http://doi.org/10.1007/s10902-018-9976-0

Zhou, J., O'Brien, K. S., \& Heim, D. (2014). Alcohol consumption in sportspeople: The role of social cohesion, identity and happiness. International Review for the Sociology of Sport, 49(3-4), 278-293. http://doi.org/10.1177/1012690213493105

Zullig, K. J., Huebner, E. S., \& Pun, S. M. (2009). Demographic correlates of domainbased life satisfaction reports of college students. Journal of Happiness Studies, 10(2), 229-238. http://doi.org/10.1007/s10902-007-9077-y 


\title{
Appendices
}

\section{Appendix A. Letter of Information and Consent}

\section{Western\&HealthSciences}

\section{Letter of Information and Consent}

\author{
Study Title \\ Healthy and Happy: Creating and Evaluating a Catalyst to Improve the Health of University \\ Students via an Online Training System
}

Name of Principal Investigator

Co-Investigator

Contact Information

What is this study about?

You are invited to participate in a research study about happiness and health because you responded to a call for research participants. Happiness has been found to be linked to many outcomes including quality of life, academic performance, and health. In this study online video modules will guide you to explore ways to enhance your happiness, physical wellbeing, and mental health. Online questionnaires and optional focus groups will be used to collect information to evaluate the effectiveness of the modules in promoting happiness

\section{Why are you doing this study?}

The purpose of this study is to evaluate online happiness video modules that are based on positive psychology and happiness theories. The video modules will teach you to explore ways to enhance your own happiness, physical wellbeing, and mental health. As physical and mental health are an increasing concern on university campuses, teaching happiness skills offers an innovative approach to enhance happiness and improve outcomes related to academic achievement and health.

There are no conflicts of interest to declare related to this study.

What will happen to you during this study? 
Participation in the study will span a period of 4 weeks and will involve completing online questionnaires before watching any of the videos and again after completing all of the videos. The online questionnaires include a demographic questionnaire as well as a questionnaire with questions about health indicators and behaviours such as mental health; physical health; alcohol, drug, and tobacco use; physical activity; subjective well-being, happiness literacy; expressions of gratitude; and life satisfaction. These questionnaires will take about 20-30 minutes to complete. If any of your responses indicate that you are experiencing high emotional or psychological anxiety or stress you will receive a follow-up email within $\mathbf{2 4}$ hours of submitting your questionnaire with additional information about how you can access mental health resources on campus.

After completing the initial questionnaires, you will spend approximately 30 minutes per week online watching videos and completing short self-study activities. You will receive one new video each week that you will be able to watch on your own schedule. After completing all of the online videos, you will be asked to complete the questionnaires again.

OWL will be used to deliver the video modules about happiness and also for access to the questionnaires.

Following completion of the videos and questionnaires, you will be invited via email to participate in an optional focus group on campus which will last approximately 60 minutes. All research participants will be invited via email to participate in an optional focus group that will be conducted by two members of the research team. The focus groups will be audio recorded and the purpose will be to (1) learn your thoughts, ideas, and views regarding the content of the video modules and their impact on your concept of happiness; (2) identifying specific strategies, topics, and video module components that you believed were important; (3) learning if, and how, you will incorporate the knowledge from the video modules into your life; and (4) obtaining feedback to change or improve the modules. If you choose to participate in the focus group you will be asked to complete an additional (hard copy) of another consent from when you arrive at the focus group, prior to your participation.

\section{Will the study help you?}

Your participation in this study is voluntary. You may decide not to be in this study at any time. Even if you consent to participate you have the right to not answer individual questions or to withdraw from the study at any time. If you choose not to participate or to leave the study at any time it will have no effect on your academic standing.

You do not waive any legal right by consenting to this study.

If you decide to withdraw from the study, you have the right to request withdrawal of information collected about you. If you wish to have your information removed, please let the researcher know.

\section{Are there any risks to participating in the study?}


Sometimes during self-reflection there is a risk that you may experience emotional or psychological anxiety/stress. If at any time you experience any of these feelings please let the study investigators know. Resources (both online and on-campus options) will always be available on the OWL site for you as well. There are no known risks to filling out the questionnaires for this study, and there is no economic risk or cost to participating in this study.

\section{Are there any benefits to participating in the study?}

Through this study you will have the opportunity to learn about happiness skills that may benefit your physical, emotional, and mental well-being. You may experience an increase in positive emotion, quality of life, academic performance, and you may make more positive health behaviour choices.

The potential benefits to society are speculative at this point. If findings from this study demonstrate that happiness that can be learned, there may be positive individual benefits and eventually, there may be possible benefits to society.

How many participants will be enrolled in this study?

We anticipate that 400 students will be enrolled in this study.

What will happen with the information in the study?

Every effort will be made to protect your personal information. Your personal identifying information (such as your name, enrollment status, program of study, year of study, date of birth, and your unique subject code) will be stored separately from any study data.

If data is collected during the project which may be required to report by law we have a duty to report.

The researchers will keep any personal information about you in a secure and confidential location for a minimum of 5 years. A list linking your study number with your name will be kept by the researcher in a secure file, separate from your study file.

If the results of the study are published, your name will not be used.

Is there compensation for participation in the study?

You have the option to have your name entered into a draw to win one of $34 \$ 100$ gift cards to the Book Store at Western.

Who do I contact if I have any other questions about the study? 
How do you consent to participating in this study?

You indicate your voluntary agreement to participate by responding to the online questionnaires. 


\section{Appendix B. Eligibility Survey (via Qualtrics)}
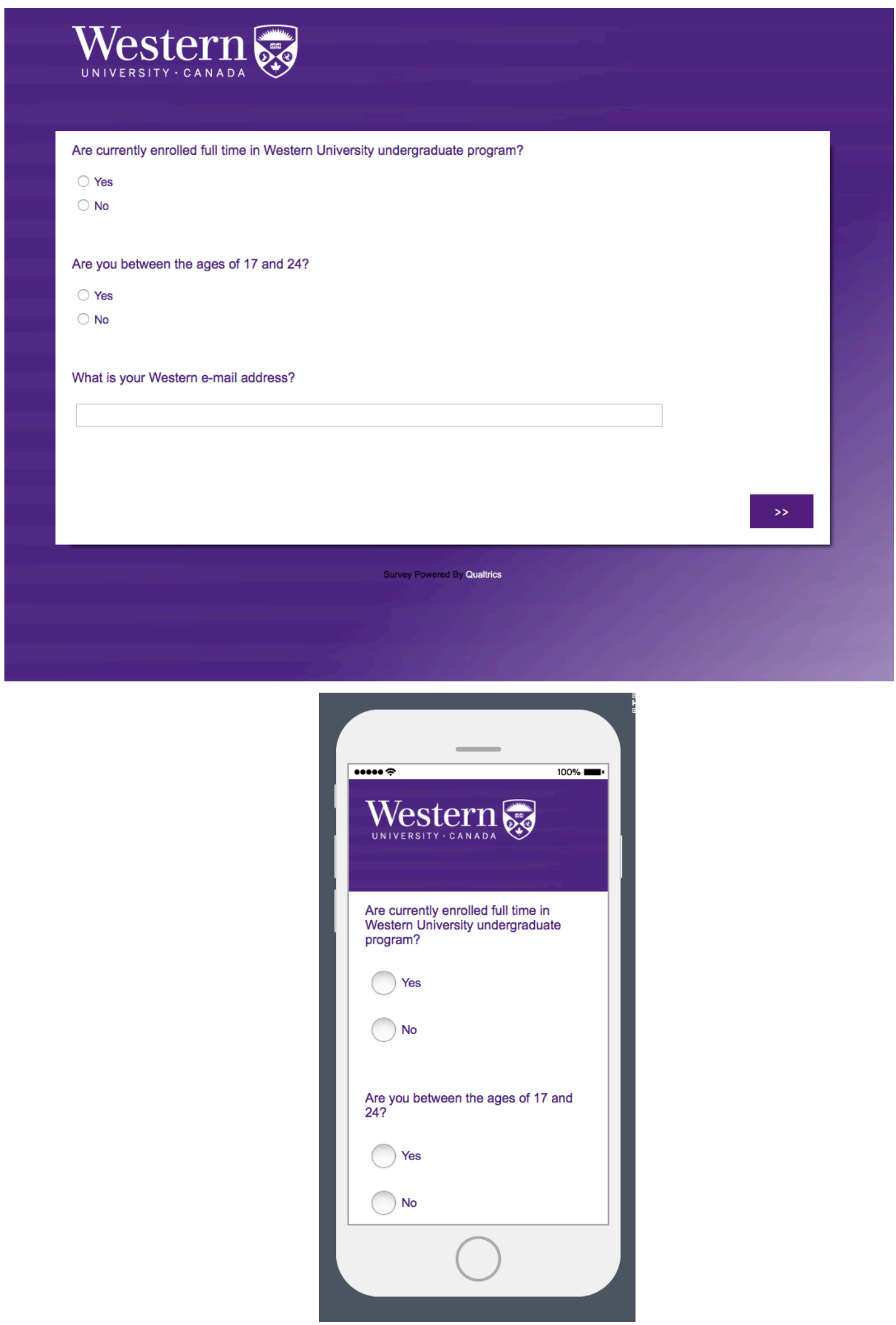


\section{Appendix C. Study Main Page on OWL}

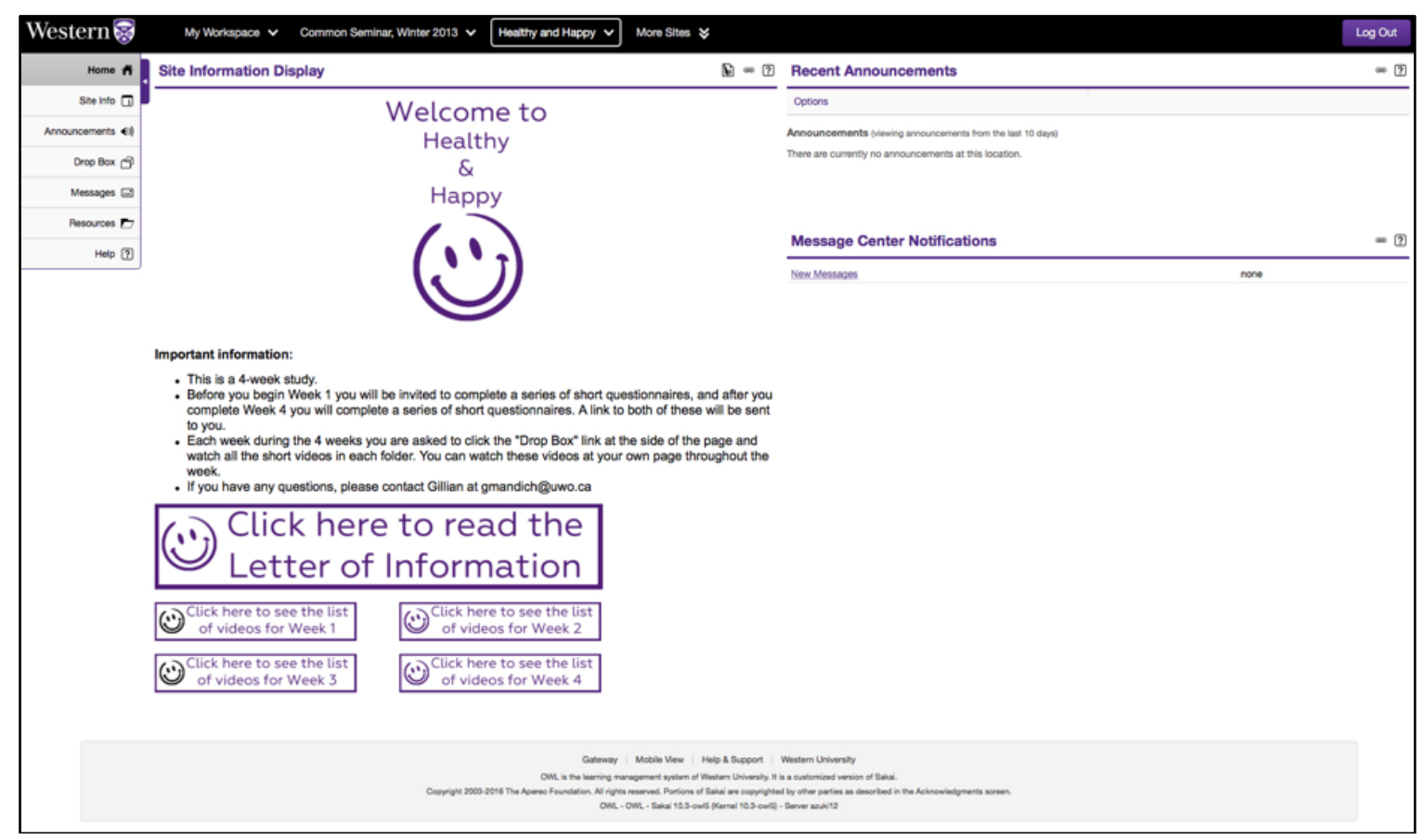




\section{Appendix D. Demographic Questionnaire}

\section{Western:HealthSciences Demographic Questionnaire}

Date of Birth:

Faculty:

Program of Study:

Year of Study:

Please answer the following questions to the best of your ability. If you unsure how to answer any of the questions, please give the answer that is true for you in general or for you most of the time. You can leave any questions you do not wish to answer blank.

I am an international student.

$\square$ Yes

$\square$ No

What is your current gender identity?

$\square$ Male

$\square$ Female

$\square$ Transgender

$\square$ Other

$\square$ I prefer not to respond to this question

Have you ever been diagnosed with a mental health problem?

$\square$ Yes, before coming to Western

$\square$ Yes, after coming to Western

$\square$ Never

Have you ever been diagnosed with a chronic health problem (e.g. diabetes, asthma)?

$\square$ Yes, before coming to Western

$\square$ Yes, after coming to Western

$\square$ Never

Have you ever sought professional help for school related difficulties (academics/stress)?

$\square$ Yes, before coming to Western

$\square$ Yes, after coming to Western

$\square$ Never 
Where do you presently live? (Select one best response.)

$\square$ In residence

$\square \quad$ At home with parent(s)

$\square$ At home with spouse/partner

$\square$ In a university-owned apartment/townhouse

$\square$ Off-campus in an apartment/house with at least one other person who is not a parent or spouse/partner

$\square$ Off-campus in an apartment/house on my own

$\square$ In fraternity/sorority house

How are your tuition expenses paid? Check all that apply.

$\square$ Family

$\square$ Loans

$\square$ Scholarship

$\square$ Self-funded

How are your living expenses paid? Check all that apply.

$\square$ Family

$\square$ Loans

$\square$ Scholarship

$\square$ Self-funded

How are your personal expenses paid? Check all that apply.

$\square$ Family

$\square$ Loans

$\square$ Scholarship

$\square$ Self-funded

During your university studies have you ever been placed on academic probation?

$\square$ Yes

$\square$ No 


\section{Appendix E. Pre/Post Program Questionnaire}

\section{Western:HealthSciences}

\section{Pre/Post Questionnaire}

Please answer the following questions to the best of your ability. If you unsure how to answer any of the questions, please give the answer that is true for you in general or for you most of the time. You can leave any questions you do not wish to answer blank.

\section{Lifestyle Information}

My weight is maintained at a level appropriate for my height and frame.

$\square$ Never (almost never) true of me

$\square$ Seldom true of me

$\square$ Usually true of me

$\square$ Always (almost always) true of me

I feel confident in my ability to accomplish my goals.

$\square$ Never (almost never) true of me

$\square$ Seldom true of me

$\square$ Usually true of me

$\square$ Always (almost always) true of me

I satisfactorily accomplish all important daily tasks (e.g., class assignments, test preparation, room/apartment cleaning, eating, and sleeping).

$\square$ Never (almost never) true of me

$\square$ Seldom true of me

पUsually true of me

$\square$ Always (almost always) true of me

\section{Health Information}

I exercise for 30 minutes or more at least 3 times per week.

$\square$ Never (almost never) true of me

$\square$ Seldom true of me

口Usually true of me

$\square$ Always (almost always) true of me 
I plan my activities to make sure that I have adequate time for sleep.

$\square$ Never (almost never) true of me

$\square$ Seldom true of me

$\square$ Usually true of me

$\square$ Always (almost always) true of me

When I have experienced stress or tension this term,

$\square$ I have most often sought relief by listening to music, reading, or visiting friends.

$\square$ I have most often had a few drinks or beers to relax.

$\square$ I have most often exercised, worked out, or played a sport.

$\square$ I have kept on going and ignored the stress.

$\square$ I have had occasions when it became too much to handle and I had to take days off to relax or rest/sleep.

I use tobacco products (smoke, chew, or dip).

$\square$ Never

$\square$ Once a week or less

$\square$ Several times a week

$\square$ Most days

$\square$ Everyday

I use illicit drugs.

$\square$ Never

$\square$ Once a week or less

$\square$ Several times a week

a Most days

$\square$ Everyday

I have more than one drink (i.e., 1.5 ounces of liquor, 5 ounces of wine, or 12 ounces of beer).

$\checkmark$ Never

$\square$ Once a week or less

$\square$ Two to three times a week

$\square$ Most days 


\section{Social Information}

In regard to social issues (e.g., homelessness, environmental pollution, or AIDS),

$\square$ I don't think much about them.

$\square$ I am concerned, but haven't taken any specific actions.

$\square$ I contribute money to organizations that address the issue(s), but that is the extent of my involvement.

$\square$ I am actively involved in organizations that address the issues(s).

How many close friends do you feel you could go to for support and to confide in?

$\square$ None

$\square$ 1-2

$\square$ 3-5

$\square 6-8$

$\square$ more than 9

Do you have leisure activities that you do just for fun?

$\square$ Yes

- Please list the activities:

$\square$ No

\section{Gratitude}

To what extent do you feel grateful right now, at the present moment?

$\square$ Very Slightly/Not at All

$\square$ A Little

$\square$ Moderately

$\square$ Quite a Bit

$\square$ Extremely

To what extent do you feel appreciative right now, at the present moment?

$\square$ Very Slightly/Not at All

$\square$ A Little

$\square$ Moderately

$\square$ Quite a Bit

$\square$ Extremely 
To what extent do you feel thankful right now, at the present moment?

$\square$ Very Slightly/Not at All

$\square$ A Little

$\square$ Moderately

$\square$ Quite a Bit

$\square$ Extremely

\section{Authentic Happiness Inventory}

Please select the option that most applies to you.

\#1

I feel like a failure.

I do not feel like a winner.

I feel like I have succeeded more than most people.

As I look back on my life, all I see are victories.

I feel I am extraordinarily successful.

\#2

I am usually in a bad mood.

I am usually in a neutral mood.

I am usually in a good mood.

I am usually in a great mood.

I am usually in an unbelievably great mood.

\#3

When I am working, I pay more attention to what is going on around me than to what I am doing.

$\square$ When I am working, I pay as much attention to what is going on around me as to what I am doing.

$\square$ When I am working, I pay more attention to what I am doing than to what is going on around me.

1] When I am working, I rarely notice what is going on around me.

$\square$ When I am working, I pay so much attention to what I am doing that the outside world practically ceases to exist.

\#4

My life does not have any purpose or meaning.

I do not know the purpose or meaning of my life.

I have a hint about my purpose in life.

I have a pretty good idea about the purpose or meaning of my life.

I have a very clear idea about the purpose or meaning of my life.

Version Date: 20/07/2016 
\#5

I rarely get what I want.

Sometimes, I get what I want, and sometimes not.

Somewhat more often than not, I get what I want.

I usually get what I want.

I always get what I want.

\#6

I have sorrow in my life.

I have neither sorrow nor joy in my life.

I have more joy than sorrow in my life.

I have much more joy than sorrow in my life.

My life is filled with joy.

\#7

Most of the time I feel bored.

Most of the time I feel neither bored nor interested in what I am doing.

Most of the time I feel interested in what I am doing.

Most of the time I feel quite interested in what I am doing.

Most of the time I feel fascinated by what I am doing.

\#8

I feel cut off from other people.

I feel neither close to nor cut off from other people.

I feel close to friends and family members.

I feel close to most people, even if I do not know them well.

I feel close to everyone in the world.

\#9

By objective standards, I do poorly.

By objective standards, I do neither well nor poorly.

By objective standards, I do rather well.

By objective standards, I do quite well.

By objective standards, I do amazingly well.

\#10

$\square$ I am ashamed of myself.

a I am not ashamed of myself.

$\square$ I am proud of myself

$\square \quad$ I am very proud of myself.

$\checkmark$ I am extraordinarily proud of myself. 
\#11

Time passes slowly during most of the things that I do.

Time passes quickly during some of the things that I do and slowly for other things.

Time passes quickly during most of the things that I do.

Time passes quickly during all of the things that I do.

- Time passes so quickly during all of the things that I do that I do not even notice it.

\#12

In the grand scheme of things, my existence may hurt the world.

My existence neither helps nor hurts the world.

My existence has a small but positive effect on the world.

My existence makes the world a better place.

My existence has a lasting, large, and positive impact on the world.

$\# 13$

I do not do most things very well.

I do okay at most things I am doing.

I do well at some things I am doing.

I do well at most things I am doing.

I do really well at whatever I am doing.

\#14

I have little or no enthusiasm.

My enthusiasm level is neither high nor low.

I have a good amount of enthusiasm.

I feel enthusiastic doing almost everything.

I I have so much enthusiasm that I feel I can do most anything.

\#15

I do not like my work (paid or unpaid).

I feel neutral about my work.

For the most part, I like my work.

I really like my work.

I truly love my work. 
\#16

- I am pessimistic about the future.

I am neither optimistic nor pessimistic about the future.

I feel somewhat optimistic about the future.

I feel quite optimistic about the future.

I feel extraordinarily optimistic about the future.

\#17

I have accomplished little in life.

I have accomplished no more in life than most people.

I have accomplished somewhat more in life than most people.

I have accomplished more in life than most people.

I have accomplished a great deal more in my life than most people.

\#18

I am unhappy with myself.

I am neither happy nor unhappy with myself--I am neutral.

I am happy with myself.

I am very happy with myself.

I could not be any happier with myself.

\#19

My skills are never challenged by the situations I encounter.

My skills are occasionally challenged by the situations I encounter.

My skills are sometimes challenged by the situations I encounter.

My skills are often challenged by the situations I encounter.

My skills are always challenged by the situations I encounter.

\#20

I I spend all of my time doing things that are unimportant.

I spend a lot of time doing things that are neither important nor unimportant.

I spend some of my time every day doing things that are important. I spend most of my time every day doing things that are important.

I spend practically every moment every day doing things that are important. 
\#21

- If I were keeping score in life, I would be behind.

$\square$ If I were keeping score in life, I would be about even.

$\square$ If I were keeping score in life, I would be somewhat ahead.

- If I were keeping score in life, I would be ahead.

$\square$ If I were keeping score in life, I would be far ahead.

\#22

- I experience more pain than pleasure.

$\square$ I experience pain and pleasure in equal measure.

$\checkmark$ I experience more pleasure than pain.

$\square$ I experience much more pleasure than pain.

$\square$ My life is filled with pleasure.

\#23

I do not enjoy my daily routine.

I feel neutral about my daily routine.

- I like my daily routine, but I am happy to get away from it.

$\square$ I like my daily routine so much that I rarely take breaks from it.

$\square$ I like my daily routine so much that I almost never take breaks from it.

\#24

My life is a bad one.

My life is an OK one.

\. My life is a good one.

1. My life is a very good one.

$\square$ My life is a wonderful one. 


\section{Subjective Happiness Scale}

In general, I consider myself:

1 - Not a very happy person

2

3

4

5

6

7 - A very happy person

Compared to most of my peers, I consider myself:

1- Less Happy

2

3

4

5

6

7 - More Happy

Some people are generally very happy. They enjoy life regardless of what is going on, getting the most out of everything. To what extent does this characterization describe you?

1 - Not At All

2

3

4

5

6

7 - A Great Deal

Some people are generally not very happy. Although they are not depressed, they never seem as happy as they might be. To what extent does this characterization describe you?

1 - A Great Deal

2

3

4

5

6

7 - Not At All 


\section{Fordyce Emotions Questionnaire}

In general, how happy or unhappy do you usually feel? Select the ONE statement that best describes your average happiness.

Extremely happy (feeling ecstatic, joyous, fantastic)

Very happy (feeling really good, elated)

Pretty happy (spirits high, feeling good)

Mildly happy (feeling fairly good and somewhat cheerful)

Slightly happy (just a bit above neutral)

Neutral (not particularly happy or unhappy)

Slightly unhappy (just a bit below natural)

Mildly unhappy (just a bit low)

Pretty unhappy (somewhat "blue", spirits down)

- Very unhappy (depressed, spirits very low)

$\square$ Extremely unhappy (utterly depressed, completely down)

Consider your emotions a moment further. On the average, what percent of the time do you feel happy? What percent of the time do you feel unhappy? What percent of the time do you feel neutral (neither happy nor unhappy)? Select the percentage of time that you feel happy, unhappy, and neutral. Make sure that the three numbers add up to $100 \%$.

Percent of the time you feel happy on average:

Percent of the time you feel unhappy on average:

Percent of the time you feel neutral on average: 


\section{Oxford Happiness Inventory}

Below are a number of statements about happiness. Please indicate how much you agree or disagree with each by entering a number in the blank after each statement, according to the following scale:

$$
\begin{aligned}
& 1=\text { strongly disagree } \\
& 2=\text { moderately disagree } \\
& 3=\text { slightly disagree } \\
& 4=\text { slightly agree } \\
& 5=\text { moderately agree } \\
& 6=\text { strongly agree }
\end{aligned}
$$

Please read the statements carefully, because some are phrased positively and others negatively. Don't take too long over individual questions; there are no "right" or "wrong" answers (and no trick questions). The first answer that comes into your head is probably the right one for you. If you find some of the questions difficult, please give the answer that is true for you in general or for most of the time.

1. I don't feel particularly pleased with the way I am.

2. I am intensely interested in other people.

3. I feel that life is very rewarding.

4. I have very warm feelings towards almost everyone.

5 . I rarely wake up feeling rested.

6. I am not particularly optimistic about the future.

7. I find most things amusing.

8. I am always committed and involved.

9. Life is good.

10. I do not think that the world is a good place.

11. I laugh a lot.

12. I am well satisfied about everything in my life.

13. I don't think I look attractive.

14. There is a gap between what I would like to do and what I have done.

15. I am very happy.

16. I find beauty in some things.

17. I always have a cheerful effect on others.

18. I can fit in (find time for) everything I want to.

19. I feel that I am not especially in control of my life.

20. I feel able to take anything on.

21. I feel fully mentally alert.

22. I often experience joy and elation.

23. I don't find it easy to make decisions. 
24. I don't have a particular sense of meaning and purpose in my life.

25. I feel I have a great deal of energy.

26. I usually have a good influence on events.

27. I don't have fun with other people.

28. I don't feel particularly healthy.

29. I don't have particularly happy memories of the past. 


\section{Flourishing Scale}

Below are 8 statements with which you may agree or disagree. Using the 1-7 scale below, indicate your agreement with each item by indicating that response for each statement.

7 - Strongly agree

6 - Agree

5 - Slightly agree

4 - Neither agree nor disagree

3 - Slightly disagree

2 - Disagree

1 - Strongly disagree

I lead a purposeful and meaningful life My social relationships are supportive and rewarding I am engaged and interested in my daily activities I actively contribute to the happiness and well-being of others I am competent and capable in the activities that are important to me I am a good person and live a good life I am optimistic about my future People respect me

\section{Open-Ended Questions}

Please answer the following questions to the best of your ability. You can leave any questions you do not wish to answer blank.

What does happiness mean to you?

Did you learn anything from the videos in the study that impacted your life?

Did your view of happiness change after watching the videos in the study? If so, why and how?

Have you learned anything from the videos in the study that you have, or plan to, incorporate into your life? If so, what did you learn and how will you apply it into your life?

Have your thoughts, behaviours, or actions changed based on what you've learned in this study?

Thank you for completing this survey!

Version Date: 20/07/2016 


\title{
Appendix F. Email To Be Sent To Participants Who Report Indications of High Anxiety, Stress, or Suffering
}

\section{Western $\% H e a l t h S c i e n c e s$}

\author{
Email to be sent to participants who report indications of \\ high anxiety, stress or suffering
}

Hello, my name is Gillian Mandich and I am one of the team members from the study, "Healthy and Happy: Creating and Evaluating a Catalyst to Improve the Health of University Students via an Online Training System" led by Dr. Linda Miller.

As was stated in the Letter of Information, resources (both online and on-campus options) are always available to you because sometimes during self-reflection there is a risk that you may experience emotional or psychological anxiety/stress. The resources are:

- The Wellness Education Centre

- The Student Development Centre

- $\underline{\text { Student Health Services }}$

These resources can be found under the "resources" tab under the study in your OWL. If at any time you experience any experience emotional or psychological anxiety/stress please let myself know

Thank your participation in this study, Gillian 


\title{
Appendix G. Email Script for Program Feedback Questionnaire
}

\section{Western\&HealthSciences}

\section{Email Script for Post-Program Questionnaire}

(to be sent to all participants who completed the entire online program)

\section{Subject Line: Healthy and Happy: Invitation to participate in an online questionnaire}

Thank you for your participation in "Healthy and Happy: Creating and Evaluating a Catalyst to Improve the Health of University Students via an Online Training System"

\begin{abstract}
Because the end of the program is during exam time, we have decided to cancel the focus groups and instead are requesting your feedback from an online questionnaire. This questionnaire will have the same questions as we were planning to ask at the focus group, and it can be found on OWL. I have attached an additional Letter of Information that describes the questionnaire and procedures in more detail. The Letter of Information can also be found on OWL and is at the start of the questionnaire.
\end{abstract}

If you wish to participate, there is a new tab in the program's OWL site called "POST PROGRAM QUESIONNAIRE" that will take between 10-20 minutes to complete.

If you have any questions, please reply to this email.

Thank you,

Gillian

Version Date: 13/04/2017 


\section{Appendix H. Program Feedback Questionnaire Letter of Information and Consent}

\section{Western\&HealthSciences}

\section{Online Questionnaire Letter of Information and Consent}

Study Title

Healthy and Happy: Creating and Evaluating a Catalyst to Improve the Health of University Students via an Online Training System

Name of Principal Investigator

Co-Investigator

Contact Information

What is this study about?

You are invited to participate in this online questionnaire because you have completed online modules in a research study about happiness. This optional online questionnaire will be used to collect information to evaluate the effectiveness of the modules in promoting happiness

Why are you doing this study?

The purpose of this online questionnaire is to evaluate online happiness video modules that are based on positive psychology and happiness theories. As physical and mental health are an increasing concern on university campuses, teaching happiness skills offers an innovative approach to enhance happiness and improve outcomes related to academic achievement and health.

There are no conflicts of interest to declare related to this study.

What will happen to you during this study?

All research participants who completed the online video modules have been invited to participate in an online questionnaire that will take about 10-20 minutes to complete. The questionnaire can be found in the study's OWL site, and purpose will be to (1) learn your thoughts, ideas, and views regarding the content of the video modules and their impact on your concept of happiness; (2) identifying specific strategies, topics, and video module components 
that you believed were important; (3) learning if, and how, you will incorporate the knowledge from the video modules into your life; and (4) obtaining feedback to change or improve the modules.

Will the study help you?

Your participation in this study is voluntary. You may decide not to be in this online questionnaire at any time. Even if you consent to participate you have the right to not answer individual questions or to withdraw at any time. If you choose not to participate or to leave the study at any time it will have no effect on your academic standing.

You do not waive any legal rights by consenting to this study.

If you decide to withdraw from the study, you have the right to request withdrawal of information collected about you. If you wish to have your information removed, please let the researcher know.

\section{Are there any risks to participating in the study?}

Sometimes during self-reflection there is a risk that you may experience emotional or psychological anxiety/stress. If at any time you experience any of these feelings please let the study investigators know. Resources (both online and on-campus options) will always be available on the OWL site for you as well. There is no economic risk or cost to participating in this study.

\section{Are there any benefits to participating in the study?}

Through this online questionnaire you will have the opportunity to learn about happiness skills that may benefit your physical, emotional, and mental well-being.

The potential benefits to society are speculative at this point. If findings from this study demonstrate that happiness that can be learned, there may be positive individual benefits and eventually, there may be possible benefits to society.

What will happen with the information in the study? Every effort will be made to protect your personal information. Your personal identifying information (such as your name, enrollment status, program of study, and year of study) will be stored separately from any study data.

If data is collected during the project which may be required to report by law, we have a duty to report.

The researchers will keep any personal information about you in a secure and confidential location for a minimum of 5 years. If the results of the study are published, your name will not be used.

\section{Is there compensation for participation in the study?}


No, there is no compensation for your participation in this study.

Who do I contact if I have any other questions about the study?

If you have any questions about your rights as a research participant or the conduct of this study, you may contact The Office of Human Research Ethics

How do you consent to participating in this study?

You indicate your voluntary agreement to participate by responding to the online questionnaire. 


\section{Appendix I. Program Feedback Questionnaire}

\section{Western屏HealthSciences}

\section{Post-Program Online Questionnaire}

1. What does happiness mean to you?

2. What makes you happy?

3. What makes you feel unhappy?

4. How often do you feel happy?

5. How important is it to you to feel happy?

6. Are your friends happy? Why or why not?

7a. Please recall the video modules you watched online. Did the video content impact your concept of happiness? And if so, how?

b. Did your view of happiness change after watching the videos? If so, why?

c. Did you continue to think about the videos after you watched them? If so, when and why?

d. Did certain videos have more of an impact than others? If so, which ones?

e. Did you learn anything from the videos that impacted your life?

f. Have you learned anything from the videos that you have or plan to incorporate into your life?

g. Did you share anything you learned in the videos with your friends? If so, what?

h. Was there anything about the videos you would change, improve, or remove?

Thank you for your participation. 


\section{Appendix J. Video Summaries}

\section{Week One (28 minutes, 12 seconds total)}

1.1 Video one (2 minutes, 39 seconds): What makes you happy?

- This introductory video welcomes students to the course and shows clips of students from all over the world sharing what makes them happy.

1.2 Video two (2 minutes, 34 seconds): Happy as a goal and the benefits of happiness

- This video shares research about the benefits of happiness.

1.3 Video three (9 minutes, 49 seconds): How to define and measure happiness

- The history of positive psychology and the science of happiness are explained. The conceptual domains of happiness are clarified. Different methods for studying and measuring happiness are discussed.

1.4 Video four (2 minutes, 46 seconds): Misconceptions about happiness

- Misconceptions about happiness and what happiness does not mean and are explained. The difference between happiness and sadness is explained.

1.5 Video Five (1 minute, 42 seconds): Gratitude exercise

- The exercise three good things is explained. Students are instructed to remember and list three good things that happened that day.

1.6 Video six (8 minutes, 37 seconds): Positive emotions

- Positive emotions are explained and research and examples of them are shared. 


\section{Week Two (35 minutes, 37 seconds total)}

2.1 Video one (4 minutes, 29 seconds): Social connection and happiness

- This video explains why social connection and relationships are very important for happiness.

2.2 Video two (13 minutes, 25 seconds): Happiness and healthy relationships, romantic relationships, and marriage

- Scientific studies of happiness and marriage are explained. What makes for a happy marriage or romantic partnership and keys to avoid bad relationships are taught.

2.3 Video three (5 minutes, 46 seconds): Friendships

- The history and neurophysiology of friendship are explained. Why friendships matter, the science of friendship, the benefits of social support, and the relationship between friendships and happiness are discussed.

2.4 Video four (11 minutes, 42 seconds): Empathy

- Empathy is defined. Research about empathy, types of empathy, and the relationship between empathy and happiness are taught. 


\section{Week Three (28 minutes total)}

3.1 Video one ( 2 minutes, 36 seconds): Roadmap for Week 6

- This video is an introduction to the week. Students are told that this week they will learn to look inward in a non-judgmental way. They will learn about mindfulness and what it has to do with happiness.

3.2 Video two (10 minutes, 13 seconds): Want to be happier?

- This TEDx talk by Matt Killingsworth talks about his an app, "Track Your Happiness", that lets people report their happiness in real time. He shares his research that found that people are often happiest when they are lost in the moment.

3.3 Video three (2 minutes, 21 seconds): Stay in the moment

- Meditation and the benefits of being in the present moment are taught.

3.4 Video four (8 minutes): Mindfulness techniques

- This video explains the benefits of mindfulness, what mindfulness and mindfulness-based stress reduction techniques are, and how to practice mindfulness.

3.5 Video five ( 3 minutes, 39 seconds): We are the stars of our own movie

- This video shares tips to help cultivate mindfulness and mediate.

3.6 Video six (1 minute, 11 seconds): Mindful breathing

- Breath awareness and mindful breathing are discussed. 


\section{Week Four (31 minutes, 2 seconds total)}

4.1 Video one (6 minutes, 35 seconds): Introduction to gratitude

- In this video gratitude is defined and what it has to do with happiness is explained. The benefits of having a grateful mindset on physical health, mental health, and happiness are described.

4.2 Video two (8 minutes, 11 seconds): The power of gratitude

- This video talks about how gratitude can heal, energize, and change lives. It explains qualities of grateful people, practices to boost gratitude, and how to measure gratitude.

4.3 Video three ( 6 minutes, 38 seconds): Gratitude brings happiness

- Why gratitude makes people happier and neutralizes negative emotions is explained.

4.4 Video four ( 2 minutes, 55 seconds): Challenges to gratitude

- Myths, challenges, and obstacles to cultivate gratitude are discussed in this video.

4.5 Video Five ( 6 minutes, 42 seconds): Final reflections

- In this final video, the video content is summarized, and key lessons are reviewed. Viewers are asked some final reflection questions and are encouraged to take the principles and practices from the course and continue to apply them in their life. 


\section{Appendix K. Ethics Approval October 21, 2016}

Primkipal lervstigatur.

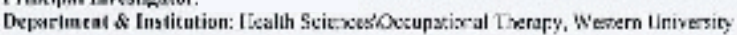

Revitw Type: Dukigseded

I5IEB File Number: 105294

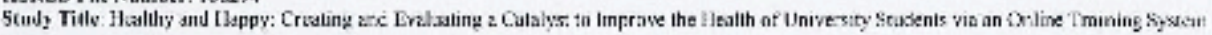

HSLRER Inidial A puroral Dite: Oucker 21, 2015

HSHKBB Fxpiry Dale, Qelobe: 21, 2013

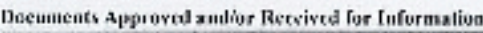

\begin{tabular}{|c|c|c|}
\hline Lecument Rame & S'ammevs & $\begin{array}{l}\text { Version } \\
\text { Date }\end{array}$ \\
\hline $\begin{array}{l}\text { Wevem Inweraity } \\
\text { Prakesl }\end{array}$ & Received O:tober 4,2315 & \\
\hline Ikxivilment levms & Radio Rezruirnent & 201611 (1) \\
\hline Kecnuiment Items & Siaselte Hax, i.mant & $\left.2016 / 1 a 1^{\prime}\right)$ \\
\hline Rsxuilment levms & Recruitmsnt Posier & $2016: 10013$ \\
\hline Recruitment Itema & Somole Tweets & $201 f_{1} 1720$ \\
\hline Revenitment Hems & Clsssruom Recruilment & 201661079 \\
\hline Recruilment llems & Mass amail Kexruilmert & $2016 / 1019$ \\
\hline Recouitmen, lieses & 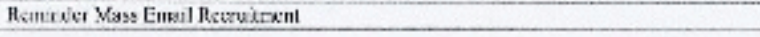 & 2016010619 \\
\hline $\begin{array}{l}\text {-iviar of lafurralion } \\
\text { \& Cowasa: }\end{array}$ & & $2016519 / 25$ \\
\hline $\begin{array}{l}\text { Weter of haforralion } \\
\text { B Consert }\end{array}$ & Tocus Group & $2016 / 1379$ \\
\hline Listrumenis & PrePost Questionnairs & 201600720 \\
\hline instruments & Demagnank Quession taire & 20160720 \\
\hline Instruments & 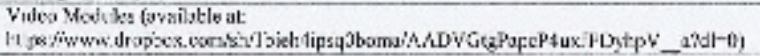 & \\
\hline insin moris & Tocus Group G.ido & 20169925 \\
\hline Dther & 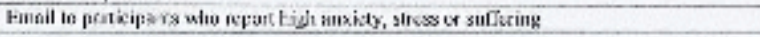 & $2016 v 14 / 26$ \\
\hline
\end{tabular}

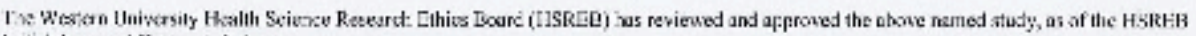

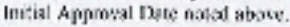

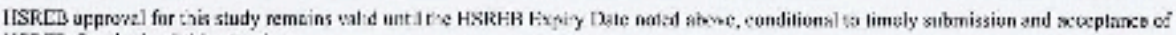
ISFCEB Contiruing thies Kerisw.

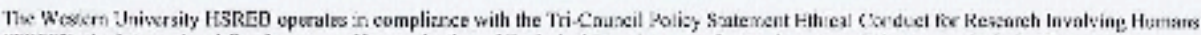

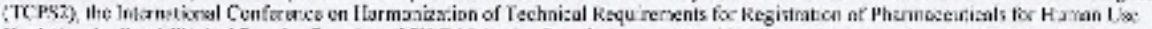

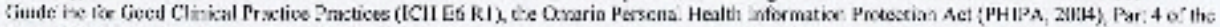

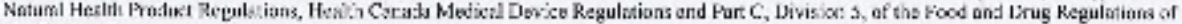
Health thenadz

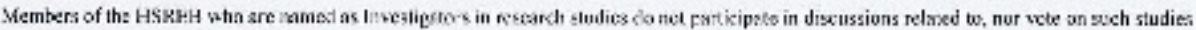
whec they are prewnte: wo the RrH

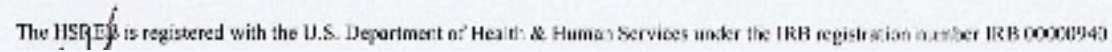




\section{Appendix L. Ethics Approval Revised December 15, 2017}

Westerm Research

Research Ethics

Principal Investigator:

Department \& Institution: Heal th SciencesłOccupational Therapy, Western University

Review Type: Delegated

HSREB File Number: 108294

Study Title: Healthy and Happy: Creating and Evaluating a Catalyst to Improve the Health of University Students via an Online Training System

HSREB Amendment Approval Date: Decembcr 15, 2016

HSREB Expiry Date: Octoter 21, 2017

Documents Approved and/or Received for Information:

\begin{tabular}{|l|l|l|}
\hline Document Name & Comments & Version Date \\
\hline Revised Westem University Protocol & Received December 7,2016 & \\
\hline
\end{tabular}

The Westem University Health Science Research Ethics Board (HSREB) has reviewed and approved the amendment to the above named study, as of the HSREB Initial Approval Date noted above,

IISREB approval for this study remains valid until the HSREB Expiry Date noted above, conditional to timely submission and accoptance of HSREB Continuing Ethics Review.

The Western University HSREB operates in compliance with the Tri-Council Policy Statement Ethical Conduct for Rescarch Involving Humans (TCPS2), the International Conference on Harmonization of Technical Requirements for Registration of Pharmaceuticals for Human Us: Guideline for Good Clinical Practice Practices (ICH E6 R1), the Ontario Personal Health Information Protection Act (PHIPA, 2004), Parl 4 of the Natural Health Product Regulations, Health Canada Medical Device Regulations and Part C, Division 5, of the Food and Drug Regulations of Health Canada.

Members of the HSREB who are named as Investigators in rescarch studics do not participate in discussions related to, nor vote on such studies when they are presented to the REB.

The HSREB is registered with the U.S. Department of Health \& Human Services under the IRB registration number IRB 00000940. 


\section{Appendix M. Ethics Approval Revised February 10, 2017}

Principal Investigator:

Department \& Institution: Health SciencestOccupational Therapy, Western University

Review Type: Delegated

IISRED File Number: 108294

Study Title: Healthy and Happy: Creating and Evaluating a Catalyst to Improve the Health of University Studerts via an Online Training System

HSREB Amendment Approval Date: February 10, 2017

ISREB Expiry Date: October 21, 2017

Documents Approved and/or Received for Information:

\begin{tabular}{|l|l|l|}
\hline Document Name & Comments & Version Date \\
\hline Revised Westem University Protowol & Received February 10,2017 & \\
\hline Revised Letter of Information \& Consent & & $2017 / 02 ; 0]$ \\
\hline
\end{tabular}

The Western University Health Science Research Ethics Board (HSREI3) has revicwed and approved the amendment to the above named study, as of the HSREB Initial Approval Date noted above.

HSREB approval for this study remains valid until the IISR RB Expiry Date noted above, conditional to timely submission and acceptance of HSRISB Conlinuing Ethies Review.

The Westem University HSRIEB operates in compliance with the Tri-Council Policy Statement Ethical Conduct for Rescarch Involving Humans (TCPS2), the International Conference on Hamonization ol Technical Requirements for Registration of Pharmaceuticals for Human Use Guidcline for Good Clinical Practice Practices (ICH F6 R1), the Ontario Personal Health Information Protection Act (PHIPA, 2004), Part 4 of the Natural Health Product Regulations, Health Canada Medical Device Regulations and Part C, Division 5, of the Food and Drug Regulatisms of Health Canada.

Members of the HSREB who are named as Investigators in rescarch studies do not parlicipate in discussions related to, nor vote on such studies when they are presented to the REB.

The HSREB is registered with the U.S. Department of I lealth \& Human Services under the IRB registrfition number IRB 00000940. 


\section{Appendix N. Ethics Approval Revised April 13, 2017}

\section{Western}

Research

\section{Western University Health Science Research Lthics Board HSRFB Amendment Approval Notiec}

I'rincipal Investigntor:

Depurtment \& Institution: Ileilth SeiencestOccupationil Therapy, Westem Liviversity

Revicw Type: Delegated

HSREB File Number: .08201

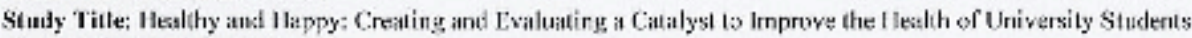
vin un Orline Training System

HSREB Amendmeat Approval Date: Apri! 13, 2017

HSREB Expiry Date: October 21, 2017

Documenis Approyed andior Received for Information:

\begin{tabular}{|l|l|l|}
\hline Document Name & Comments & $\begin{array}{l}\text { Version } \\
\text { Date }\end{array}$ \\
\hline Revised Western University Protocol & Received April 13, 2017 & \\
\hline Recruitment Items & $\begin{array}{l}\text { Email Seript for Ondine Post-Program } \\
\text { Questionnaire }\end{array}$ & $2017 / 04 / 13$ \\
\hline $\begin{array}{l}\text { Revised Sub-Study Letter of } \\
\text { Informution \& Consent }\end{array}$ & Online Post-Program Questionnaire & $2017 / 04 / 13$ \\
\hline Instruments & Online Post-Program Questionnaire & $2017 / 04 / 10$ \\
\hline
\end{tabular}

The Westem University Health Science Research Ethics Board (HSREB) has reviewed and approved the amendment to the above named sludy, as of the HSREB Initial Approval Date noted above.

HSREB approval for this study remains valid until the HSREB Expiry Date noted above, conditional to timely submission and acceptance of HSREB Continuing Ethics Review.

The Western University HSREB operates in compliance with the Tri-Council Policy Statement Ethical Conduct for Research Involving Humans (TCPS2), the International Conference on Jarmonization of Technical Requirements for Registration of Pharmaceuticals for Human Uso Guideline for Good Clinical Practice Practices (ICH E6 R1), the Ontario Personal Health Information Protection Act (PHIPA, 2004), Part 4 of the Natural Health Product Regulations, Health Canada Medical Device Regulations and Part C, Division 5, of the Food and Drug Regulations of Health Canada.

Members of the HSREB who are named as Investigators in reseerch studies do not participate in discussions related to, nor vote on such studies when they are presented to the REB.

The HSREB is registered with the U.S. Department of Health \& Human Services under the IRB registratidn number IRB 00000940 . 


\section{Appendix O. Email Script for Recruitment}

\section{Western\&HealthSciences}

\section{Email Script for Recruitment}

(to be used when the contact information is publicly available)

\section{Subject Line: Western Undergrad Mass Email Research Recruitment}

You are being invited to participate in a study that we, Gillian Mandich and Dr. Linda Miller, are conducting. Briefly, the research study is about happiness and health. On your own time once per week for four weeks you will be asked to watch online video modules that will guide you to explore ways to enhance your happiness, physical wellbeing, and mental health. You will be asked to complete a series of questionnaires at the beginning and end of the study. Following the completion of the online modules you will also be invited to participate in a focus group. In appreciation for your time, you will be entered into a draw to win one of five $\$ 100$ gift cards to the Book Store at Western.

If you would like more information or would like to participate in this study, please click on this link to access the eligibility survey (it will take 1 minute to complete):

https://uwo.eu.qualtrics.com/SE/?SID=SV e4APHBUTURhM9wx

One e-mail reminder will be sent out in one week with a reminder of your invitation to participate.

Thank you,

Gillian Mandich, PhD Candidate

Western University 


\section{Appendix P. Reminder Email Script for Recruitment}

\section{Western\&HealthSciences}

\section{Reminder Email Script for Recruitment}

(to be used when the contact information is publicly available)

\section{Subject Line: Invitation to participate in research}

An email was sent to you one week ago and we wanted to send you a quick reminder about our study.

You are being invited to participate in a study that we, Gillian Mandich and Dr. Linda Miller, are conducting. Briefly, the research study is about about happiness and health. On your own time once per week for four weeks you will be asked to watch online video modules that will guide you to explore ways to enhance your happiness, physical wellbeing, and mental health. You will be asked to complete a series of questionnaires at the beginning and end of the study. Following the completion of the online modules you will also be invited to participate in an optional focus group. In appreciation for your time, you will be entered into a draw to win one of five $\$ 100$ gift cards to the Book Store at Western.

If you would like more information or would like to participate in this study, please click on this link to access the eligibility survey (it will take 1 minute to complete):

https://uwo.eu.qualtrics.com/SE/?SID=SV e4APHBUTURhM9wx

Thank you,

Gillian Mandich, PhD Candidate

Western University 


\section{Appendix Q. Recruitment Poster}

\section{Western\&HealthSciences}

ARE YOU INTERESTED IN EXPLORING WAYS TO

ENHANCE YOUR HAPPINESS, PHYSICAL WELLBEING, \& MENTAL HEALTH?

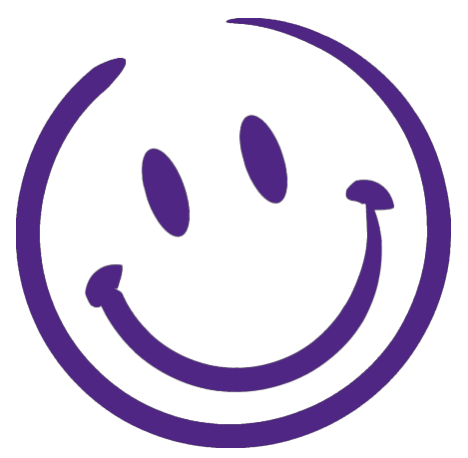

We are looking for volunteers to take part in a study about happiness and health who meet the following criteria: full-time, main campus undergraduate students aged 17-24.

If you are interested and agree to participate you would be asked to complete 4 short online video modules based on positive psychology and happiness theories, complete a series of brief questionnaires at the beginning and end of the study, and participate in an optional focus group.

In appreciation for your time, you will be entered into a draw to win one of five $\$ 100$ gift cards to the Book Store at Western.

For more information about this study, or to volunteer for this study, Gillian Mandich

Health and Rehabilitation Science, Western University 


\section{Appendix R. Script for Classroom Recruitment}

\section{Western\&HealthSciences}

\section{Script for Classroom Recruitment}

Hello, my name is Gillian Mandich and I am from Western University, The Department of Health and Rehabilitation Science. I am here today to talk to you about a research study about happiness and health which is being done under the supervision of Dr. Linda Miller.

I am currently recruiting participants who are main campus undergraduate students between the ages 17 to 24 who would like to participate in this study. Briefly, the study involves online video modules that will guide you to explore ways to enhance your happiness, physical wellbeing, and mental health. The study is four weeks long and on your own time once per week for four weeks you will be asked to watch short online videos that explore ways to enhance your happiness, physical wellbeing, and mental health. You will also be asked to complete a series of questionnaires at the beginning and end of the study. Following the completion of the online modules you will also be invited to participate in an optional focus group. In appreciation for your time, you will have the option to be entered into a draw to win one of five $\$ 100$ gift cards to the Book Store at Western.

If you are interested in participating or have any questions; please contact me at

Thank you for considering participation in this study. 


\title{
Appendix S. Sample Tweets for Recruitment
}

\section{Western\&HealthSciences}

\section{Sample Tweets for Recruitment}

\author{
**Requests to send tweets will be sent to the following accounts: @WesternU, @HS4091b, \\ @WesternHSSA, @gillianmandich, @NewsAtGazette, @kingsatwestern, @westernuPropel, \\ @chrwradio, @MediaWesternU, @uwogazette, @westernuWSS, @westernuSuccess, \\ @FHSSC,@LSSatWestern, @IveyHealth, @WesternUSC from @gillianmandich with the \\ following text: \\ I'm currently recruiting for a Western research study your followers may be \\ interested in. Can you please send this tweet: \\ [include text of tweet]
}

Are you an undergrad student \#WesternU who wants to participate in happiness and health research? Learn more:

https://uwo.eu.qualtrics.com/SE/?SID=SV_e4APHBUTURhM9wx

Want to learn skills to be happier \& healthier? Learn about a new study at \#WesternU \& how you can participate: https://uwo.eu.qualtrics.com/SE/?SID=SV_e4APHBUTURhM9wx

A new study invites you to watch online vids to learn ways to enhance happiness, physical wellbeing, \& mental health:

https://uwo.eu.qualtrics.com/SE/?SID=SV_e4APHBUTURhM9wx

Are you an \#undergrad at Western who wants to get involved in research? Learn about a new study in \#HealthScience:

https://uwo.eu.qualtrics.com/SE/?SID=SV_e4APHBUTURhM9wx 


\section{Appendix T. 94.9 CHRW Commercial Radio Script for Recruitment}

\section{Western\&HealthSciences}

\subsection{CHRW Commercial Radio Script for Recruitment}

Are you currently a full time, main campus undergraduate student at Western between the ages of 17 and 24? Do you want to learn ways to enhance your happiness, physical wellbeing, and mental health?

If you answered yes to those questions, then a new study at Western University might be for you. This study includes four short online video modules about happiness that are done one per week on your own time. You will be asked to complete a series of questionnaires at the beginning and end of the study. Following the completion of the online modules you will also be invited to participate in an optional focus group. In appreciation for your time, you will be entered into a draw to win one of five $\$ 100$ gift cards to the Book Store at Western.

Please email Gillian at

to participate or for more information. 


\section{Appendix U. Advertisement for Western Gazette Newspaper}

\section{Western\&HealthSciences}

\section{Advertisement for Western Gazette Newspaper}

\section{Bolded title: Research Participants Needed}

As a doctoral candidate I am conducting a study about about happiness and health. If you are a full-time, main campus undergraduate student between the ages 17 to 24 who is interested in watching short online video modules that will guide you to explore ways to enhance your happiness, physical wellbeing, and mental health you may be eligible to participate. In addition to the short videos, you will be asked to complete a series of questionnaires at the beginning and end of the study and will also be invited to participate in a focus group at the end of the study. In appreciation for your time, you will be entered into a draw to win one of five $\$ 100$ gift cards to the Book Store at Western.

If you are interested in participating, please contact Gillian at 
Appendix V. Western Gazette Newspaper Printed Advertisement

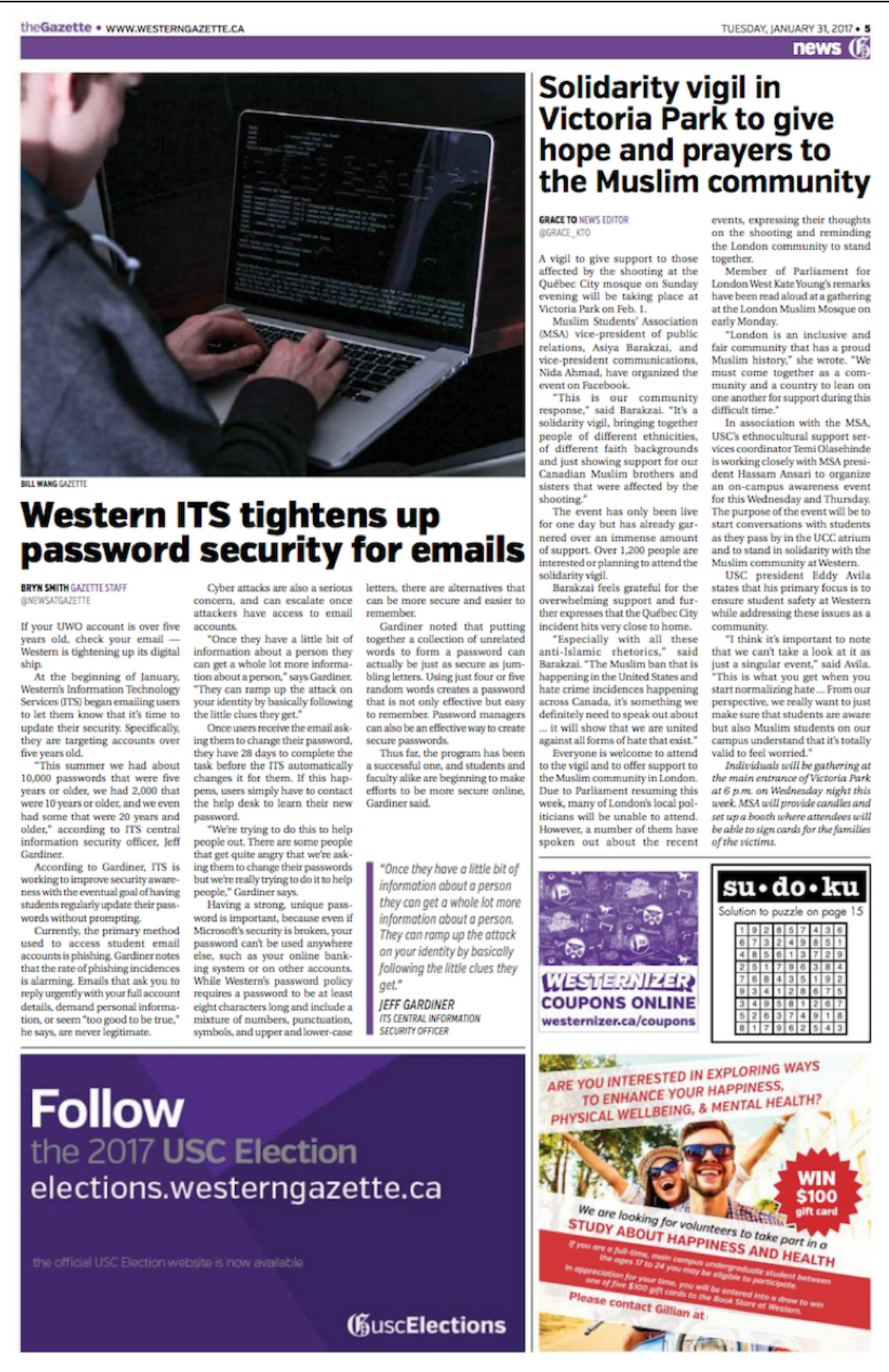




\section{Curriculum Vitae}

\section{Name:}

\section{Post-secondary Education and Degrees:}

Western University

London, Ontario, Canada

$2003-2007$ BHSc

Western University

London, Ontario, Canada

$2010-2012$, MSc

Western University

London, Ontario, Canada

2012 - present PhD

\section{Honours and Awards:}

Student Innovation Scholar - Pierre L. Morrissette Institute for

Entrepreneurship, Richard Ivey School of Business 2017

Canadian Obesity Network Student and New Professional Rising Star Award 2015

Western University 3 Minute Thesis Competition Finalist 2015

Faculty of Health Sciences Recognition of Achievement 2014

Best Oral Presentation 27th Annual Western Research Forum presented by the Society of Graduate Students (SOGS) at Western University 2014

Best Oral Presentation Western University's Health and Rehabilitation Sciences Graduate Research Forum: Bringing Your Creativity to Life 2014

Canadian Obesity Network Student and New Professional Dr. Jennifer Irwin Behavioural Aspects of Obesity Award 2013

Ontario Graduate Scholarship-Science \& Technology 2013 - 2014 Western University 3 Minute Thesis Competition Finalist 2013 
Ontario Graduate Scholarship-Science \& Technology May 2012 April 2013

Best Oral Presentation The University of Western Ontario's Health and Rehabilitation Sciences Graduate Research Forum: Brewing Research, Steeped in Ideas 2012

Western University 3 Minute Thesis Competition Finalist 2012

Ontario Graduate Scholarship-Science \& Technology 2011 - 2012

\section{Related Work Experience}

Course Instructor: HS4901B - Health and Social Media Western University

January 2016 - April 2016

Course Instructor: HS1001A - Personal Determinants of Health Western University

May 2015 - June 2015

Course Instructor: HS1001A - Personal Determinants of Health Western University

November 2013 - December 2013

Course Evaluator: HS1002A - The Social Determinants of Health Western University

September 2014 - December 2014

Teaching Assistant: HS1002A - Functional Anatomy Health

Practicum

Western University

April 2013 - May 2013

Project Coordinator: A community-based healthy lifestyle patientcentered education program of middle-aged (30-59) and older $(60+)$ adults with prediabetes

Brescia University College

June 2010 - June 2013

Research Assistant: Diabetes Team

Schulich School of Medicine and Dentistry, Western University May 2012 - September 2012

Teaching Assistant: Kin 2222A/HS2300A - Systemic Approach to Functional Anatomy 
Western University

September 2010 - April 2012

Research Assistant: Public Health Research, Education and

Development (PHRED) Program

Middlesex-London Health Unit

June 2007 - November 2011

Research Assistant: Kids Skills Clinic

Western University

January 2006 - June 2007

\section{Publications:}

Mandich, G. \& Miller, L. (2015). Healthy and Happy: Creating and Evaluating a Catalyst to Improve the Health of University Students via an Online Training System. [Abstract]. Canadian Journal of Diabetes, 39(1), S43. doi:

http://dx.doi.org/10.1016/j.jcjd.2015.01.164

Mandich, G., Burke, S., Gaston, A., \& Tucker, P. (2015). The physical activity levels and sedentary behaviours of Latino children in Canada. International Journal of Environmental Research and Public Health, 12(5), 5528-5539. doi: 10.3390/ijerph120505528

Shier, A., Colby, P., Mandich, G., Battram, D.S., Dworatzek, P.D.N., Hramiak, I., Mathyssen, J., Giroux, I. (2013). Impact of a Community Lifestyle Intervention Program (PREPARE) for Adults Diagnosed with Prediabetes in London, Ontario. [abstract]. Canadian Journal of Diabetes 37(4), S69.

Mandich, G. \& Burke, S. M. (2013). C.H.A.M.P. families: A qualitative investigation of health professionals' views of and suggestions for the development of a caregiverfocused childhood obesity intervention. [Abstract]. Canadian Journal of Diabetes, 37(2), S273.

Vanderloo, L. ${ }^{*}, \&$ Mandich, $G^{*}$. (2013). Battling bullying: Not all children face the same fight. The Canadian Journal of Community Mental Health, 32(4): 85-88. doi:

10.7870/cjcmh-2013-032

${ }^{*}$ Authors contributed equally to this work

*This work was submitted as overall winner of the Health Science Inquiry "Economic, and Environmental Determinants of Mental Health and Addiction" writing contest

Vanderloo, L. ${ }^{*}$ \& Mandich, $G^{*}$. (2013). Battling bullying: Not all children face the same fight. Health Science Inquiry**, 4(1), 71-72.

${ }^{*}$ Authors contributed equally to this work

${ }^{* *}$ Health Science Inquiry is a peer-reviewed journal for students 
Giroux, I., Broxterman, J. N., Battram, D., S., Dworatzek, P. D. N., Mandich, G. E., Colby, P., Mathyssen, J., \& Hramiak, I. (2012) Impact of a pilot group lifestyle behaviour change program (PREPARE) on nutritional and health characteristics in adults with prediabetes. [Abstract]. Canadian Journal of Diabetes, 36(5) (Suppl): PS6.

Burke, S. M., \& Mandich, G. E. (2012). Physical activity among Latino children: A qualitative examination of barriers and facilitators. [Abstract]. Journal of Sport and Exercise Psychology, 34(Suppl.), S209.

Mandich, G*., \& Vanderloo, L*. (2012). Obesity and diabetes among children:

Nutrition-related barriers and future opportunities. Health Science Inquiry, 2(1), 75-76.

${ }^{*}$ Authors contributed equally to this work

Callaghan, C., Mandich, G., \& He, M. (2010). Healthy Vending machine pilot project in four Ontario secondary schools. Canadian Journal of Dietetic Practice and Research, 71(4), 186-191.

Kurtz, J., Battram, D. S., Killough, G., Francis, L., Mandich, G., \& He, M. (2010) "Pause-2-Play": A pilot school-based obesity prevention program. The Brazilian Journal of Mother and Child Health, 10(3), 303-311.

He, M., Harvey, E., Battram, D. S., Mandich, G., Clarson, C.; \& Harris, S. B. (2009, October). A culturally sensitive community-based obesity prevention program targeting Latino-Canadian children: a pilot study. [Abstract]. Canadian Journal of Diabetes, 33(3) (Suppl): P-1287, 280-281.

He, M., Callaghan, C., Evans, A., \& Mandich, G. (2009). Healthy eating champions award for elementary schools: findings from a process evaluation. Canadian Journal of Dietetic Practice and Research, 70(2), 101-4. 